\title{
A Review on the Synthesis and Characterization of Metal Organic Frameworks for Photocatalytic Water Purification
}

\author{
Jorge Bedia * ${ }^{D}$, Virginia Muelas-Ramos, Manuel Peñas-Garzón ${ }^{\mathbb{D}}$, Almudena Gómez-Avilés, \\ Juan J. Rodríguez and Carolina Belver ${ }^{D}$ \\ Departamento de Ingeniería Química, Facultad de Ciencias, Universidad Autónoma de Madrid, \\ Campus Cantoblanco, E-28049 Madrid, Spain; virginia.muelas@uam.es (V.M.-R.); \\ manuel.pennas@uam.es (M.P.-G.); almudena.gomeza@uam.es (A.G.-A.); \\ juanjo.rodriguez@uam.es (J.J.R.); carolina.belver@uam.es (C.B.) \\ * Correspondence: jorge.bedia@uam.es; Tel.: +34-91-497-2911
}

Received: 15 November 2018; Accepted: 26 December 2018; Published: 7 January 2019

\begin{abstract}
This review analyzes the preparation and characterization of metal organic frameworks (MOFs) and their application as photocatalysts for water purification. The study begins by highlighting the problem of water scarcity and the different solutions for purification, including photocatalysis with semiconductors, such as MOFs. It also describes the different methodologies that can be used for the synthesis of MOFs, paying attention to the purification and activation steps. The characterization of MOFs and the different approaches that can be followed to learn the photocatalytic processes are also detailed. Finally, the work reviews literature focused on the degradation of contaminants from water using MOF-based photocatalysts under light irradiation.
\end{abstract}

Keywords: metal organic frameworks; photocatalysis; water purification

\section{Water Purification by Photocatalysis}

The availability of quality water is a major problem in the current societies. Water needs have increased annually, from 1990s, almost 1\% according to the continuous growth of the worldwide population, consumption patterns, and economic development [1,2]. It is noteworthy that this is a both hemispheres issue, affecting regions such as Southern Europe, Western South America, Southern Africa, and countries like China or Mexico [3]. By 2025, global water demand for the most water-intensive activities, agriculture and energy production, is expected to increase about $60 \%$ and $80 \%$, respectively. Besides this, the world population prospects establish a population growth in the range of the $22-32 \%$ by 2050 .

However, the surface water availability remains almost invariable and the quality of this water is being deteriorated because of the continuous release of chemicals to the environment, mainly nutrients due to the intensification of the agricultural production [4,5]. In this sense, pesticides, such as herbicides, insecticides, and fungicides, are also well-known water pollutants [6]. Moreover, the group of emerging contaminants (ECs) includes the wide range of personal care products, pharmaceuticals, cyanotoxins, steroids and hormones, plasticizers, caffeine, detergents, fragrances, etc. [7]. ECs are compounds that have appeared in the last decades, being detected in low concentrations in the water streams and without a proper regulation in most cases, resulting in a risk for human health, environment, and also economic activities [8,9]. All of those water pollutants can be introduced to the environment by multiple pathways, among which are industries disposal, hospital effluents, domestic wastewater, sewage treatment plants (STPs), and water treatment plants (WTPs) [10]. For all previous reasons, international agreements, such as the United Nations 2030 Agenda for Sustainable 
Development, establish specific targets for improving the water quality management. In this sense, wastewater treatment is a crucial step inside the water cycle. Further investigation for the improvement of the technologies for wastewater treatments may suppose a great deal of opportunities, especially in the new context of circular economy [11].

The treatment and purification of wastewater consist in the removal of the contaminants by the combination of physical, biological, and/or chemical processes. In the case of physical methods, gravity as natural force (such as for sedimentation) or barriers, such as membranes or filters, are commonly used for separating and concentrating the pollutant. In this field, technologies, like ultra- or nanofiltration, are able to remove macromolecules and biological matter, while inorganic ions can be separated by reverse osmosis. However, those processes are characterized by high power consumption, increasing operational costs [12]. The biological treatment of wastewater mainly includes the use of biological activated sludge for promoting the biochemical degradation routes of the different pollutants. This technology presents lower operational costs when compared to physical and chemical operations, but it also has larger time requirements. Furthermore, some of the aforementioned ECs may present bioaccumulation $[13,14]$ and persistence or inhibitory effects over the bacterial microorganisms of the activated sludge [15], drastically reducing the effectivity of the biological process. Finally, chemical processes allow for removing heavy metals by alkaline precipitation and disinfection by using UV radiation. Besides this, a family of high-power oxidant technologies, known as advanced oxidation processes (AOPs), have been deeply investigated in the last decades. These processes enable the degradation of refractory organic compounds by the in-situ generation of reactive oxygen species (ROS), mainly hydroxyl radicals $\left({ }^{\bullet} \mathrm{OH}\right.$ ). AOPs can implement iron $/ \mathrm{H}_{2} \mathrm{O}_{2}$ (Fenton processes), $\mathrm{O}_{3}$ (ozonation), electric power (electrochemical oxidation), UV, or solar radiation (heterogeneous photocatalysis), or their combination $[16,17]$.

Among AOPs that are used for water purification, heterogeneous photocatalysis are highlighted for the treatment of hazardous metal ions and the total abatement of organic pollutants [18-22]. This technology has the advantages of using $\mathrm{O}_{2}$ as the main reactive and the possibility of operating at mild conditions (ambient temperature and pressure). In heterogeneous photocatalysis, the ROS are generated after a charges separation that is caused by the irradiation of a semiconductor (photocatalyst) [23,24]. The photocatalyst, as semiconductor material, is defined by two separated energy bands: the highest energy band with electrons (known as valence band, VB) and the lowest energy band without electrons (called conduction band, CB). The energetic barrier between the aforementioned bands receives the name of band gap energy $\left(E_{g}\right)$ [25]. In this way, as represented in Figure 1, when a photocatalyst is irradiated and receives an energy that is equal or higher to its band gap energy, an electron $\left(\mathrm{e}^{-}\right)$is promoted from the valence band (generating a hole, $\mathrm{h}^{+}$, in the VB) to the conduction band. Immediately, these photogenerated charges can recombine, releasing the excitation energy as heat, or they can migrate to the surface of the semiconductor and generate the ROS. In the latter case, hydroxyl radicals $\left({ }^{\bullet} \mathrm{OH}\right)$ can be obtained by the oxidation of water molecules performed by the $\mathrm{h}^{+}$, while superoxide radical anions $\left(\mathrm{O}_{2}{ }^{\bullet-}\right)$ can be produced by the reduction of adsorbed oxygen. Moreover, superoxide radical anions can be further oxidized to hydroperoxyl radicals $\left(\mathrm{HO}_{2}{ }^{\bullet-}\right)$ by protonation. These oxidant species, coupled to direct oxidation by $\mathrm{h}^{+}$, are able to mineralize the pollutant; this is to perform the oxidation of the entire organic matter to $\mathrm{CO}_{2}$ and $\mathrm{H}_{2} \mathrm{O}$. However, besides the recombination of the pair $\mathrm{e}^{-} / \mathrm{h}^{+}$, other reactions can reduce the effectivity of the global process: combination of $\mathrm{HO}_{2}{ }^{\bullet-}$, producing $\mathrm{H}_{2} \mathrm{O}_{2}$; or protonation of $\bullet \mathrm{OH}$, resulting in the formation of water [26-28].

The increasing attention that is paid in the research field of the photocatalysis for water purification has resulted in the design and development of a wide variety of photocatalysts and their modifications. Table 1 gathers some of the most investigated (and some other novel) semiconductor materials for the photocatalytic purification of wastewater. Thus, further investigation is necessary for outstanding the real behavior of these materials in diverse contexts: i.e., different water matrix or the degradation of emerging contaminants in real wastewaters. In addition to this, the stability of the material 
is a recurring issue. For example, metal sulfides might present low photochemical stability under irradiation, resulting in their dissolution, while corrosion in aqueous media is other major drawback for some semiconductor materials [29]. This is not the case for titanium dioxide $\left(\mathrm{TiO}_{2}\right)$, which is the most used and researched photocatalyst. $\mathrm{TiO}_{2}$ has been utilized for both air and water purification [30,31]. This semiconductor is characterized by high activity in photocatalysis, besides high chemical stability and low biological toxicity [32,33]. However, the use of $\mathrm{TiO}_{2}$ powder has the main disadvantages of low porosity, poor adsorption, and the difficult management for its recovery. Moreover, the principal photocatalytic phase of $\mathrm{TiO}_{2}$, anatase, can be only activated by UV radiation due to its high band gap energy ( $3.2 \mathrm{eV}$, corresponding to $\lambda \leq 387 \mathrm{~nm}$ ). This fact supposes an important drawback inside the current trend of using solar energy (in which UV only represent the $5 \%$ of the total electromagnetic spectrum) for photocatalytic applications [28,34]. For these reasons, $\mathrm{TiO}_{2}$ modifications, by means of morphological (e.g., supporting on activated carbon or graphene, immobilized over fibers, forming heterojunctions with other materials) and electronic (e.g., doping with heteroatoms, metal deposition, combination with other semiconductors, sensitization with dyes) approaches, have been frequently researching lines in photocatalysis. In any case, the synthesis of a $\mathrm{TiO}_{2}$-based photocatalyst for real wastewater purification using not only UV light (and using visible and solar light) is still a challenging frontier for the upcoming years.

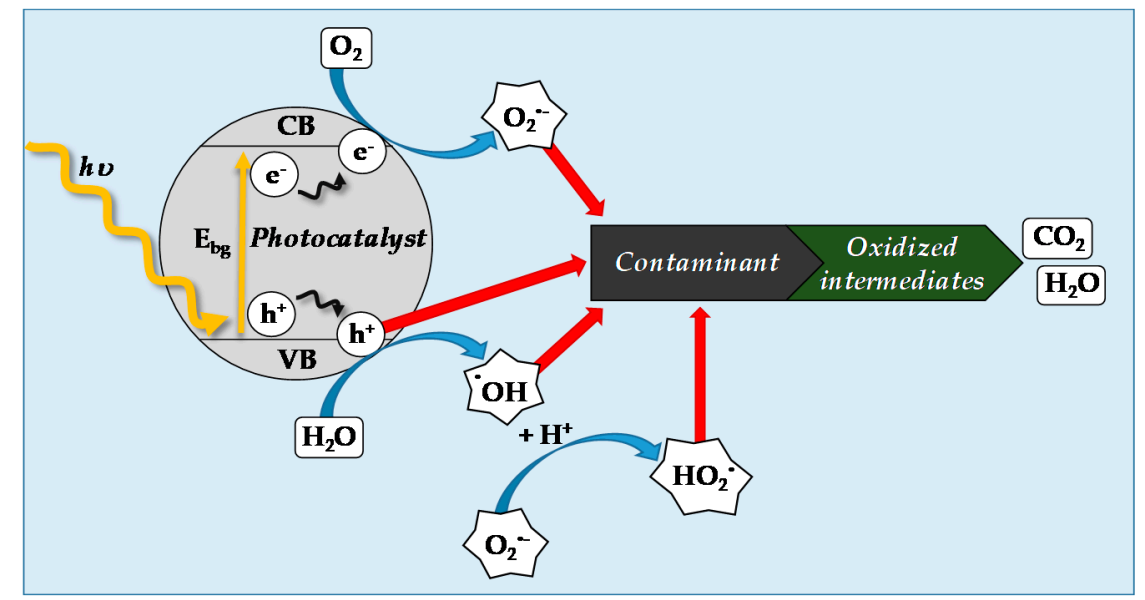

Figure 1. Schematic representation of reactive oxidant species generation and contaminant oxidation after the irradiation of a photocatalyst in aqueous solution.

Table 1. Different types of photocatalysts used for the removal of pollutants in water.

\begin{tabular}{ccc}
\hline Photocatalyst Type & Examples & Ref. \\
\hline Metal oxides & $\mathrm{TiO}_{2}, \mathrm{ZnO}, \mathrm{WO}_{3}, \mathrm{CeO}_{2}, \mathrm{Fe}_{2} \mathrm{O}_{3}, \mathrm{In}_{2} \mathrm{O}_{3}$ or $\mathrm{Bi}_{2} \mathrm{O}_{3}$ & {$[35-37]$} \\
\hline Metal sulfides & $\mathrm{ZnS}, \mathrm{CdS}, \mathrm{MoS}_{2}, \mathrm{Bi}_{2} \mathrm{~S}_{3}$ or $\mathrm{CuS} / \mathrm{ZnS}$ & {$[38-40]$} \\
\hline \multirow{2}{*}{ Ternary compounds } & Titanates $\left(\mathrm{BaTiO}_{3}, \mathrm{SrTiO}_{3}\right.$ or $\left.\mathrm{La}_{2} \mathrm{Ti}_{2} \mathrm{O}_{7}\right)$ & {$[41-43]$} \\
& Tungstates $\left(\mathrm{Bi}_{2} \mathrm{WO}_{6}\right.$ or $\left.\mathrm{ZnWO}_{4}\right)$ & {$[44,45]$} \\
Metalates $\left[\mathrm{A}_{x} \mathrm{~B}_{\mathrm{y}} \mathrm{O}_{\mathrm{z}}\right]\left(\right.$ such as $\left.\mathrm{BiVO}_{4}\right)$ & {$[46,47]$} \\
\hline Non-metal semiconductors & $\mathrm{g}^{-\mathrm{C}_{3} \mathrm{~N}_{4}, \text { graphene }}$ & {$[48-50]$} \\
\hline Multicomponent materials & $\mathrm{Bi}_{2} \mathrm{~S}_{3} / \mathrm{Bi}_{2} \mathrm{O}_{3} / \mathrm{Bi}_{2} \mathrm{O}_{2} \mathrm{CO}_{3}$ & \\
& $\mathrm{Bi}_{2} \mathrm{O}_{2} \mathrm{CO}_{3} / \mathrm{Bi}_{2} \mathrm{O}_{4}$ & {$[51-53]$} \\
& $\mathrm{BiVO}_{4} / \mathrm{Bi}_{2} \mathrm{O}_{2} \mathrm{CO}_{3}$ & {$[49]$} \\
& g- $\mathrm{C}_{3} \mathrm{~N}_{4}$-heterojunctions & {$[54]$} \\
\hline
\end{tabular}


Simultaneously, during this last two decades, another type of materials has received special attention photocatalysis, regarding the broad range of possibilities that the interaction between metal clusters and organic linkers may present. This is the case of metal organic frameworks (MOFs), whose crystalline structure provides a robust and well-defined network and also a high development of the surface area [55]. These characteristics, coupled with the wide number of different available linkers and metal clusters for their synthesis, allow for obtaining semiconductor materials with redshifted absorption in the electromagnetic spectrum and suitable open porosity and very low framework density [56-58]. In this sense, three different approaches will be suitable for obtaining MOFs with photocatalytic activity [29]: (i) encapsulating chromophores in the internal structure (MOFs would act as a passive cage for reactions); (ii) promoting $\mathrm{e}^{-} / \mathrm{h}^{+}$separation in the metal cluster (as it occurs in metal oxides); or, (iii) synthesizing MOFs using organic linkers with absorption bands displaced to the visible region in the spectrum, so promoted electrons can move to the metallic cluster, avoiding charges recombination. Therefore, the use of MOFs for the photocatalytic treatment of pollutants in water is an interesting strategy for water purification. The photodegradation of water contaminants with MOFs has been studied from the early 2000s [59], and it continues to nowadays [60]. Since that, a wide range of chemical and structural modifications has been applied to enhance the photoresponse of MOFs. The aim of this work is to review the latest progress in the synthesis, characterization, and application of MOFs for the photocatalytic purification of water.

\section{Metal Organic Frameworks (MOFs)}

Metal organic frameworks (MOFs) are a class of porous materials with modular structure. This allows a very wide structural diversity and the possibility of synthesizing materials with tailored properties for specific applications, such as gas storage, drug delivery, separation processes, catalysis, light harvesting and energy conversion, sensing, and so on. MOFs are formed by the assembly of two components: cluster or metal ion nodes, which are also called secondary building units (SBUs), and organic linkers between the SBUs, usually given rise to crystalline structures with significant porous texture development [61]. For example, Figure 2 represents the SBU (metal node) and organic linker used for the synthesis of two well-known MOFs, namely MOF-5 and HKUST-1. The combination of these structures results in a huge number of possibilities, and therefore of different MOFs with tailored properties. Figure 3 represents the different MOFs that were obtained using the same SBU and different organic linkers. As can be observed, diverse pore shapes can be obtained, depending on the linker.

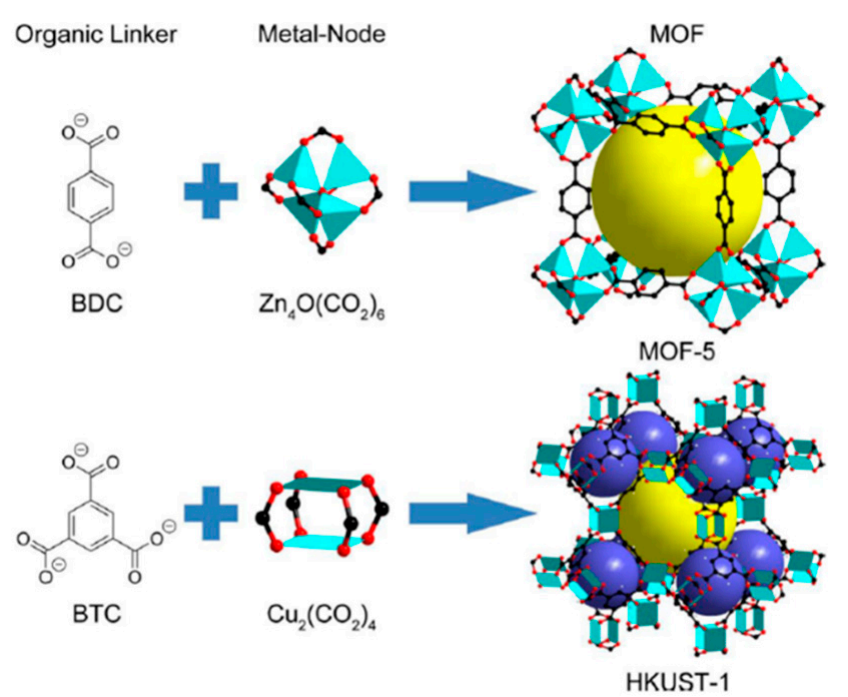

Figure 2. Secondary building units (SBUs) (metal node) and organic linkers used for the synthesis of MOF-5 and HKUST-1. Yellow and blue spheres represent the free spaces in the framework and they have no chemical meaning (reproduced from ref. [62]). 
The organic linkers are generally polytopic linkers, such as carboxylates, phosphonates, sulphates, azole, and heterocyclic compounds [63]. Some of the most representative SBUs and organic linkers that are used for the formulation of MOFs are depicted in Figure 4. The first reference to metal organic frameworks was reported by Yaghi et al. [64], who synthesized MOF-5 in 1995. Since then, a large number of these materials have been analyzed in the literature and grouped under different denominations. For example, UIO-based MOFs, like UIO-66, are from Universitetet i Oslo, MIL are from Materials of Institute Lavoisier or ZIF-based MOFs referred to Zeolite Imidazolate Framework, among others.

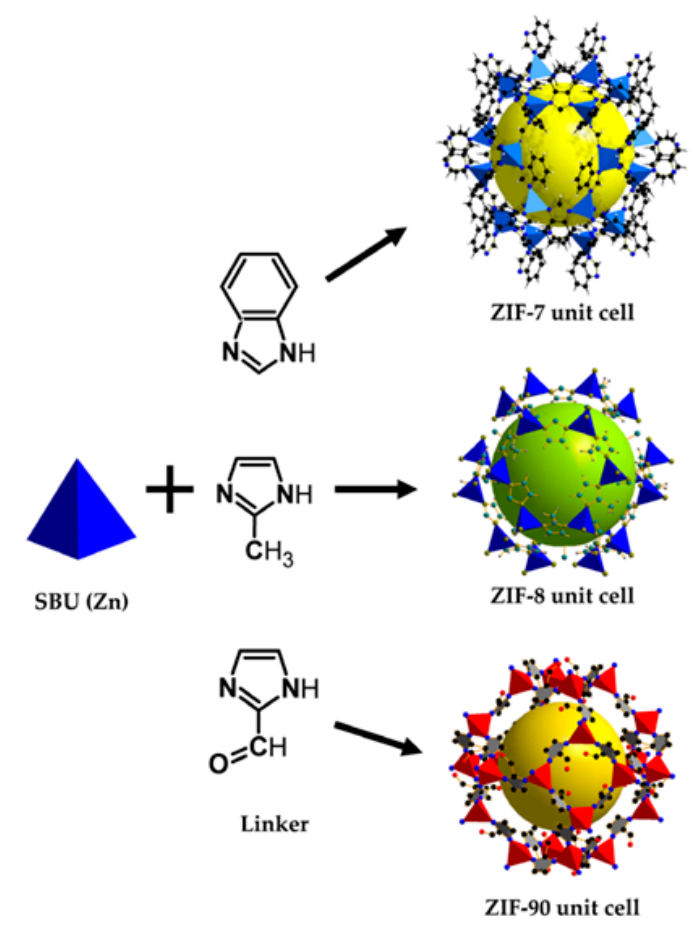

Figure 3. Different metal organic frameworks (MOFs) obtained using the same SBU and different organic linkers (reproduced from ref. [65]).

One of the most studied applications of MOFs is gas adsorption and storage due to their, in some cases, extremely high porosity, with surface areas higher than $6000 \mathrm{~m}^{2} \cdot \mathrm{g}^{-1}$. In the case of hydrogen storage, materials with low volume and with fast adsorption kinetics at relatively low pressure and at ambient temperature are needed. Recent reviews $[66,67]$ about hydrogen storage on MOFs have appeared since the first study reported by Rosi et al. in 2003 [68]. $\mathrm{CO}_{2}$ capture and storage technology has been investigated to mitigate its effect as a greenhouse gas [69,70]. Methane storage, as main component of natural gas, has also been a relevant issue. In this sense, MOFs have been considered as promising candidates due to their high and tuneable porosity and easily immobilized functional sites [71]. Not only gas storage, but also gas separation applications with MOFs have been widely studied in literature. In these sense, the adsorption of toxic gases, such as $\mathrm{CO}, \mathrm{NH}_{3}$, or sulphur, and nitrogen dioxides has been the main purpose in different studies [72,73].

Multifunctional MOF-based materials, such as magnetic sensors or low-dimensional magnetic materials, can be included in the applications due to their magnetic properties of some MOFs. These properties are ferromagnetic, antiferromagnetic, ferrimagnetic, frustration, and canting [66]. Moreover, MOF luminosity has been developed with different designs by combining metal ions, organic linkers, or guest molecules. Thus, sensing devices can be prepared for selective ion monitoring, stress-induced chemical detection, anisotropic photoluminescence probes, and/or the presence of guest/solvent molecules [66]. 
By other side, development of a controllable drug delivery system is required to enhance the therapeutic efficacy. MOFs, as compared to traditional porous materials, possess predominance of large surface areas, tunable pore size and shape, adjustable composition, and functionalized pore surface, which confer to them unique advantages for promising applications in adsorption and the release of therapeutic agents [66,74]. In this sense, the use of zirconium-based MOFs for drug delivery and biomedicine applications has been recently reviewed due to the their optimal stability towards hydrolysis and post-synthetic modifications with low toxicity [75].

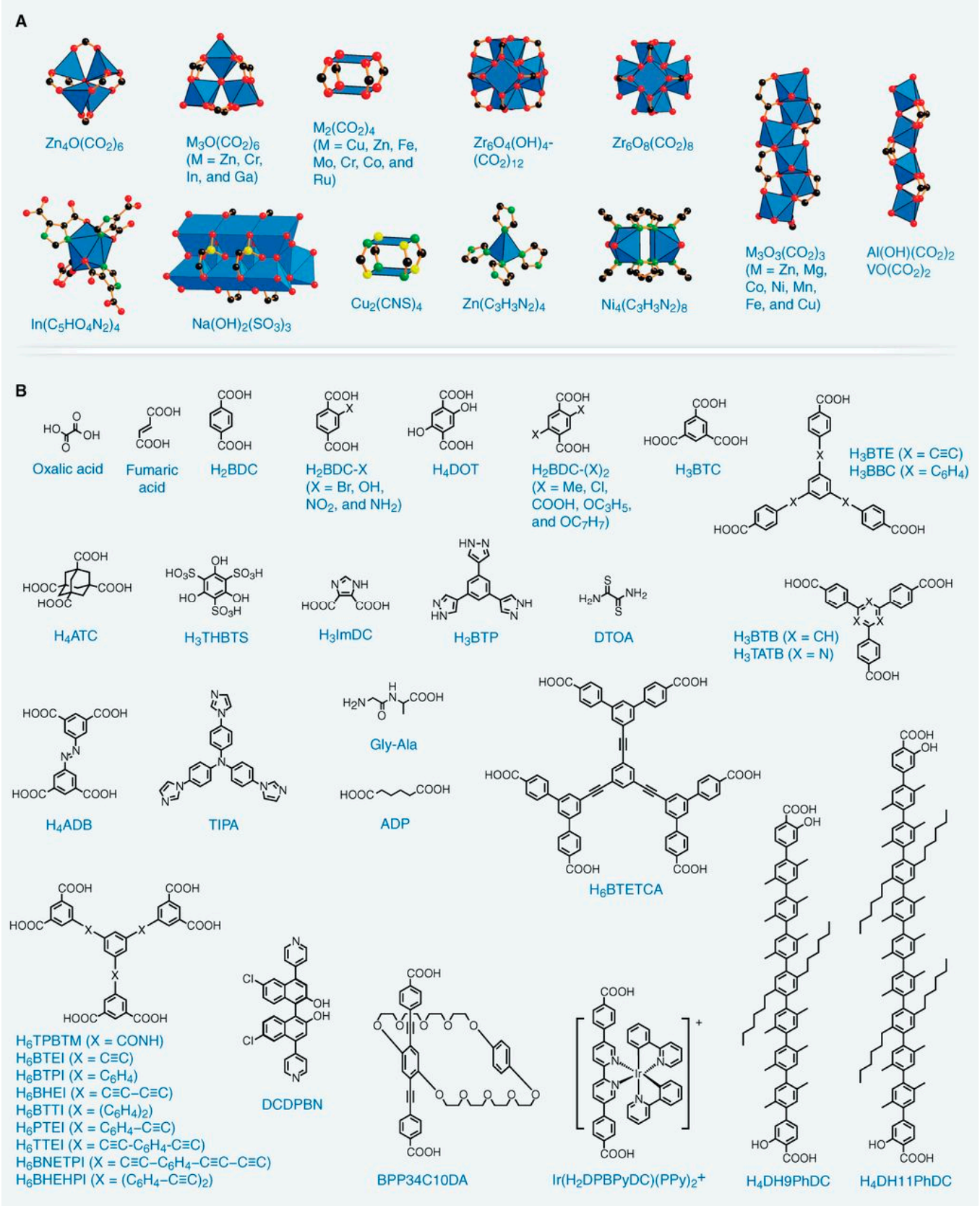

Figure 4. Inorganic secondary building units (A) and organic linkers (B) commonly used in MOF synthesis (reproduced with permission from ref. [76]).

Photocatalytic applications of MOFs have also been widely analysed due to their semiconductor properties [77]. Many studies are focused on the photocatalytic degradation of organic pollutants, mainly dyes, and the photoreduction of heavy metals, both in water solutions. In these applications, 
it is crucial to assure the stability of MOF in water for large periods of time and wide $\mathrm{pH}$ ranges [78] (see "Aqueous stability testing" in Section 4). Other pollutants coming from agricultural (pesticides, veterinary drugs), industrial (nitrobenzene), or municipal (personal care or pharmaceutical products) waste streams can be removed or degraded while using MOFs [79].

\section{Synthesis of MOFs}

Figure 5 summarizes the different approaches and synthesis conditions that are commonly used for MOF preparation reported in the literature [80]. The conventional method is usually performed in liquid-phase by mixing organic ligands, metal SBU, and a solvent for a certain time. The product of the reaction is filtered and dried by evaporation to obtain a purified MOF [81]. The most used method for the synthesis of MOFs is hydrothermal/solvothermal synthesis via conventional electrical heating at a controlled temperature. Generally, high-solubility organic solvents, such as dimethyl formamide, diethyl formamide, acetonitrile, acetone, ethanol, or methanol, are used in solvothermal reactions. To avoid the problems that are related to the different solubility of the initial reagents, mixtures of solvents can be used. Solvothermal synthesis can be performed at different temperatures. At the lower temperatures, glass vials can be used, while at temperatures higher than $130^{\circ} \mathrm{C}$, the synthesis is generally performed in small volume Teflon-lined autoclaves [82]. Hydrothermal synthesis of MOFs constitutes a more environmental friendly approach that substitutes the use of organic solvents for water [83]. The literature contains different attempts to synthesize MOFs with water due to the inexpensive and environmentally friendly character of this solvent. For instance, carboxylate-based MOFs were synthesized using organic salts (instead of their homologous protonated organic ligands) as anionic linker sources, so that their solubility and the deprotonation steps, which necessarily take place in the formation of MOFs, are notably favored in aqueous solution [84]. Nevertheless, these syntheses usually require long reaction times for an optimal crystallization, in order to accelerate the crystallization and obtain more uniform crystals with lower size, other alternative synthesis routes have been researched, such as microwave-assisted, electrochemical, sonochemical, mechanochemical, and spray-drying synthesis. These methods try to synthesize MOFs in a shortened time and with higher quality. The choice of the solvent is crucial in liquid-phase reactions and it is based on different characteristics, such as redox potential, reactivity, solubility, or stability, among others. The nature of the solvent also determines the thermodynamic and activation energy of the reaction. Besides the liquid-phase, some studies have focused on MOF synthesis by solid-state synthesis.

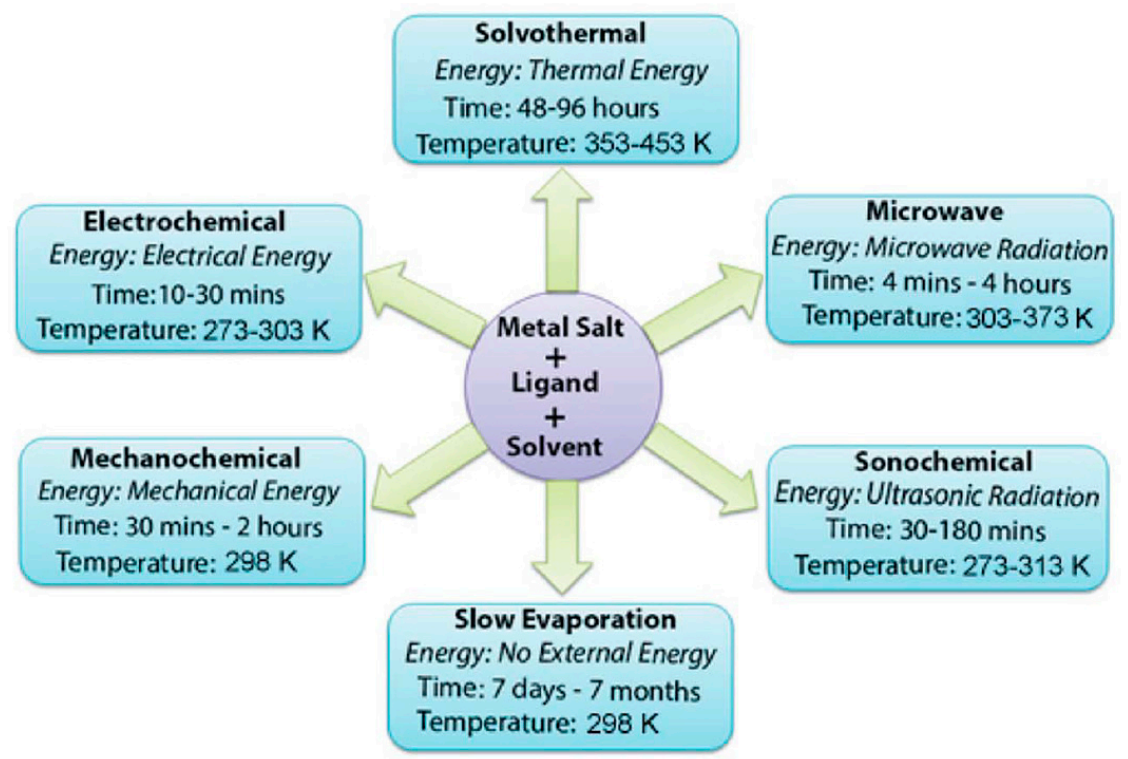

Figure 5. Different approaches and synthesis conditions commonly used for MOF preparation (reproduced from ref. [80]). 
The slow evaporation synthesis does not need any external energy supply. However, the advantage of using room temperature results in significantly longer synthesis times than other methods. In this synthesis, the initial solution is progressively concentrated by the slow evaporation of the solvent. In some cases, the process uses a mixture of solvents to increase the solubility of the reagents and accelerate the process by the faster evaporation of low-boiling solvents [85]. Microwave-assisted synthesis provides a very rapid method for the synthesis of MOFs [86,87]. Besides the lower synthesis times in relation with the solvothermal method, microwave heating can also result in higher crystallinity, porous texture development, particle size reduction, and better morphology control. Microwave-assisted synthesis is based on the interaction between electromagnetic waves and mobile electric charges, such as polar solvent molecules or ions in the solution. In sonochemical synthesis, the reagents undergo chemical change due to the application of intensive ultrasonic radiation $(20 \mathrm{kHz}-10 \mathrm{MHz})$. Ultrasound produces chemical and/or physical transformations by cavitation, which involves the formation and growth of small bubbles in the liquid phase. The collapse of these bubbles creates local hot spots of a short lifetime with high temperature and pressure, which generate homogeneous nucleation centres and reduce the crystallization time when compared with conventional solvothermal methods [88-90]. The mechanochemical method is based on mechanical agitation and collision between substances. It has the advantage of being a solvent-free procedure, resulting in less energy (because no heating is necessary), high efficiency, and simple process [91,92]. In liquid-assisted grinding (LAG), a small amount of solvent is added into a solid reaction mixture to facilitate the grinding [93]. Electrochemical synthesis does not require metal salts in the solution and offers the continuous production of MOFs, which constitutes a main advantage in an industrial process [94]. Furthermore, this method allows for the direct synthesis of thin films of MOFs over a surface at mild temperatures, reducing the effects of film cracking observed with other methods. The most studied electrosynthesis method is anodic dissolution, which uses an electrode as the source of metal ions. The electrode is located in a solution with the organic linker and often with an electrolyte. Upon applying an appropriate voltage or current, the metal dissolves and the metal ions that are required for the MOF formation are released near the electrode surface. The metal ions then immediately react with the linkers that are present in the solution and the MOF is formed close to the electrode surface. Thus, unlike the other synthesis methods, the metal ion is not supplied by a salt precursor but by the oxidation of the electrode.

Other methods, less analyzed, include spray-drying synthesis, diffusion methods, or ionothermal synthesis. The spray-drying method consists in the atomization of a solution containing the MOF precursors into a spray of microdroplets using a two-fluid nozzle. The inner nozzle injects the solution and the outlet compresses gas. The droplets are therefore surrounded by the gas at a controlled temperature. The evaporation of the solvent increases the precursor concentrations at the surface, until the critical concentration for reaction is reached, and the crystallization begins $[95,96]$. The diffusion methods can be divided into gas phase, liquid phase, or gel diffusion. In these methods the reaction rate is controlled by the diffusion of one of the reagents. In gas phase diffusion, a volatile organic ligand solution is used as a solvent, while in liquid phase diffusion both metal ions and organic ligands are dissolved in immiscible solvents [97]. To carry out the gel diffusion, the formation of MOF crystals comes from the mixture of the metal ions solution and the organic ligand dispersed in a gel substance [98]. The synthesis of MOFs by the diffusion method is often conducted under a mild reaction conditions, but it requires long reaction times. The ionothermal method uses an ionic liquid as structural template, charge balance group, or reaction medium. Thereby, this method provides a pure ionic environment. The physicochemical properties of MOFs can be controlled by changing the composition of the ionic liquid. Employing an ionic liquid has benefits, such as a good thermal stability, lower melting point, and wider liquid range [99].

The synthesis of MOFs usually requires the final steps of purification and/or activation. Purification consists of the removal of impurities, such as metal oxides, recrystallized linker, or dense hybrid compounds, not occluded inside the pores. This can be carried out by sieving or based on the densities of the synthesized products. Nevertheless, most often impurities are removed by solvent 
treatment at elevated temperatures. Activation entails the removal of guest molecules from the pores. Various techniques are used to get the activation of MOFs, such as vacuum drying, solvent exchange, or supercritical drying. In some cases, the heating of the MOF under vacuum can be enough to assure the activation. However, it also occurs that after vacuum drying lower surface areas than expected are obtained. This behaviour can be ascribed to the framework collapse due to the high surface tension and capillary forces that are produced by the liquid to gas-phase transformation of the trapped solvent molecules, especially if the solvent has a high boiling point and/or high surface tension. To avoid this problem, the solvent can be exchanged with a lower boiling point/lower-surface tension solvent prior to heating under vacuum. For the exchange, the MOF should be soaked in the new solvent during enough time to assure the complete solvent exchange. The soaking time can be from a few hours to several days (nuclear magnetic resonance spectroscopy can be used to assure the complete solvent exchange). Afterwards, the MOF will be activated at a temperature above the boiling point of the new solvent but below the decomposition temperature of the framework. If conventional solvent exchange is unsuccessful, activation can be achieved by exchange with supercritical carbon dioxide $\left(\mathrm{scCO}_{2}\right)$, which avoids the liquid to gas-phase transformation. Prior to use $\mathrm{scCO}_{2}$, the MOF should be exchanged with a solvent miscible with $\mathrm{CO}_{2}$, such as ethanol or methanol. With this last technique, activation is achieved, even if the MOF has a quite breakable structure [100]. A new technique has been recently reported to activate different MOFs with UV-vis lamp [101]. The localized light-to-heat conversion that is produced in the MOF crystals upon irradiation enables a very fast solvent removal, thereby significantly reducing the activation time to $30 \mathrm{~min}$ and suppressing the need for time-consuming solvent exchange procedures and vacuum conditions. It is necessary to highlight that during all steps that are necessary for the purification and activation, the integrity of the framework must be verified, since high temperature can result in the collapse of the structure of the MOF or even in side chemical reactions that can alter the surface chemistry and properties of the final material. In order to know whether the purification/activation steps are correctly performed, it is usually convenient to compare the experimental measured surface areas with those calculated by computational modelling or previously reported in other studies. If the experimental surface area is similar to the computationally derived, then the activation procedure seems well performed. If the experimental area is significantly lower than the theoretical one, this is indicative of a collapse of the frameworks or an incomplete solvent removal.

\section{Modification of MOFs}

The performance of MOFs in different applications can be improved by modifying their chemical groups or other components. In the case of photocatalytic applications, some of the MOFs show relatively high band gap values and therefore they can only harvest UV light, which limits their application. The different strategies to enhance photocatalytic activity of MOFs include: (i) Functionalization; (ii) Deposition of metal nanoparticles; (iii) Combination with semiconductors in different types of heterostructures; and, (iv) Sensitization with dyes.

Functionalization of MOFs can be achieved by two different approaches. The first is based on the synthesis of the functionalized MOF using an organic linker containing the desired functional groups. This approach avoids the modification of an already synthesized MOF. However, this procedure has some limitations and it might not be easily generalized because either of the groups could interfere with the formation of the desired material or the properties (thermal stability, solubility) of the functionalized linker might not be compatible with the synthetic conditions. The more complex the functions to be introduced, the more difficult the synthesis by self-assembly because of their reactivity towards the metallic precursors [102]. A clear example of this methodology is the inclusion of amine groups by replacing terephthalic acid by 2 -aminoterephthalic acid as organic linker in the synthesis of MIL-125(Ti) MOF to obtain $\mathrm{NH}_{2}$-MIL-125(Ti). This change in the organic linker resulted in a much higher photocatalytic activity of the resulting MOF [103]. The second functionalization approach is post-synthetic modification (PSM), consisting in the functionalization of a previously synthesized 
MOF. The main difficulty with post-synthetic modification is to not distort the structure of the starting material during the process. Different routes have been developed to access post-functionalized MOFs based on different chemical interactions while keeping the same native structure [104]. PSMs can be divided in four different categories, as summarized in Figure 6, namely covalent PSM, which is produced by the covalent modification of the organic linker; dative PSM, involving the coordination of a metal centre to a linker with vacant coordination site; inorganic PSM, which is produced by the modification of the SBUs; and, ionic PSM, as result of the exchange of a counter-ion in a cationic or anionic MOF. For covalent or dative PSM, the MOF normally needs to have a reactive group present on a linker. This group is often referred to as a ' $t a g$ ', which is defined as a group or functionality that is stable and non-structure-defining during MOF formation, but that can be transformed by a post-synthetic modification [105].

(a)

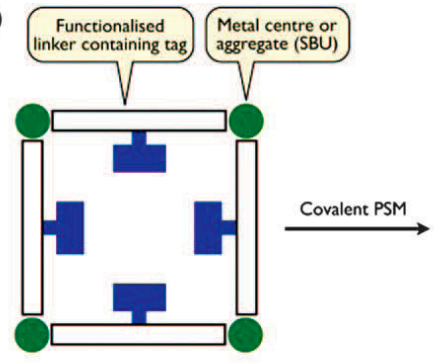

(b)

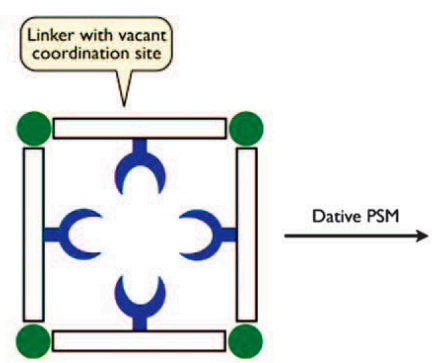

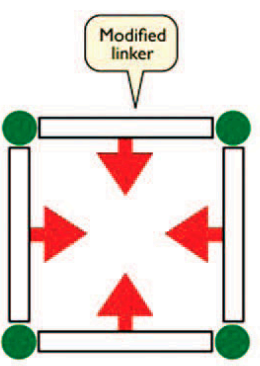

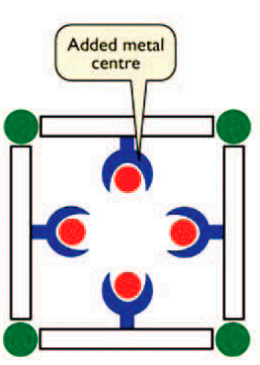

(c)

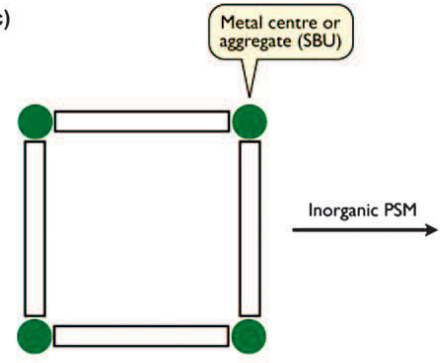

(d)

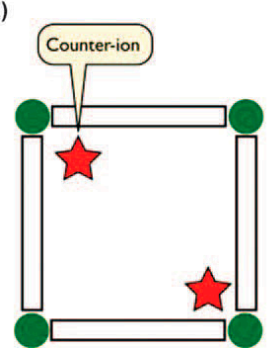

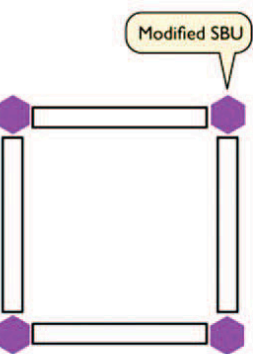

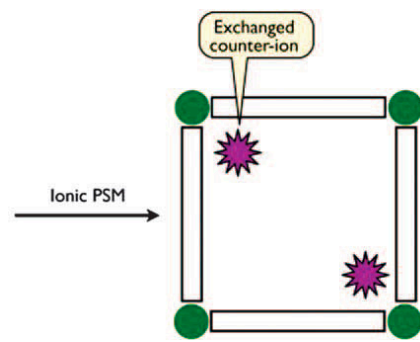

Figure 6. Post-functionalization strategies for MOFs modification (reproduced with permission Reproduced by permission of The Royal Society of Chemistry [29]).

Different covalent transformations have been successfully carried out in the literature to modify preassembled MOFs. These transformations include varied chemical reactions, such as amide coupling, imine condensation, urea formation, salicylaldehyde condensation, $\mathrm{N}$-alkylation, click reactions, bromination, and protonation. Many of these transformation reactions have been implemented in amino-functionalized MOFs, due to the higher reactivity of the amino functional group. It should be mentioned that most PSM reactions involve the increase of the size and complexity of the functional groups into the pores. However, it is also possible to make this group smaller, while simultaneously unmasking a protected functional group. This class of reactions has been termed post-synthetic deprotection (PSD) [29] and it can achieved by thermolysis and photolysis reactions. Dative PSM reactions can be divided into two types: those in which the metal coordinates to a neutral site of the organic ligand, and those in which coordination occurs by the deprotonation of the ligand, such as the conversion of hydroxyl groups into alkoxides (incorporating metal centres). Inorganic PSM can be included in a wider functionalization category, namely post-synthetic exchange (PSE), which includes the modification/substitution of the SBU (inorganic PSM) or of the organic linker. Inorganic PSM reactions include transmetalation at inorganic nodes, oxidation, and the reduction of the framework metal centres or substitution of metal centres. On the other hand, PSE by substitution of framework ligands includes solvent-assisted linker exchange (SALE) and solvent-assisted linker incorporation (SALI). Finally, ionic MOFs are those in which the framework has a cationic or anionic charge, with counter-ions being present in the pores to balance these charges. Many ionic MOFs 
can undergo post-synthetic ion-exchange processes (ionic PSM), during which the cations or anions initially present in the pores are substituted for others.

There are other possible MOF transformations that can be viewed as post-synthetic modifications, including the formation of nanoparticles within the porosity of the MOF (deposition of metal nanoparticles). In recent years, metal nanoparticles (NPs) have gained popularity because of their application in heterogeneous catalysis. Different methods have been developed to load metals nanoparticles in MOFs, such as incipient wetness impregnation or double solvents method, based on the use of a hydrophilic and a hydrophobic solvent [106]. Generally, these processes require the use of strong reducing agents, like $\mathrm{NaBH}_{4}$ or $\mathrm{H}_{2}$, to obtain the desired metal NPs, which compromises the stability of the framework. Recently, photoreduction has been used for the reduction of the metal nanoparticles with promising results [107].

Dye-sensitization is considered to be a mature way of enhancing the visible light harvesting. In 1991, it appeared in a report to create a solar cell from dye-sensitized colloidal $\mathrm{TiO}_{2}$ films for the first time [108]. Since then, some studies have analysed the post-modification of MOFs by sensitization with dyes. For instance, the sensitization of Pt@UiO-66 with Rhodamine B or UiO-66 with Erythrosin (ErB) enhanced the photocatalytic activity under visible-light for $\mathrm{H}_{2}$ production $[109,110]$. Similarly, Qin and co-workers utilized a dye photosensitizer to get ZIF-67 as a co-catalyst for photochemical $\mathrm{CO}_{2}$ reduction [111].

Finally, combination of MOF with semiconductors can show great advantages when compared with pure MOFs due to the synergetic effect. For example, MOF heterostructures combined with typical semiconductors (e.g., $\mathrm{ZnO}, \mathrm{TiO}_{2}$, and graphene) have been demonstrated to exhibit exciting catalytic abilities, also with great changes in luminescence and adsorption properties. In the case of photocatalysis, the construction of heterostructures can reduce the recombination, improve light absorption, and show better charge separation, as will be described in detail in Section 6 .

\section{Characterization of MOFs}

The resulting MOFs that are prepared by different methodologies should be further characterized with diverse physicochemical techniques for determining their properties. From the point of view of water treatment by photocatalysis, it is also important to know its structural and textural properties, studying its homogeneity, while determining its electronic and light absorption properties, and, of course, its stability in water. The techniques more useful for the characterization of MOFs are described below.

\subsection{Powder X-ray Diffraction (PXRD)}

PXRD is widely used to determine the structural parameters and crystallinity of the MOFs. The structural identification can be performed by comparing the diffractogram of the synthesized MOF with a previous one reported in literature or a simulated pattern generated by single crystal X-ray and included in a database, or through the use of computational modeling [112]. With this technique, it is possible to identify the crystalline structure, different polymorphic forms, distinguish between amorphous and crystalline material, and estimate its crystallinity percentage. Once the crystalline structure of the MOF is identified, it is possible to determine the crystallographic parameters, such as unit cell size, lattice parameters, and crystallite size. The formers can be refined from diffraction data by different methodologies that assume a mathematical adjustment, such as the non-linear least squares method [113]. Once the diffraction peaks are identified, the crystallite size is calculated using the Scherrer's equation, usually with the most intense no-overlapped peak [114]:

$$
D=\frac{K \cdot \lambda}{\beta \cdot \cos \theta}
$$


being $D$ the crystallite size, $K$ a size factor (values among $0.84-0.98$ depending on the equipment), $\beta$ the full width at half maximum height of the peak (FWHM), and $\theta$ the Bragg angle for the peak identified in the diffraction pattern.

This characterization technique is extensively used by researchers working on MOFs because it allows for understanding the crystallization of a MOF, but it also serves to verify the creation of a new MOF or heterojunction or composite. In photocatalytic applications, the stability of the MOF is also determined by XRD technique. The used-MOF is recovered from the medium after reaction, washed, and then dried. Thus, its diffraction pattern is recorded and compared with the pristine MOF, checking the possible differences and thus determining if the structure of the MOF is stable [115].

Unlike X-ray diffraction, there are other techniques based on the absorption of X-rays that are less used in the characterization of MOFs, mainly because they require the use of complex synchrotron radiation installations. Extended X-ray absorption fine structure (EXAFS or XAFS) is an oscillatory modulation in the X-ray absorption coefficient on the high-energy side of an absorption edge, which analyses the types and numbers of atoms in the local environment of the absorbing atom and accurate absorber-neighbor distances [116]. On the other hand, X-ray absorption near-edge structure (XANES) gives information about the energy band width, the valence state, and the bond angles [117].

\subsection{Nitrogen Adsorption-Desorption at $-196^{\circ} \mathrm{C}$}

This technique is commonly used in MOFs characterization because it allows for determining the textural parameters, such as surface areas, pore volumes, average pore size, and pore size distributions. This approach studies the $\mathrm{N}_{2}$ adsorption over the surface of a solid at the boiling temperature of liquid nitrogen, resulting in an adsorption isotherm. The shape of the isotherm provides information about the homogeneity of the solid [118]. In 1985, the International Union of Pure and Applied Chemistry (IUPAC) classified the physisorption isotherms into six types [119]. However, Thommes et al. [120] refined the original IUPAC classifications of physisorption isotherms, where Type I and IV isotherm were divided in I(a), I(b), IV(a), and IV(b), respectively. The same happens with the types of hysteresis loops. IUPAC classification identified four different loops and Thommes et al. [120] recently found two more types, resulting in six types of hysteresis loops that are related to the underlying adsorption mechanism and pore structure. To get useful information, the MOF must be properly vacuum dried and heated before $\mathrm{N}_{2}$ adsorption/desorption isotherm. However, in some cases, this pre-treatment reduces the surface areas due to framework collapse [112,121]. This collapse could often be related to the capillary forces and the high surface stress that occurred in the interphase between the gas and the confined molecules of the solvent [122].

In general, MOFs are solids with high surface areas $\left(>2000 \mathrm{~m}^{2} \cdot \mathrm{g}^{-1}\right)$ and porosity, with the majority microporous materials describing type I isotherms. The most common approach used to calculate the surface area of MOFs is the Brunauer-Emmett-Teller (BET) method [123], which permits the comparison with other porous materials. However, special attention must be paid with highly porous three-dimensional (3D) MOF frameworks, since the BET model was designed for flat surfaces and it may not correctly describe the MOFs adsorption data [124]. The presence of microporous is usually determined by the t-plot method, which compares the adsorption isotherm data of a porous sample and of a nonporous material [125]. Analogous to the BET modelling, the pore volume and pore size distribution can be extracted from the $\mathrm{N}_{2}$ adsorption isotherm, although it must be cautious when using the mathematical models. The density functional theory, commonly named DFT model [126], is widely used for analyzing the pore size distributions of MOFs in the range of meso- and micropores, while the Barrett-Joyner-Halenda (BJH) method is only used for mesopores and Horwath-Kawazoe (HK) for micropores $[125,127]$. Of course, the accurate fit of the experimental data depends on the available equipment, mainly for the micropores analysis that requires adsorption data at very low relative pressures, and the porosity of MOFs. For instance, if the studied MOF has flexible pores or they are randomly ordered, the DFT approach is questionable because it assumes that the pores are rigid and of a well-defined shape [128]. 


\subsection{Ultraviolet-Visible Diffuse Reflectance Spectroscopy (UV-vis DRS)}

UV-vis DRS is frequently used in the characterization of photocatalysts because provides information about the optical properties and allows for knowing the wavelength range in which the semiconductor absorbs the light. By this technique, an absorption spectrum is recorded in the UV-visible wavelength range, usually from 190 to $900 \mathrm{~nm}$, appearing in the absorption band. MOFs are a very interesting type of semiconductor because, depending on its composition, they can behave as an inorganic semiconductor, organic or both. When an inorganic semiconductor is excited by light with enough energy, the electrons are able to move from the valance band (VB) to the conduction band (CB), leaving a hole in the VB. The mechanisms followed by organic semiconductors are very similar, but the electronic transitions are among the highest occupied molecular orbital (HOMO) and the lowest unoccupied molecular orbital (LUMO) of an organic compound. Since MOFs are organometallic compounds constituted of metal oxo-clusters and organic linkers, when they are excited by light of an appropriate energy, the $\mathrm{e}^{-}$transitions can occur between the VB and CB of the metal oxo-cluster and/or between the HOMO and LUMO of the organic linker [129]. Thus, the absorption spectrum can be formed by several bands, depending on which constituent promotes electronic transitions. An interesting example of the UV-vis characterization was reported by Horiuchi et al. [130] comparing the light absorption of MIL-125 and $\mathrm{NH}_{2}$-MIL-125. MIL-125 showed an absorption band below $350 \mathrm{~nm}$, due to the $\mathrm{e}^{-}$transitions in the Ti-oxo-cluster, while the $\mathrm{NH}_{2}-\mathrm{MIL}-125$ showed a broad band up to $500 \mathrm{~nm}$ with two peaks, associated to electronic transitions in both the Ti-oxo-clusters and the $\mathrm{NH}_{2}$-linkers.

UV-vis DRS is also a useful tool to determine the band gap energy $\left(E_{g}\right)$ of a semiconductor. For this purpose, the Tauc Plot approximation is usually employed [131,132]. This model determines the $E_{g}$ by the equation:

$$
\alpha h v=A\left(h v-E_{g}\right)^{1 / n}
$$

where $\alpha, h, v, E_{g}$, and $A$ are the absorption coefficient, Planck constant, radiation frequency, band gap, and a constant, respectively. The value of $n$ depends on the semiconductor type, being $1 / 2$ for direct semiconductors and 2 for indirect ones. From this equation, it is possible to build a plot of $(\alpha h v)^{1 / n}$ vs. $h v$, called Tauc Plot [131]. For a direct band gap semiconductor, the plot with $n=1 / 2$ shows a linear Tauc region just above the optical absorption edge, while indirect band gap materials show the Tauc region on the $n=2$ plot. Extrapolation of this line to the photon energy axis yields the semiconductor band gap- a key indicator of its light harvesting efficiency under solar illumination. Figure 7 depicts an example of the UV-vis absorption spectra and the respective Tauc plots for a variety of modified-MIL-125(Ti) MOFs [133]. It can be seen that these MOFs have an absorption band up to $460 \mathrm{~nm}$, shifting the absorption to the visible region and yielding direct semiconductors with band gap values close to $2.85 \mathrm{eV}$. These values are lower than the characteristic band gap of $\mathrm{TiO}_{2}$ semiconductor $(3.2 \mathrm{eV})$ that is usually used in photocatalytic applications.
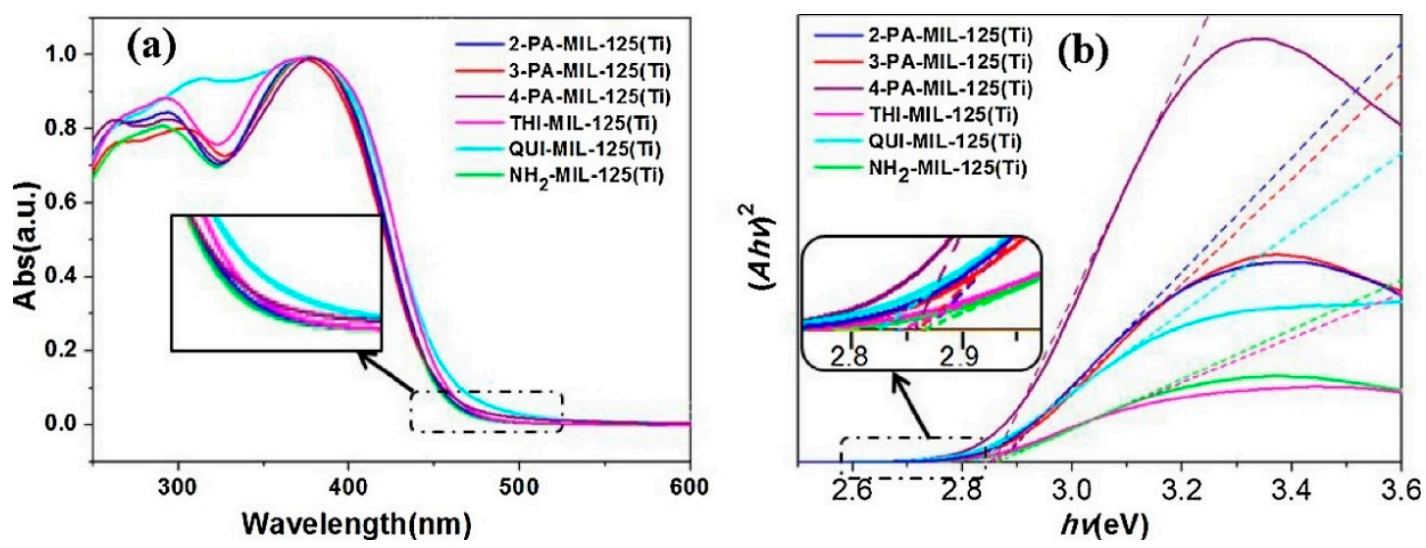

Figure 7. (a) UV-vis DRS spectra and (b) Tauc plots of $\mathrm{NH}_{2}-\mathrm{MIL}-125$ and aromatic heterocycle-grafted $\mathrm{NH}_{2}$-MIL-125 (reproduced with permission from ref. [133]). 


\subsection{Scanning Electron Microscopy (SEM) and Transmission Electron Microscopy (TEM)}

The SEM technique is routinely used for MOFs characterization. It generates high-resolution two-dimensional (2D) images that display the shape of the material and its spatial variations, revealing information about the external morphology, dispersion, and mixture of phases. The porous structure that characterizes MOFs gives rise to particles of curious shapes, such as cubes, bars, rhombohedra, and so on, yielding a varied morphology (see an example in Figure 8). Depending on the SEM equipment used and the insulating nature of some MOFs, the SEM characterization can require a previous pretreatment by coating the surface with a conductive material, usually gold [124]. To avoid this drawback, researchers have access to Field Emission Scanning Electron Microscope (FESEM). This equipment works with a field emission gun that provides extremely focused electron beams, which enhances the spatial resolution working at low potentials. This characteristic reduces the charging effect on insulating materials and even avoids the damage that the electron beam can induce in some sensitive MOFs. On the other hand, TEM has been widely applied to determine the grain size, particle size, and crystallographic data, such as plane indices and dislocations. Different software programs can be used to analyze the microscopy images (e.g., ImageJ, Cell Profiler). With those tools, it is possible to determine the particle size, measuring different particles and creating a histogram, and the spacing between crystallographic planes. This technique is very useful for the characterization of MOFs modified by the incorporation of nanoparticles (NPs), because the collected images provides data about the size and dispersion of those NPs [134]. These microscopies can be coupled with Energy Dispersive Spectroscopy (EDS) or Energy Dispersive X-ray Analysis (EDX or EDAX), which allows for determining the elemental quantitative and qualitative composition of MOF. As an example, Gao et al. [135] synthesized Fe-MOFs that were characterized by Field Emission SEM (FE-SEM) and High-resolution TEM (HRTEM), a observing uniform spindle-like shape and a uniform microstructure and lattice structure (Figure 8). The chemical composition was studied by EDX yielding mapping results of each element that allows for knowing the homogeneity of the synthesized MOF.
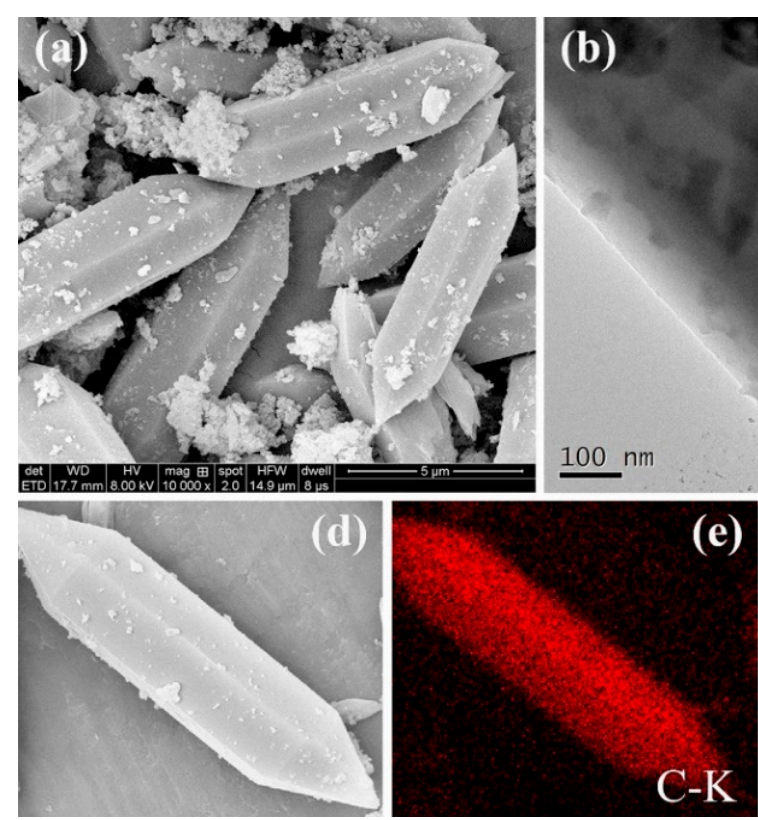
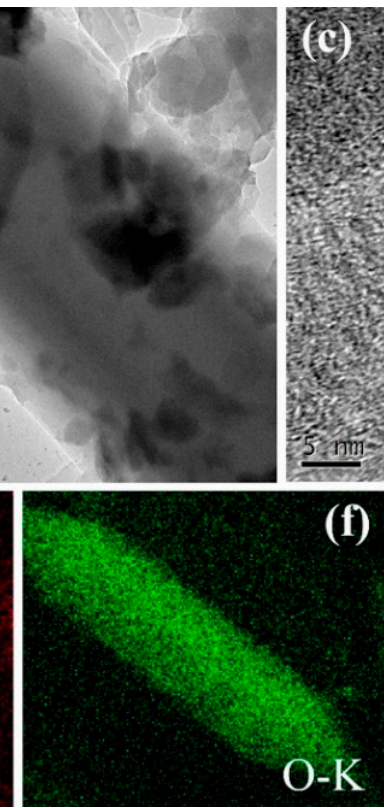

(f)
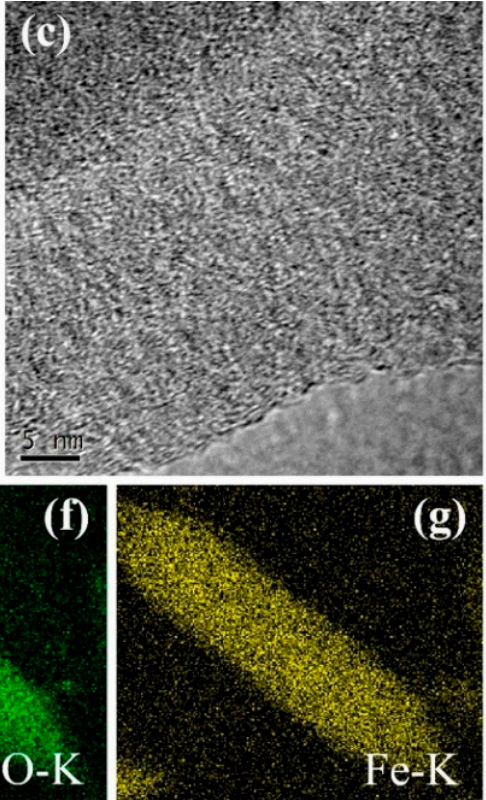

Figure 8. (a) Field Emission Scanning Electron Microscopy (FE-SEM) image of Fe-MOF; (b) Transmission Electron Microscopy (TEM) image of Fe-MOF; (c) High-resolution TEM (HRTEM) image of Fe-MOF; and, (e-g) Energy Dispersive X-ray Analysis (EDX) element mapping of C, O, and Fe obtained from (d) (reproduced with permission from ref. [135]). 


\subsection{Thermogravimetric Analysis (TGA)}

TGA measures the mass loss of a material as a function of temperature in a controlled atmosphere. This technique is useful in determining the thermal stability of the MOF and to estimate its solvent-accessible pore volume. The MOF decomposition varies depending of the carrier gas $\left(\mathrm{N}_{2}\right.$, air, or $\mathrm{O}_{2}$ ) that is used for the TGA. In a common study, the TGA curve represents the weight loss of the MOF (\%) versus temperature. This plot usually depicts a first loss of mass in the $40-110{ }^{\circ} \mathrm{C}$ range that corresponds to the removal of the solvent molecules, and a second loss between $300-600{ }^{\circ} \mathrm{C}$ that is usually assumed to the structural modification of the MOF framework, yielding the corresponding metal-oxides. It must be borne in mind that this weight loss does not have to be due to a structural change, so it is necessary to complement this study with an analysis by XRD at variable temperatures to check the change of structure [124].

\subsection{Inductively Coupled Plasma Optical Emission Spectroscopy (ICP-OES)}

ICP-OES is an elemental analysis technique that uses the emission spectra of a sample to identify and quantify the present elements [136]. ICP-OES can detect most elements at very low concentrations, so it is used to know the purity of the MOFs and the relationship between the elements that form it [124]. However, this technique does not analyze the chemical composition directly over the solid materials, but it requires that the sample be digested (dissolved) prior to analysis. The complete dissolution of MOFs is not always so easy, even employing severe treatments with $\mathrm{HNO}_{3}, \mathrm{H}_{2} \mathrm{SO}_{4}$, followed by $\mathrm{H}_{2} \mathrm{O}_{2}$ or even HF digestions. These procedures are difficult the ICP-OES analysis, because it is necessary to ensure that the dissolution is complete [124]. Due to this inconvenience, other technologies are sought that allow for knowing the elementary analysis. Wavelength Dispersive X-ray Fluorescence (WDXRF), for instance, is a novel technique used for elemental analysis applications [137-139]. In WDXRF, all elements are excited, simultaneously yielding each one a characteristic radiation emission that is detected by a detector. This technique can be used directly in solid materials, avoiding the complex dissolution of the solid required by ICP-OES.

\subsection{Aqueous Stability Testing}

MOFs must be stable in aqueous solution to efficiently carry out the photocatalytic reactions for water purification; hence, it has significant importance in testing the aqueous stability of these materials. Usually, MOFs have basic or acidic functional groups on their structure, so it has to be measured the $\mathrm{pH}$ of the water before adding the MOF and after it is removed. Even, it can be interested to determine the zeta potential of the MOF, which corresponds to the surface charge at the interface between the MOF surface and the water medium. A simple way to assess the stability in water of MOFs is to expose the material to an aqueous solution at known $\mathrm{pH}$. Subsequently, after a certain time, the MOF is filtered, washed, and dried. The stability yield can be known by comparing the mass recovered with the initial mass [124]. However, this comparison requires first a control of the structure and porosity, measuring the XRD and the $\mathrm{N}_{2}$ adsorption isotherm before and after water testing. Another option for understanding the aqueous stability is to measure the water adsorption isotherms by introducing a set partial pressure of water vapor into the MOF under vacuum [115]. As stated before, the majority of MOFs are microporous materials, where gas adsorption followed the expected type I isotherm. The shape of the respective adsorption isotherm provided details on the strength and type of interaction between the water molecule and the MOF surface. These analyses must be accompanied by XRD characterization. Thus, although most MOFs display water adsorption isotherms that are similar to those reported by other porous materials (e.g., zeolites or carbon materials), there are several MOFs that exhibit interesting adsorption behavior as a consequence of their framework flexibility. MOFs of type MIL-53 are a clear example of this behavior, in which the water adsorption produces a reversible structural transition from its large pore form to its narrow pore form, accompanying by a large reduction in their pore volume [115]. Nonetheless, for those applications in which MOFs must be 
used in aqueous phase, the best way to check the MOF stability is by immersion and stirring under the specific aqueous conditions, followed by the XRD, BET, and mass loss analysis after sample filtration.

\subsection{Photoluminescence (PL) Spectroscopy}

PL provides information about the electronic properties of semiconductors. In this spectroscopy, the material is directly excited by a light proceeding from a xenon lamp. The material absorbed the radiation, but the excess energy not adsorbed is dissipated by the material through the emission of light, known as photoluminescence. The energy emitted as light in semiconductors is related to the band gap energy, i.e., the energetic difference between the $\mathrm{CB}$ and $\mathrm{VB}$, but also with the presence of localized defect levels. In this way, photoluminescence supplies information about oxygen vacancies, structural defects, and the recombination of photogenerated charges. It is noteworthy that the intensity of the spectrum gives information about the number of recombination centres present in the MOF. A higher photocurrent response usually indicates the more efficient separation of the photogenerated charges and longer lifetime of the charge carriers [140]. As an example, Sofi et al. [141] studies the photoluminescence response of pristine HKUST- 1 and $\mathrm{Ag} / \mathrm{Ag}_{3} \mathrm{PO}_{4} / \mathrm{HKUST}-1$ heterostructure to investigate the recombination of photogenerated charge carriers. Authors attributed the decreasing of the intensity in the heterostructure to the reduction of the electron-hole recombination due to the effective separation of photoinduced charge carriers. Thus, highlights that this technique, together with the UV-vis characterization, are very useful to understand the photocatalytic activity of the MOFs.

\section{Experimental Procedures for Photocatalytic Tests}

\subsection{Photocatalytic Reactors}

There are many diverse and heterogeneous configurations of photocatalytic reactors that are devoted to water treatment processes. The most common classification divides photocatalytic reactors into (i) reactors with the photocatalyst suspended in the solution and (ii) those with the photocatalyst immobilized on a fixed support [26,142]. The former one needs an additional separation step for the recovery and recirculation of the photocatalysts' particles. In contrast, the latter allows for operating in a real continuous mode. The literature contains many different photocatalytic reactor configurations that could be sorted by this classification.

\subsubsection{Slurry Reactors}

Slurry reactors have been widely employed in many studies, probably due to their simplicity of use. Furthermore, this configuration is valid for all types of light sources, i.e., UV, visible, or solar. In these reactors, the solid photocatalyst is suspended in the aqueous solution by air bubbling or mechanical stirring. They can be externally irradiated or include submerged lamps and can operate in batch or continuous mode. Besides their simplicity, this type of reactor has other remarkable advantages, including a very high exposed surface area of photocatalyst and low mass-transfer limitations. In contrast, their main disadvantages are the problems of light penetration due to the opacity and the recovery of the fine powder photocatalysts from the liquid phase. The powder photocatalysts can be separated using filtration systems or settling tanks, which allow a continuous operation mode.

\subsubsection{Photocatalytic Membrane Reactor (PMR)}

Photocatalytic membrane reactors combine in a single set up the photocatalytic reactor and the filtration stage [143]. A membrane is used with two different purposes, to serve as photocatalyst support forming an active photocatalytic layer and/or to be used for the separation and recirculation of the photocatalytic particles [144]. In the case of the immobilization of the photocatalysts on the membrane, the irradiated surface area is very considerably reduced and the regeneration of the photocatalysts implies the replacement of the whole membrane [145]. To overcome these disadvantages, 
slurry PMRs can be used. In these reactors, the photocatalysts particles are suspended in the aqueous phase, like in slurry reactors, and the membrane is used for the recovery/confinement of the photocatalysts particles [146,147].

\subsubsection{Annular Photoreactor}

In annular photoreactors, the water solution is confined between two concentric cylinders. Usually, the inner cylinder accommodates the light lamp, which is refrigerated with flowing air, although these reactors could be also externally irradiated [148]. This configuration provides a symmetrical irradiation and allows multiple possibilities for the positioning of the photocatalyst particles. The photocatalysts could be suspended in the solution, like in slurry reactors, or immobilized on supports located in the space between both cylinders or in the internal wall of the external cylinder.

Many other reactor configurations are described in the technical literature, including microreactors, rotating annular reactors, closed-loop reactors, among many others $[26,149,150]$. It is also worth mentioning the utilization of photoreactors with parabolic deflectors to enhance the incidence of light and increase the photocatalytic activity, especially in solar photocatalytic applications [151]. The selection of the photoreactor depends on several factors, including the pollutant to be removed, its concentration, the volume of water to be treated, the type of radiation (lamps or real sunlight), and, of course, the budget. Thus, the best photoreactor depends on the technological requirements [152]. For real sunlight applications, compound parabolic photoreactor is the most used because its simple design and handling, being even about $30-200 \%$ more efficient than other solar photoreactors [153].

\subsection{Parameters Affecting the Photocatalytic Behavior}

Besides the reactor configuration, the photocatalytic activity is highly dependent on the different operational parameters. The effect of some of these parameters on the photocatalytic degradation are briefly discussed below.

\subsubsection{Photocatalyst Loading}

Usually, the increment of the amount of photocatalysts results in an increase of the photocatalytic activity, more or less accentuated depending on the reactor configuration and reaction conditions. This is due to the higher light absorption and therefore to the higher generation of the reactive radicals that are responsible of the degradation of the pollutants. However, there is a saturation effect and beyond this point it is observed a decrease of the photocatalytic with increasing photocatalysis loading. This behavior is usually attributed to the light blocking produced by the increase of the turbidity of the water due to the high number of suspended particles of the photocatalyst.

\subsection{2. $\mathrm{pH}$}

$\mathrm{pH}$ is one of the most decisive parameters affecting the overall behavior of the photocatalytic reaction. $\mathrm{pH}$ affects not only the surface charge of the photocatalytic particles, but also their self-aggregation. The analysis of the $\mathrm{pH}$ impact is usually performed based on the $\mathrm{pH}$ of point of zero charge $\left(\mathrm{pH}_{\mathrm{PZC}}\right)$ of the photocatalyst. So that, at $\mathrm{pH}$ values near $\mathrm{pH}_{\mathrm{PZC}}$, the interaction between the solved pollutants and the photocatalyst's surface is very little due to the absence of significant electrostatic forces. However, when the $\mathrm{pH}$ of the solution is lower than $\mathrm{pH}_{\mathrm{PZC}}$, the photocatalyst surface becomes positively charged and therefore it exerted an electrostatic attraction towards negatively charged compounds. This can intensify the adsorption on the photocatalyst and consequently increase the possibility of degradation of the pollutant. Finally, if the $\mathrm{pH}$ is higher than the $\mathrm{pH}_{\mathrm{PZC}}$, then the surface of the photocatalyst will be charged negatively and therefore it repulses anion compounds.

Besides to the electrostatic effect between the surface of the photocatalyst and the dissolved pollutants, $\mathrm{pH}$ can also affect significantly the interaction between the particles of the photocatalysts 
themselves. At $\mathrm{pH}$ values that ate near the $\mathrm{pH}_{\mathrm{PZC}}$ of the photocatalyst, the aggregation of the photocatalyst particles is observed, resulting in photocatalyst sedimentation [154].

\subsubsection{Temperature}

The effect of the temperature on the photocatalytic activity in the water purification processes has been extensively analyzed in the literature. It is generally accepted that the increase of the reaction temperature favors the recombination of charges and disfavors the adsorption of the pollutants on the surface on the photocatalysts [155]. Furthermore, the increase of the reaction temperature can also result in a decrease of the oxygen adsorbed, with a detrimental effect in the photocatalytic activity, as explained below.

\subsubsection{Dissolved Oxygen}

Dissolved oxygen plays a crucial role in the framework of photocatalytic degradation of pollutants in water. Oxygen is involved in the generation of reactive oxygen species (ROS), which are mainly responsible for the pollutant degradation by oxidation reactions. Furthermore, dissolved oxygen also guarantees enough electron scavengers to avoid recombination effects, stabilize radical intermediates, and it is directly involved in some of the intermediate photocatalytic reactions [156]. The amount of dissolved oxygen can be approximated by the Henry's Law at the reaction conditions. The increment of the temperature of the aqueous medium produces a reduction of the dissolved oxygen concentration.

\subsubsection{Contaminant Initial Concentration}

The initial concentration of the contaminant also has a significant effect on the kinetics of the photocatalytic degradation reaction. A significant increase in the contaminant concentration results in slower photodegradation rates, which are mainly due to (i) the surface of the photocatalyst can be saturated by the adsorbed molecules of the contaminant and (ii) a decrease of the photonic efficiency [157].

\subsubsection{Light Wavelength}

The light wavelength can show a very significant effect on the photocatalytic degradation depending on the photocatalyst characteristics. Nowadays, the studies can be classified according to the light wavelength in UV, visible, or solar irradiation. The band gap value of the photocatalyst allows for estimating the wavelength of the irradiated light that can activate it. For instance, $\mathrm{TiO}_{2}$ in anatase phase has a band gap value of around $3.2 \mathrm{eV}$, and it can be activated with a light wavelength of $\lambda<380 \mathrm{~nm}$ [26]. In contrast, other semiconductor with lower band gaps, such as some types of MOFs, can be activated with lights of higher wavelengths, including visible or solar radiation that cover a wide range of wavelengths [158-160].

\subsubsection{Light Intensity}

In water applications, it is generally accepted that relatively high light intensity values are needed to obtain a proper photocatalytic reaction rate. This is due to the needing of a minimum number of photons to activate the surface of the photocatalyst. Initial studies confirmed a linear relationship between contaminant conversion and incident radiant lux [161]. However, later a different relation between the reaction rate and light intensity changes was demonstrated. With increasing light intensity, the linear dependency between the reaction rate and radiant flux changes from linear $(r=k \cdot \Phi)$ to a square $\operatorname{root}\left(r=k \cdot \Phi^{0.5}\right)$ and finally to zero order $(r=k)$. This behavior can be explained by the saturation of the photocatalyst surface. 


\subsection{Kinetics and Modelling}

Most of the studies reported in the literature fitted their experimental results to simplified Langmuir-Hinshelwood models. The kinetic mechanisms should consider the contaminant and the oxygen molecules. However, oxygen is usually in great excess in the reaction media and therefore its concentration can be considered to be constant during the whole reaction. The photocatalytic reaction can be described by a first-order reaction following the expression:

$$
r=-\frac{d C_{a d s}(t)}{d t}=k \cdot C_{a d s}(t)
$$

where $r$ is the reaction rate, $C_{a d s}(t)$ is the amount of contaminant adsorbed on the photocatalyst at time $t$ and $k$ is the rate constant. While considering that the adsorption-desorption equilibrium follows a Langmuir isotherm, the previous equation can be written as:

$$
r=\frac{k \cdot K_{L} \cdot C(t)}{1+K_{L} \cdot C(t)}
$$

being $K_{L}$ the Langmuir constant and $C(t)$ the concentration of the contaminant in the solution at time $t$. Generally, photocatalytic degradations are performed with low concentrations of the contaminant, therefore $K_{L} \cdot C(t)<<1$, and the equation can be simplified to:

$$
r=-\frac{d C(t)}{d t}=k \cdot K_{L} \cdot C(t)=k_{a p p} \cdot C(t)
$$

where $k_{\text {app }}$ is the product of $k$ and $K_{L}$ known as apparent rate constant. The integration of this equation between 0 and $t$, results in:

$$
\ln \left(\frac{C_{0}}{C_{t}}\right)=k \cdot t
$$

being $C_{0}$ and $C_{t}$ the contaminant concentrations in the solution at times 0 and $t$, respectively. The representation of $\ln \left(C_{0} / C_{t}\right)$ versus reaction time, $t$, allows for obtaining the value of the apparent rate constant from the slope of the line adjusting the experimental data.

\section{Water Purification by Photocatalysis Using MOFs}

Their outstanding properties and their versatility make MOFs ideal candidates for photocatalytic applications. One hot topic in photocatalysis is water purification to remove diverse pollutants, including heavy metals, nitrates, priority pollutants or emerging pollutants, and inactivate different pathogens. The use of MOFs in this application is subject to their photochemical response but also to their stability in water. They must maintain their structural and textural properties at the same time as their photocatalytic activity after successive uses. The literature reports several strategies to develop photoactive materials that are based on MOFs, which have been classified in three groups depending on the photocatalytic mechanism and they can be seen in Figure 9 [162-164]. The first approach exploits the semiconductor dots properties of the metal clusters, which act as dispersed nanosemiconductors that are isolated by the organic linkers. This approach results in type I MOFs that can be more efficient than conventional semiconductors because: (i) their high porosity, which favors the presence of the pollutant close to the semiconductor dots and the photogenerated charges; (ii) their high density of photoactive dots; and, (iii) the organic linker can also absorb light, acting as antennae and thus increasing the photoresponse of the catalyst [163]. Type II MOFs are synthesized using organic linkers with photoresponse, such as dye-based linkers, which are separated by the metal clusters. The linkers act as antennas absorbing the light and transferring the photogenerated charges to the metal clusters, described as linker-metal cluster charge-transfer mechanism (LCCT) [129]. Finally, type III MOFs is the simplest approach in which the MOFs are used as a porous matrix and the photoactive species are encapsulated within its porous structure. 


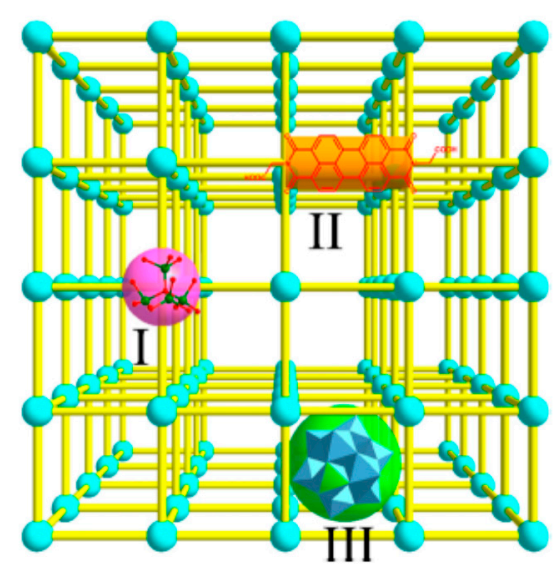

Figure 9. Illustration of the types of MOF developed for photocatalytic applications (reproduced with permission from ref. [163]).

While the promising photochemical properties of MOFs were described from the end of nineteens, their application in water purification began a decade later. The main drawback of these materials was their stability in water. As an example, Alvaro et al. [165] reported in 2007 the photodegradation of phenol in water using the MOF-5, but its instability was further reported by Hausdorf et al. [166], who observed that its structural modification depended of the water environment. It was not until 2013, when Laurier et al. [167] described the photocatalytic activity of several Fe-MOFs (MIL-88B, MIL-100, and MIL-101, all based on $\mathrm{Fe}_{3}-\mu_{3}$-oxo clusters) for the degradation of Rhodamine $6 \mathrm{G}$ under visible light $(550 \mathrm{~nm})$. Although the dye degradation was not complete, these MOFs were more active than the conventional $\mathrm{TiO}_{2}$ and their crystallinity was reasonably maintained after reaction. Since then, several works have been published regarding the use of MOFs in water treatment. Among the most studied MOFs stand out ZIF-8, UiO-66(Zr), and MIL-125(Ti) [168], whose photocatalytic mechanism corresponds to type II, and MIL-101, MIL-53, and MIL-88B (all Fe-based type I MOFs), in which the light is used by the Fe-O cluster, so as the photogenerated electron is transferred to $\mathrm{Fe}^{3+}$ from $\mathrm{O}^{2-}[129,169]$. Moreover, the literature shows additional strategies to promote the photocatalytic activity of MOFs in order to enlarge their visible light absorption, thus favoring their behavior under solar light.

One approach consists in functionalizing the organic linker to shift its photoresponse to higher wavelengths. Shi et al. [50] synthesized several amine-functionalized Fe-MOFs ( $\mathrm{NH}_{2}$-MIL-88B, $\mathrm{NH}_{2}$-MIL-53, and $\mathrm{NH}_{2}$-MIL-101) with high stability and activity for the photoreduction of $\mathrm{Cr}(\mathrm{VI})$ in water under visible light. Authors concluded that the incorporation of an amine group in the organic linker enhanced the activity of the MOFs because both the $\mathrm{NH}_{2}$-linker and the Fe-cluster were excited under visible light. Authors proposed a mechanism that is based on a dual excitation, as shown in Figure 10, which promotes the electron transfer and reduces the recombination of charges. The other strategy used in the design of more efficient photocatalysts is to support metal nanoparticles on MOFs. A recent example was reported by Liang et al. [170]. Authors loaded Pd NPs on MIL-100(Fe), leading to active photocatalysts for the photodegradation under visible light of three PPCPs (Pharmaceuticals and Personal Care Products), theophylline, ibuprofen, and bisphenol A. It was concluded that Pd NPs minimized the recombination of photogenerated electron-hole pairs, improving the photocatalytic performance. Another effective plan of action is to combine MOFs with other semiconductors achieving interesting and promising heterojunctions. In this approach, the porous network of the MOF can favor the dispersion of the other semiconductor, yielding to more active centres [129]. For instance, Mosleh and Rahimi [171] recently analyzed the photodegradation of abamectin pesticide using $\mathrm{Cu}_{2}(\mathrm{OH}) \mathrm{PO}_{4}$-HKUST- 1 through the sonophotocatalytic technique. The MOF showed a band gap value of $2.59 \mathrm{eV}$ and an almost complete degradation of the pesticide. 


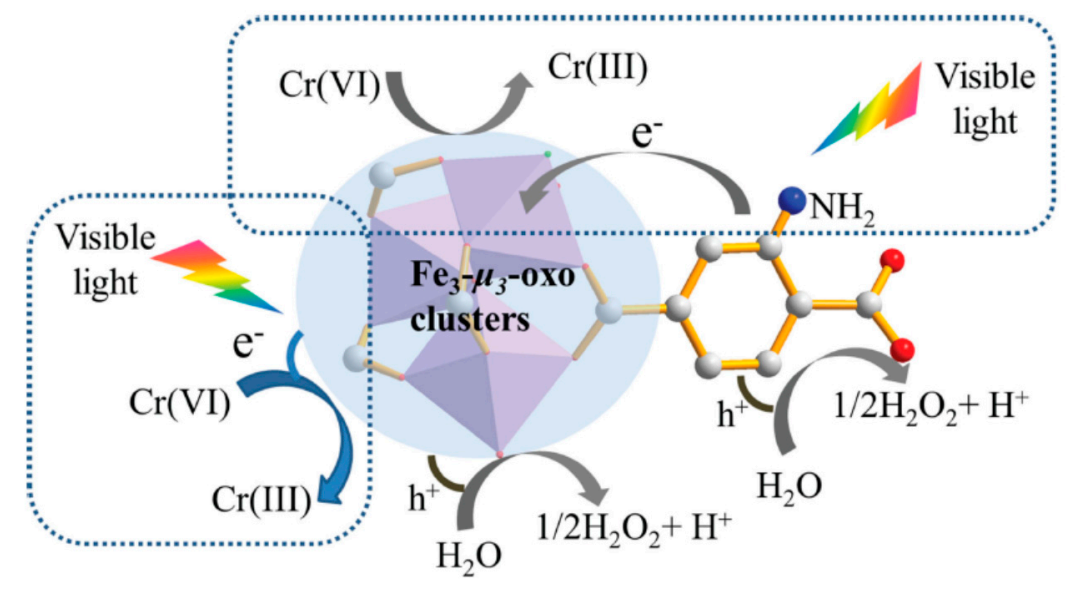

Figure 10. Scheme of the dual excitation mechanism proposed by Shi et al. for the photoreduction of $\mathrm{Cr}(\mathrm{VI})$ with $\mathrm{NH}_{2}-\mathrm{Fe}-\mathrm{MOFs}$ (reproduced from ref. [50]).

A great development has been performed on synthesizing MOFs and modifying MOFs, using the methodologies that are described in Section 3, in order to look for a next generation of photocatalysts that are more active and stable. Since literature summarized a certain diversity of MOFs for water treatment by photocatalysis, the following subsections have been established, paying particular attention to the nature of the pollutant, mainly dyes, heavy metals, priority, and emerging pollutants. Moreover, since the research in photocatalysis tends to use solar light as an energy source, we have focused the attention on those works that use visible and solar light for water treatment, leaving in the background the previous works dedicated to the use of UV radiation. Finally, a subsection has been included in which the stability and recyclability of these promising photocatalysts are studied.

\subsection{Photodegradation of Dyes}

Dye effluents are usually discharged from different industries, such as textile, rubber, paper, leather, plastics, cosmetic, and printing. Their presence in water is responsible of important damages to aquatic organisms and humans by mutagenic and carcinogenic effects. Most of the dyes are stable and non-biodegradable, due to their chemical structure that is characterized by a large aromatic degree. Thus, their removal by conventional biological technologies turns out to be inefficient. In this scenario, photocatalysis appeared as a promising technology for the removal of organic dyes from wastewater. Moreover, numerous MOFs have been tested as photocatalysts for the degradation of dyes, which has been summarized in several reviews [78,172-175]. However, most of articles are just focused on the removal of commercial dyes in synthetic waters instead of real dyestuffs water. Methylene blue $(\mathrm{MB})$, Methyl orange (MO), and Rhodamine $\mathrm{B}(\mathrm{RhB})$ have been different to the most used dyes as target pollutants, mainly because they are easy to analyze. Many examples can be found in the review reported by Wu et al. [172], where it stands out that around $60 \%$ of the articles used UV light, while $30 \%$ used visible irradiation, and only $5 \%$ utilized sunlight as energy source. This issue is mainly due to the lower conversion rates that are achieved by pure MOFs when using solar light; even in some cases additional oxidant (such as $\mathrm{H}_{2} \mathrm{O}_{2}$ or persulfate) is needed to favor the degradation rate. Table 2 appointed some relevant examples of pure MOFs that are used for dyes degradation that is classified according to the type of radiation employed. 
Table 2. Relevant examples of MOFs for dyes degradation, along with the dye target and the light used.

\begin{tabular}{|c|c|c|c|}
\hline MOFs & Dye Target $^{1}$ & Light Source & Reference \\
\hline $\mathrm{Cu}(\mathrm{II})$-pyrazole MOFs & $\mathrm{MB}, \mathrm{MO}$ & $\mathrm{UV}\left(+\mathrm{H}_{2} \mathrm{O}_{2}\right)$ & [176] \\
\hline $\mathrm{Cd}(\mathrm{II})$-imidazole MOFs & $\begin{array}{l}\mathrm{MB}, \mathrm{MO} \\
\mathrm{MO}\end{array}$ & UV & $\begin{array}{l}{[177]} \\
{[178]}\end{array}$ \\
\hline Zn(II)-imidazole MOFs & $\mathrm{MO}$ & UV & [178] \\
\hline ZIF-8 (Zn-imidazole MOF) & $\mathrm{MB}$ & UV & [179] \\
\hline $\operatorname{Ag}(\mathrm{I})-\mathrm{MOFs}$ & $\begin{array}{c}\text { R6G } \\
12 \text { azo dyes (among them } \\
\mathrm{MO}, \mathrm{AO} 7, \mathrm{CR} \text { and EBT) }\end{array}$ & UV & $\begin{array}{l}{[180]} \\
{[181]}\end{array}$ \\
\hline MIL-125 (Ti-MOF) & MB & UV & [182] \\
\hline MIL-88B, MIL-100, MIL-101 (Fe-MOFs) & R6G & visible & [167] \\
\hline MIL-53 (Fe-MOF) & $\begin{array}{l}\text { MG, RhB } \\
\text { MB }\end{array}$ & visible & $\begin{array}{l}{[183]} \\
{[184]}\end{array}$ \\
\hline MIL-88A & $\mathrm{MB}$ & visible & [185] \\
\hline NTU-9 (Ti-MOF) & $\mathrm{RhB}, \mathrm{MB}$ & visible & [174] \\
\hline $\begin{array}{l}\mathrm{Cu}(\mathrm{II}) \text {-imidazole MOFs } \\
\mathrm{Zn}(\mathrm{II}) \text {-imidazole MOFs }\end{array}$ & $\mathrm{MB}$ & visible & [174] \\
\hline TMU (Zn-MOF) & $\mathrm{CR}$ & UV and visible & [186] \\
\hline $\mathrm{UiO}-66$ (Zr-MOF) & MB & visible & [187] \\
\hline $\mathrm{Cu}$ (II)-imidazole MOFs & $\mathrm{RhB}, \mathrm{MB}$ & natural light & [188] \\
\hline $\mathrm{Cu}$ (II)-pyrazine MOFs & MB & sunlight & [189] \\
\hline UiO-66 (Zr-Ti MOFs) & MB & sunlight & [190] \\
\hline
\end{tabular}

${ }^{1} \mathrm{R} 6 \mathrm{G}=$ rhodamine $6 \mathrm{G} ; \mathrm{AO}$ = acid orange 7 ; $\mathrm{CR}=$ congo red; $\mathrm{EBT}=$ eriochrome black $\mathrm{T} ; \mathrm{MG}=$ malachite green .

Among the MOFs used under UV light stands out several Cd(II)-imidazole MOFs, as reported by Liu et al. [177]. Their study for the $\mathrm{MB}$ and $\mathrm{MO}$ degradation demonstrated that the $\mathrm{Cd}(\mathrm{II})$ complexes formed with the linkers were excited by UV light, generating the photogenerated charges that are required for dyes degradation. In a posterior work, Zhang et al. [178] tested other Cd(II)-imidazole MOFs for MO degradation and demonstrated that the adequate band gap was not the only factor that controlled the activity, had to take into account other factors, such as its efficiency in the transference and separation of charges. Zn(II)-imidazolate MOF, named ZIF-8, also revealed a high activity for the MB degradation under UV light due to the excitation of the Zn-complexes [179]. Regarding the types of MOFs described before, it has been reported that the ligand of $\mathrm{Ag}(\mathrm{I})$-tetrazole MOFs was relevant in the design of active photocatalysts for the R6G degradation [180]. Using ligands with more delocalized $\pi$ electrons (such as ethylenediamine and 5,5'-tetrazolate) favored the linker-metal cluster charge-transfer mechanism (LCCT), resulting in higher degradation rates.

Nevertheless, it is noteworthy that the technological application of photocatalysis tends to the use of solar light as an energy source. For this reason, many researchers are currently working on the design of MOFs with the aim of enhancing their activity under visible light. Different Fe-based MOFs have been tested for the photodegradation of dyes under visible light [158]. Among them, MIL-88B (based on terephthalate linkers) showed higher activity for R6G degradation than others MIL-100 and MIL-101 MOFs, which was associated to the visible light absorption of the Fe-oxo-clusters that formed the structure (being a type-I MOF) [167]. However, regarding the degradation rates, none of these Fe-based MOFs achieved full conversion values of the dye. Similar behavior has been reported by different authors when MIL-53 was used as photocatalyst under visible light. Although it absorbed the light in the visible region because of its low band gap, it only managed to degrade $40 \%$ of $\mathrm{RhB}$ after $6 \mathrm{~h}$ of reaction [183] and only 3\% of MB after $1 \mathrm{~h}$ [184]. Something similar occurred when using 
MIL-88A as photocatalyst. The degradation of MB only achieved $40 \%$ of conversion, requiring the incorporation of $\mathrm{H}_{2} \mathrm{O}_{2}$ as oxidant to achieve $100 \%$ conversion [185].

Since titanium dioxide is by far the most used photocatalyst, several researchers have focused on the preparation of Ti-MOFs. NTU-99 has been described as an efficient catalyst, achieving the complete degradation of $\mathrm{RhB}$ and $\mathrm{MB}$ in short times (20-80 min) and maintaining its activity after successive reaction cycles [191]. Although MIL-125 showed activity for other photocatalytic applications $\left(\mathrm{CO}_{2}\right.$ transformation and/or water splitting), its effectiveness in water purification is not so interesting [192-194]. For instance, under UV light, the MB conversion reached was $96 \%$ after $6 \mathrm{~h}$, but it should be noted that only by adsorption $90 \%$ of MB was removed from the solution (without light), so its photocatalytic activity is quite low [182]. More interesting is the design of MOFs with activity under solar light. In this sense, UiO-66(Ti) was successfully synthesized from UiO-66(Zr) MOF, reaching more than $80 \%$ of $\mathrm{MB}$ degradation under simulated sunlight [190]. Its activity was related to the light absorption by the titanium-oxo-clusters, which results in the generation of superoxide and hydroxyl radicals that are able to oxidize the dye.

The choice of adequate metal clusters is an important issue during the design of active MOFs. It has been described that the d-d spin of some metals could shift the absorption of the MOF to the visible region. Nevertheless, the ligands also play an important role in the photocatalytic activity for dyes degradation [173]. N,O-donor and $\mathrm{N}$-containing ligands are often selected for the synthesis of stable and functional MOFs. Using N,O-donor ligands results in the formation of chromophore blocks that provide $\pi-\pi$ transitions by light absorption. This property induces the shift of the absorption band to higher wavelengths. Interesting results were reported by Qiao et al. [174]. These authors prepared novel $\mathrm{Cu}-\mathrm{MOFs}$ with a mixture of N,O-donor ligands (pyridine- and imidazole-based ligands) able to degrade about $70-80 \%$ of several dyes (MO, MB and $\mathrm{RhB}$ ) under visible light in less than $4 \mathrm{~h}$. Complete conversion of MB was achieved after $2.5 \mathrm{~h}$ with a Co-MOF using triazaindolizine-based ligand as Co linker. Nevertheless, there are no data on their stability, reusability, or toxicity, and no reported works that better describe its performance from a technological point of view. N-donor ligands were also selected because they have lone electron pairs in their structure that can be faster transferred to the metal clusters [186], however the photocatalytic performances were below the expected. As an example, azine-functionalized $\mathrm{N}$-donor ligands were used for synthesizing Zn-MOFs [186]. Although the catalysts have low band gap values (2.2-2.6 eV), their photocatalytic activity was low, achieving only $40 \%$ conversion of congo red dye under visible light. Surprisingly, despite reducing the band gap, this type of catalysts (based on $\mathrm{N}$-donor ligands) showed better activity when evaluated under UV radiation $[186,195]$, which shows that the reduction of the band gap is not the only factor to be considered in the design of visible active photocatalysts. Based on these N-ligands, the modification of known MOFs by introducing $-\mathrm{NH}_{2}$ in the ligand has been studied $[103,168,173]$. Its incorporation usually results in the reduction of the band gap, extending the light absorption to the visible region. This behavior is ascribed to the conjugated $\pi$ electron transition from the amine-ligand to the metal-clusters. Nevertheless, as occurred with $\mathrm{N}$-donor ligands, although the $\mathrm{NH}_{2}-\mathrm{MOFs}$ had narrow band gaps, their photocatalytic activity did not stand out for dyes removal. Mu et al. demonstrated that UiO-66- $\mathrm{NH}_{2}$ had worse photocatalytic performance for $\mathrm{RhB}$ degradation than UiO-66 in spite of its lower band gap [196].

As has been said so far, the activity of MOFs in terms of dye conversion values is quite limited, mainly for their application under solar light. In addition, the stability of these MOFs in aqueous solutions is also an important drawback. For these reasons, different modifications are currently under study with a double aim to enhance the activity under solar light (achieving higher conversion rates) and the stability in aqueous solutions. Although in the literature there is a wide range of examples, this review focuses the attention on those modifications that are designed for the use of solar radiation. These modifications are similar to those made over other semiconductors that can be divided into: metal doping, metal nanoparticles decoration, and combination with free-metal semiconductors $[168,172,173]$. These modifications are mainly focused on (i) enhancing the light 
absorption, extending it to the visible region; (ii) generating electrons and holes; (iii) keeping the charges separated avoiding the recombination process; and, (iv) improving the stability. The following subsections collect information on this.

\subsubsection{Metal Doping}

The partial substitution of the metal centre of MOFs can enhance the photocatalytic activity under visible light, similar to what happens with other semiconductors [197]. The substitution of the pristine metal by other one yields the introduction of new energy levels, resulting in metal-to-metal charge transfers. These new assemblies are expected to improve the photocatalytic activity of the pristine MOF. Wang et al. [190] demonstrated that the replacement of $\mathrm{Zr}$ by Ti in UiO-66 was an effective way to increase the MB conversion rate under solar light. The Ti incorporation narrows the band gap of UiO-66 and enhances the absorption properties, which is attributed mainly to the electron donor properties of Ti. Other interesting example was reported by Li et al. [198] by the substitution of Zn by Ni in ZIF-8, resulting in a new MOF, denoted as BIT-11. This MOF achieved the complete disappearance of MB in less than $30 \mathrm{~min}$ under visible light. This behavior was ascribed to the photogenerated electrons of $\mathrm{Ni}$ atoms that have a variable valence. This MOF is also interesting because its structure changes slightly in water. Water molecules induced a chemical de-coordination resulting in a stable four-coordinated Ni clusters, denoted as BIT-11b.

The $\mathrm{NH}_{2}$-MIL-125 has been also modified by metal doping to enhance the MB photodegradation under simulated sunlight [199]. $\mathrm{Cr}$ (III) and $\mathrm{Ag}$ (I) were used as dopants, resulting in doped-MOFs that reached the total degradation of MB. Chromium was able to induce the formation of structural defects at the same time that incorporates new energy levels where the photogenerated electrons can migrate. By other side, silver atoms can act as electrons traps reducing the recombination processes and herby enhancing the photocatalytic activity. The stability of Ag-MIL-125, which maintained its activity even after five cycles of use, is also noteworthy.

\subsubsection{Metal Nanoparticles Decoration}

Different researchers have demonstrated that the incorporation of noble metal nanoparticles over the surface of the MOF improved its photocatalytic performance [168,173]. Nevertheless, most of those works study other photocatalytic applications, mainly hydrogen production, so there have not been many articles related to the degradation of dyes published. Liang et al. [134] reported an interesting work comparing effectiveness based on deposited metal. Pt, Pd, and Ag were loaded over MIL-100 applied in the methyl orange (MO) degradation upon visible light. Although all metals enhanced the activity, Pt@MIL-100 showed the highest conversion values, reaching complete degradation after $40 \mathrm{~min}$. It was also remarkable the stability of these M@MIL-100 that maintained the activity after five cycles of utilization and did not show any structural change. Pt@MIL-100 clearly exhibited the highest photocurrent density when compared with the other modified-MOFs, which showed that $\mathrm{Pt}$ was more effective in keeping the charges separated and avoiding the electron-hole recombination. Authors also detailed the mechanism that can be seen in Figure 11. Less expensive alternatives than $\mathrm{Pt}$ NPs have been explored in the literature. In this sense, Co-doped UiO-66 nanoparticles were synthesized by a one-step solvothermal method and tested for the degradation of tetracycline from wastewater [200]. Cu NPs have been also tested in different MOF-based materials for photocatalytic applications [201,202].

\subsubsection{Heterostructures Combining Different Components}

When compared to other strategies, an interesting solution is to assemble different semiconductors to construct novel heterostructures with improved activity under visible and solar light. The bibliography gathers different possibilities of combination, but it is necessary to emphasize that the objectives in all of them are to favor the absorption of visible light, to generate the charges and, perhaps most importantly, to keep them separated [168,172]. Without forgetting, of course, the 
requirement that these heterostructures must be stable and maintain their activity after successive uses. Some examples of these strategies are listed in Table 3.

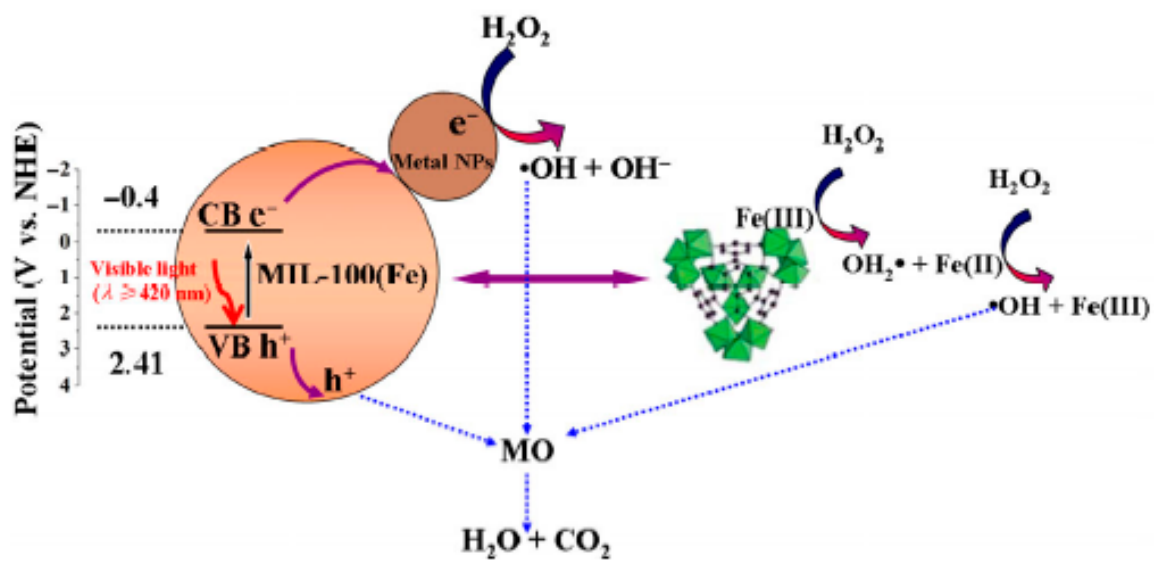

Figure 11. Scheme of the mechanism proposed for the Methyl orange (MO) photodegradation with several M@MIL-100 (M = Pt, Pd, Ag) under visible light (reproduced with permission from ref. [134]).

MOF combination with metal oxides commonly used in photocatalysis has been an interesting way to create novel photocatalysts. It is possible to find some examples combining the conventional $\mathrm{TiO}_{2}$ and $\mathrm{ZnO}$ oxides with different MOFs, but most of those heterostructures have been just proved under UV light [168]. An interesting heterojunction was recently reported, combining $\mathrm{TiO}_{2}$ nanosheets with MIL-100(Fe), but its photocatalytic performance under visible light requires the addition of $\mathrm{H}_{2} \mathrm{O}_{2}$ as oxidant to increase the amount of radicals that are responsible of the MB oxidation [203]. Something similar occurs by combining Fe-based MOF with iron oxides. They required the addition of $\mathrm{H}_{2} \mathrm{O}_{2}$, thus converting in a photo-Fenton like process. Beside this, Feng et al. [204] constructed recently a magnetic modified MOF based on $\mathrm{Fe}_{2} \mathrm{O}_{3} / \mathrm{MIL}-53(\mathrm{Fe})$. Although the best photocatalyst was not able to completely degrade the MB tested, the reusability of the photocatalysts was very interesting because it can be recovered from aqueous solution by a magnet thanks to the paramagnetic properties provided by the inclusion of $\mathrm{Fe}_{2} \mathrm{O}_{3}$.

Table 3. Heterostructures based on MOFs for dyes degradation under visible and solar light.

\begin{tabular}{|c|c|c|c|c|}
\hline MOFs & Dye Target $^{1}$ & Degradation Rate & Light Source & Reference \\
\hline $\mathrm{Fe}_{2} \mathrm{O}_{3} / \mathrm{MIL}-53(\mathrm{Fe})$ & MB & $70 \%-240 \mathrm{~min}$ & visible & [204] \\
\hline $\mathrm{BiVO}_{4} / \mathrm{UiO}-66$ & RhB & $100 \%-140 \mathrm{~min}$ & visible & [160] \\
\hline $\mathrm{Bi}_{2} \mathrm{WO}_{6} / \mathrm{UiO}-66$ & RhB & $100 \%-180 \mathrm{~min}$ & visible & [205] \\
\hline $\mathrm{Bi}_{2} \mathrm{MoO}_{6} / \mathrm{UiO}-66$ & RhB & $95 \%-120 \mathrm{~min}$ & visible & [206] \\
\hline $\mathrm{Bi}_{2} \mathrm{MoO}_{6} / \mathrm{MIL}-100$ & RhB & $90 \%-90 \mathrm{~min}$ & visible & [207] \\
\hline $\mathrm{BiOBr} / \mathrm{UiO}-66$ & $\mathrm{RhB}$ & $100 \%-15 \mathrm{~min}$ & visible & [208] \\
\hline $\mathrm{BiOBr} / \mathrm{NH}_{2}-\mathrm{MIL}-125$ & RhB & $100 \%-100 \mathrm{~min}$ & visible & [209] \\
\hline $\mathrm{Ag}_{2} \mathrm{CO}_{3} / \mathrm{UiO}-66(\mathrm{Zr})$ & RhB & $100 \%-120 \mathrm{~min}$ & visible & [210] \\
\hline $\mathrm{AgI} / \mathrm{UiO}-66(\mathrm{Zr})$ & RhB & $100 \%-60 \mathrm{~min}$ & visible & [211] \\
\hline $\mathrm{Ag}_{3} \mathrm{PO}_{4} / \mathrm{MIL}-53(\mathrm{Fe})$ & RhB & $100 \%-90 \mathrm{~min}$ & visible & [212] \\
\hline $\mathrm{g}-\mathrm{C}_{3} \mathrm{~N}_{4} / \mathrm{MIL}-125$ & $\mathrm{RhB}$ & $100 \%-60 \mathrm{~min}$ & visible & [213] \\
\hline $\mathrm{g}-\mathrm{C}_{3} \mathrm{~N}_{4} / \mathrm{MIL}-100$ & RhB & $100 \%-240 \mathrm{~min}$ & visible & [214] \\
\hline $\mathrm{g}-\mathrm{C}_{3} \mathrm{~N}_{4} / \mathrm{MIL}-53(\mathrm{Al})$ & RhB & $100 \%-75 \mathrm{~min}$ & visible & [215] \\
\hline $\mathrm{rGO} / \mathrm{NH}_{2}-\mathrm{MIL}-125$ & MB & $100 \%-30 \mathrm{~min}$ & visible & [216] \\
\hline rGO/MIL-88(Fe) & $\mathrm{RhB}, \mathrm{MB}$ & $100 \%-20 \mathrm{~min}$ & sunlight & [217] \\
\hline GO/MIL-101(Cr) & MG & $92 \%-60 \mathrm{~min}$ & sunlight & [218] \\
\hline
\end{tabular}

${ }^{1} \mathrm{RhB}=$ rhodamine $\mathrm{B} ; \mathrm{MB}=$ methylene blue; $\mathrm{MG}=$ malachite green. 
Bismuth based materials are another typical class of semiconductor studied that have attracted wide attention as visible-light-driven photocatalysts because of their narrow band gap. $\mathrm{Bi}_{2} \mathrm{WO}_{6}$ was assembled on UiO-66( $\mathrm{Zr}$ ) for the removal of $\mathrm{RhB}$ under visible lights. The data demonstrated the high activity of these composites that depended on the Bi: $\mathrm{Zr}$ ratio used during the synthesis. $\mathrm{RhB}$ was totally degraded after $3 \mathrm{~h}$ of reaction due to the formation of $\mathrm{O}_{2}{ }^{--}$and $\mathrm{h}^{+}$as main active species [205]. Further, same authors were also able to synthesize several $\mathrm{BiOBr} / \mathrm{UiO}-66$ composites that were more efficient than $\mathrm{Bi}_{2} \mathrm{WO}_{6} / \mathrm{UiO}-66$, achieving total elimination of $\mathrm{RhB}$ in just 15 min under visible light [208]. The activity of this composite was also attributed to the generation of active $\mathrm{O}_{2}{ }^{\bullet-}$ and $\mathrm{h}^{+}$species. More recently, $\mathrm{Bi}_{2} \mathrm{MoO}_{6}$ was coupled to UiO-66, yielding novel photocatalysts with a similar photocatalytic activity than $\mathrm{Bi}_{2} \mathrm{WO}_{6} / \mathrm{UiO}-66$ for the removal of $\mathrm{RhB}$ under visible light [206]. It is noteworthy that all these heterostructures were better than the pristine UiO-66, which just achieved $\mathrm{RhB}$ conversion values close to $40 \%$. The combination of MOFs with bismuth compounds improves the photocatalytic activity because it favors the separation of charges, inhibiting the recombination and thus generating more radical species [209].

Several silver-based materials have been also used as a component to promote the photocatalytic activity for dyes degradation. $\mathrm{Ag}_{2} \mathrm{CO}_{3}$ was combined with $\mathrm{UiO}-66(\mathrm{Zr})$ yielding high $\mathrm{RhB}$ degradation rates [210]. The results showed the existence of an interaction between the $\mathrm{Ag}_{2} \mathrm{CO}_{3}$ and the UiO-66, which benefited the structural stability of the composite and its photocatalytic performance. The same authors also fabricated a similar heterostructure with $\mathrm{AgI}$ and $\mathrm{UiO}-66$, achieving analogous performance for $\mathrm{RhB}$ degradation [211].

g- $\mathrm{C}_{3} \mathrm{~N}_{4}$ is a metal-free semiconductor with a low band gap $(2.70 \mathrm{eV})$ that can absorb visible light, so it has a great potential for photocatalytic applications. Its coupling with different MOFs has been considered by researches for dyes removal. g- $\mathrm{C}_{3} \mathrm{~N}_{4} / \mathrm{MIL}-125$ heterostructure was created some years ago by hydrothermal synthesis, studying the optimal ratio among both components. The photocatalytic data showed that just incorporating $7 \%$ of $g-C_{3} \mathrm{~N}_{4}$ was possible to increase the degradation rate to double [213]. The stability of this heterostructure was also remarkable, showing the same $\mathrm{RhB}$ reduction after five recycles. The photocatalytic performance was ascribed to the electron transfer in the metal-oxo-clusters, the light absorption by $\mathrm{g}-\mathrm{C}_{3} \mathrm{~N}_{4}$, and the intimate contact among both semiconductors that favors the charges separation [214].

Graphene materials have been also proved as a component to create novel heterojunctions with different MOFs for water treatment by photocatalysis. Reduced graphene oxide (rGO) and graphene oxide (GO) have been selected because of their textural and conductive properties (see examples in Table 3). $\mathrm{rGO} / \mathrm{NH}_{2}-\mathrm{MIL}-125$ turns out to be an interesting example [216]. Authors described the high photocatalytic performance of this heterojunction for MG degradation, but also demonstrated that the incorporation of rGO affected the crystallization of the MOF. Both $\mathrm{NH}_{2}$ MIL- 125 and rGO are $\pi$-rich structures that, when combined, generate strong interactions that produce the twisting of the Ti-oxo-clusters and distort the $\mathrm{NH}_{2}$-MIL-125 structure. When designing heterojunctions, it is also important to take into account the relationship between both components. This issue was also studied in this work, showing that rGO amounts higher than $20 \%$ diminished the activity, because a redundant relationship between both semiconductors occurred that caused weakness in the movement of electrons.

Continuing with the idea of achieving more efficient use of solar energy, due to the increasing environmental and energy concerns, the synthesis of ternary and hybrid systems has received great attention. These systems integrate different components (more than 2) in order to take advantage of the synergy between different heterojunctions. Table 4 summarizes some representative examples, recently reported, highlighting Z-schemes systems that are based on plasmonic structures. Most of them use silver nanoparticles and other silver compounds to enhance the photocatalytic activity. The superior activity of these ternary systems was usually attributed to the synergistic effects from the surface plasmon resonance (SPR) of silver compounds and the sequential transfer of charges via the known Z-scheme mechanism, resulting in an efficient separation of electron-hole pairs [141]. Nevertheless, 
in some cases the stability of these hybrids is not strong enough. For instance, $\mathrm{Ag} / \mathrm{AgCl} / \mathrm{MIL}-53$ exhibited high photocatalytic activity for the removal of different dyes, but its efficiency decreased after several recycles [219].

Table 4. Ternary and hybrid systems for dyes removal under visible and solar light.

\begin{tabular}{ccccc}
\hline MOFs & Dye Target $^{\text {1 }}$ & Degradation Rate & Light Source & Reference \\
\hline $\mathrm{Ag} / \mathrm{AgCl} / \mathrm{ZIF}-8$ & $\mathrm{RhB}$ & $70 \%-60 \mathrm{~min}$ & visible & {$[220]$} \\
& & $98 \%-16 \mathrm{~min}$ & sunlight & {$[221]$} \\
\hline $\mathrm{Ag} / \mathrm{AgCl} / \mathrm{MIL}-53$ & $\mathrm{RhB}, \mathrm{MB}$ & $100 \%-50 \mathrm{~min}$ & visible & {$[219]$} \\
$\mathrm{Ag} / \mathrm{Ag}_{3} \mathrm{PO} / \mathrm{HKUST}-1$ & $\mathrm{PBS}$ & $80 \%-90 \mathrm{~min}$ & visible & {$[141]$} \\
$\mathrm{Ag}_{3} \mathrm{PO} \mathrm{H}_{4} / \mathrm{MIL}-101 / \mathrm{NiFe}_{2} \mathrm{O}_{4}$ & $\mathrm{RhB}$ & $95 \%-30 \mathrm{~min}$ & visible & {$[222]$} \\
$\mathrm{Ag} / \mathrm{GO} / \mathrm{MIL}-125$ & $\mathrm{RhB}$ & $95 \%-50 \mathrm{~min}$ & visible & {$[223]$} \\
\hline $\mathrm{Pd} / \mathrm{GO} / \mathrm{MIL}-101(\mathrm{Cr})$ & brilliant green & $100 \%-15 \mathrm{~min}$ & visible & {$[224]$} \\
\hline
\end{tabular}

${ }^{1} \mathrm{RhB}=$ rhodamine $\mathrm{B} ; \mathrm{MB}=$ methylene blue; $\mathrm{PBS}$ = ponceau $\mathrm{BS}$.

\subsection{Photoreduction of Heavy Metals}

Regarding the water pollution, heavy metals turn out to be toxic pollutants whose removal is one of the challenges of many researches. Different heavy metals have been detected in surface water and industrial wastewater, with lead, mercury, cadmium, arsenic, and chromium being the most representative. These compounds cause acute toxicity on humans and aquatic organisms [225,226]. A recent review reports the use of MOFs for the removal of heavy metals from water, but it is curious that the vast majority are dedicated to elimination by adsorption [227]. There is a small number of works that try to convert these toxic species into others of lower toxicity. Among them stands out the reduction of $\mathrm{Cr}(\mathrm{VI})$ by photocatalysis. The removal of $\mathrm{Cr}(\mathrm{VI})$ is one of the objectives in environmental remediation due to the increasing use of chromium compounds in various industries, such as metal plating and tanneries. Table 5 summarizes some representative examples that are used for chromium reduction under visible light, including some pristine and modified-MOFs.

Table 5. Relevant MOFs and modified-MOFs used for $\mathrm{Cr}(\mathrm{VI})$ reduction under visible light.

\begin{tabular}{ccc}
\hline MOFs & Degradation Rate & Reference \\
\hline MIL-68 & $100 \%-5 \mathrm{~min}(\mathrm{pH}=3)$ & {$[228]$} \\
$\mathrm{NH}_{2}-\mathrm{MIL}^{-88}, \mathrm{NH}_{2}-\mathrm{MIL}-101$ & $100 \%-40 / 60 \mathrm{~min}$ & {$[50]$} \\
$\mathrm{NH}_{2}$-MIL-125 & $80 \%-60 \mathrm{~min}$ & {$[229]$} \\
\hline $\mathrm{Au}, \mathrm{Pd}, \mathrm{Pt} @ \mathrm{MIL}-100$ & $100 \%-8 \mathrm{~min}$ & {$[134]$} \\
$\mathrm{Pd} @ U$ UiO-66-NH & & {$[230]$} \\
\hline $\mathrm{rGO} / \mathrm{UiO}-66-\mathrm{NH}_{2}$ & $100 \%-100 \mathrm{~min}$ & {$[140]$} \\
$\mathrm{g}-\mathrm{C}_{3} \mathrm{~N}_{4} / \mathrm{MIL}-53(\mathrm{Fe})$ & $100 \%-100 \mathrm{~min}$ & {$[231]$} \\
$\mathrm{rGO} / \mathrm{MIL}-53(\mathrm{Fe})$ & $100 \%-180 \mathrm{~min}$ & {$[232]$} \\
\hline $\mathrm{Ag} / \mathrm{AgCl} / \mathrm{MIL}-53$ & $100 \%-80 \mathrm{~min}$ & {$[219]$} \\
\hline
\end{tabular}

Initially Fe-based MOFs, such as MIL-53 or MIL-100, were tested for reducing $\mathrm{Cr}(\mathrm{VI})$, although not too many were able to achieve high conversion rates at short times (among 1 and $2 \mathrm{~h}$ ) [227]. The continuous investigations on MOFs have allowed advancement in the development of more efficient photocatalysts. Thus, MIL-68(Fe) prepared by solvothermal methodology showed high activity under visible light in a wide $\mathrm{pH}$ range [228]. 100\% conversion rate was obtained in just $5 \mathrm{~min}$ at $\mathrm{pH}=3$. Higher $\mathrm{pH}$ values result in the same conversion rate but requires greater times, e.g., $60 \mathrm{~min}$ are required at $\mathrm{pH}=6$. The amine functionalization of different MOFs was also tested by different authors. Shi et al. [50] prepared different amine-Fe-based-MOFs and observed that the amine 
effect depends on the pristine MOF structure. Thus, while $\mathrm{NH}_{2}-\mathrm{MIL}-88$ and $\mathrm{NH}_{2}$-MIL-101 achieved complete $\mathrm{Cr}(\mathrm{VI})$ reduction among $40-60 \mathrm{~min}, \mathrm{NH}_{2}-\mathrm{MIL}-53$ only managed to reduce $10 \%$ of $\mathrm{Cr}(\mathrm{VI})$. Authors assumed that the high performance of those $\mathrm{NH}_{2}-\mathrm{MIL}(\mathrm{Fe})$ is because the incorporation of $\mathrm{NH}_{2}$ in the linker promotes the transfer of charges between the organic linker and the iron cluster and it enhances the light absorption. These $\mathrm{NH}_{2}-\mathrm{MIL}(\mathrm{Fe})$ also exhibited high stability in the reaction medium, maintaining their performance after successive reuses.

Regarding the modified-MOFs, the strategies followed so far to modify MOFs are the same as those that are described above in Section 6.1, mainly metal NPs decoration and heterostructures creation. The M@MIL-100 system described before for MO degradation was also tested for $\mathrm{Cr}(\mathrm{VI})$ reduction, demonstrating once again the activity of these modified-MOFs [134]. All of them reached the complete reduction of $\mathrm{Cr}(\mathrm{VI})$ to $\mathrm{Cr}(\mathrm{III})$ in very short times, even Pt@MIL-100 only needed 8 min, even being stable when reused in successive occasions. Different heterostructures have also been tested in the reduction of chromium by photocatalysis. Heterojunctions with $\mathrm{g}-\mathrm{C}_{3} \mathrm{~N}_{4}$ are attracting great attention, as occurred for dyes degradation, because the contact between both semiconductors inhibits the recombination process. In a recent work, g- $\mathrm{C}_{3} \mathrm{~N}_{4} / \mathrm{MIL}-153(\mathrm{Fe})$ was successfully prepared, demonstrating high conversion rates for the reduction of $\mathrm{Cr}(\mathrm{VI})$. The study revealed that the activity was not only favored by the inhibition of recombination but also because the contact improved charges mobility thanks to the good conductive properties of $\mathrm{g}-\mathrm{C}_{3} \mathrm{~N}_{4}$ [231]. Analogous performance was obtained when MIL-53(Fe) was assembled with reduced graphene oxide (rGO), which was able to minimize the charges recombination [232]. The promoter effect of $\mathrm{rGO}$ has been also observed during the $\mathrm{Cr}(\mathrm{VI})$ reduction with $\mathrm{rGO} / \mathrm{UiO}-66-\mathrm{NH}_{2}$. In this case, $\mathrm{rGO}$ acts as an electron trapper, extending the average life time of electron-hole pairs [140].

At this stands, it is noteworthy that, contrary to what happens with other semiconductors, MOFs have not been tested almost for the reduction of heavy metals other than $\mathrm{Cr}(\mathrm{VI})$. Even, the use of solar light has not been considered enough in photoreduction processes instead of what happens with the degradation of dyes. Therefore, there are still many opportunities for research in this field to apply MOFs to heavy metals remediation.

\subsection{Photodegradation of Priority Pollutants}

Different chemical pollutants were included by the Environmental Protection Agency (EPA, Washington, DC, USA) in a list because of their toxicity and their presence in urban areas and wastewater systems [233]. They were known as priority pollutants, including polycyclic aromatic hydrocarbons, pesticides, volatile organic compounds, chlorobenzenes, phthalates, and alkylphenols. Their toxicity was related to their carcinogenic and mutagenic effect on organisms and humans, aggrieved by their persistence in the environment.

Among them, phenol and related phenolic-compounds have been extensively studied as target contaminants in many technologies that are focused on water purification. Their degradation pathways are known in detail, which allows for establishing a reliable comparison between various photocatalysts. Nevertheless, not too many MOFs have been tested for phenol degradation, probably because the conversion rates achieved were not so high. For instance, Alvaro et al. [165] compared some time ago the activity of MOF- 5 with $\mathrm{TiO}_{2}$ and $\mathrm{ZnO}$ semiconductors for phenol degradation under UV light. Although, the activity per metal atom was somewhat superior, the conversion rate per gram of catalyst was considerably inferior. Even, posterior studies demonstrated the instability of MOF-5 in water systems [227]. More recently, Surib et al. [234] intercalated several metal ions ( $\mathrm{Ag}^{+}$, $\mathrm{Fe}^{3+}$, and $\mathrm{Zn}^{2+}$ ) into the porous framework of a Cd-MOF by ion-exchange, yielding a new series of photocatalysts used for the removal of 2-chlorophenol under direct daylight illumination. All of the tested modified-MOFs were more active than the common $\mathrm{TiO}_{2}$, although when intercalated with $\mathrm{Fe}^{3+}$ they achieved the highest conversion value, $93 \%$ after $5 \mathrm{~h}$ of reaction. Authors explained that this activity was due to the new energy levels that were triggered between the bands of Cd-MOF by 
the metal ion. These new levels reduced the band gap enhancing the light absorption. Despite these results, the use of MOFs in the degradation of priority pollutants is still untapped.

\subsection{Photodegradation of Emerging Pollutants}

Emerging pollutants have raised concerns in water treatment because they are found in wastewater in low concentrations due to the continued use by humans. The discharge regulations of these compounds are not completely or not at all regulated, which can result in real hazards to the human health and environment. Among the emerging pollutants, it is possible to find pharmaceuticals, personal care products, plasticizers and pesticides, among others [235]. The degradation of emerging pollutants requires highly efficient photocatalysts that are capable of absorbing visible radiation, generating the necessary charges and keeping them separate for the creation of radicals that oxidize contaminants, since these pollutants present a chemical structure that is more difficult to oxidize than dyes. Despite research into the design of MOFs with photocatalytic activity, until now there are few works dedicated to the removal of emerging pollutants and most are focused on Fe-based MOFs. Among Fe-MOFs, MIL-53, MIL-101, and MIL-100 were used for the removal of tetracycline in water solutions. MIL-101 was with difference the most active, attributed to its structure, reaching $100 \%$ disappearance of the compound [60]. However, it highlights that $60 \%$ of the tetracycline elimination was due to the adsorption process and only $40 \%$ was removed by photocatalysis. Although there were no data about the detection of byproducts, the study about the radical mechanism demonstrated that $\mathrm{O}_{2}{ }^{\bullet-}, \mathrm{h}^{+}$, and $\bullet \mathrm{OH}$ were involved in the tetracycline degradation. The MIL-100 and its derivative Pd@MIL-100 have also been evaluated in the degradation of various pharmaceuticals and personal care products (PPCPs), theophylline, ibuprofen, and bisphenol A [170]. However, their activity was quite limited and required the incorporation of additional oxidants, such as $\mathrm{H}_{2} \mathrm{O}_{2}$, to achieve conversions that are greater than $60 \%$, becoming a photo-Fenton type process.

Better results have been recently achieved by Huang et al. [236] with a novel Ag/ AgCl@MIL-88A(Fe) composite. This composite reached the total removal of ibuprofen under visible light after $3 \mathrm{~h}$ of reaction, but more interesting is the high degree of mineralization, achieving in that time a TOC reduction of $90 \%$. The stability of this composite is also remarkable. It maintains the activity after four recycles and keeps its structure, without the negligible leaching of Fe and Ag after those four cycles. Authors even studied the degradation pathway and concluded that $\mathrm{h}^{+}, \mathrm{e}^{-}$, and $\mathrm{O}_{2}{ }^{\bullet-}$ played important roles on the photocatalytic degradation. The performance of this composite is due to a synergistic effect between the plasmon resonance of $\mathrm{Ag} \mathrm{NPs}$, the light absorption of both $\mathrm{MOF}$ and $\mathrm{AgCl}$, and the charges separation due to the interconnection among the three components (Figure 12). Fun et al. [237] prepared a Ag/AgCl@ZIF-8 MOF to eliminate acetaminophen under visible light irradiation.

Interesting works have been recently reported focused on the degradation of tetracycline antibiotic. Wang et al. [238] developed a core-shell $\mathrm{In}_{2} \mathrm{~S}_{3} / \mathrm{MIL}-125$ (Ti) heterostructure that is capable of degrading $60 \%$ tetracycline after $60 \mathrm{~min}$ upon visible light. This result is very interesting when considering that the tetracycline oxidation is more difficult than that of dyes. However, compared to other conventional photocatalysts, the mineralization rate was quite low. Only $17 \%$ of tetracycline was transformed on $\mathrm{CO}_{2}$ and $\mathrm{H}_{2} \mathrm{O}$. Even, the stability of this heterostructure was not high enough, the conversion rate decreased to $45 \%$ after three successive cycles. Higher rates were obtained for the tetracycline photodegradation upon sunlight by using a novel g- $\mathrm{C}_{3} \mathrm{~N}_{4} / \mathrm{ZIF}-8$ heterostructure [239]. Total disappearance was exhibited after $60 \mathrm{~min}$ of reaction, although there are no data about the mineralization of the antibiotic. The mechanism proposed that ZIF- 8 absorbs the light yielding photogenerated electrons that are further transferred to the g- $\mathrm{C}_{3} \mathrm{~N}_{4}$. These electrons react with the $\mathrm{O}_{2}$ that is present in the medium, generating $\mathrm{O}_{2}{ }^{\bullet-}$ radicals that are involved in the tetracycline oxidation. At the same time, the holes that are generated in the ZIF- 8 can also interact with the target molecules. As occurred in other heterojunctions, the synergistic effect between both components promotes the separation of charges and inhibits the undesired recombination process. 


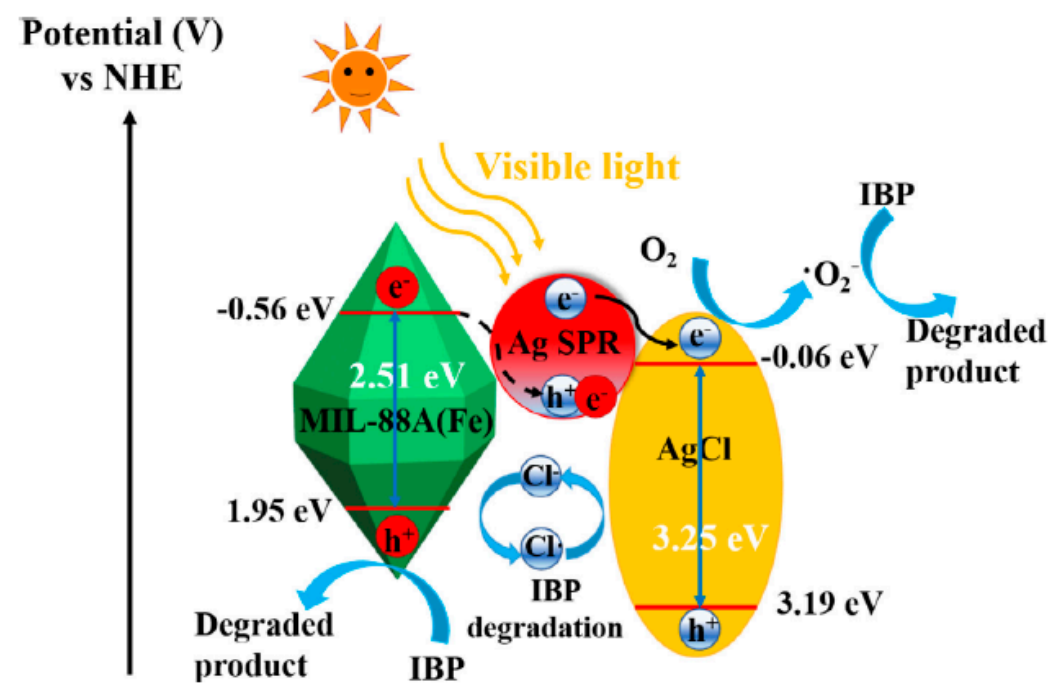

Figure 12. Scheme of ibuprofen degradation performed by Ag/AgCl@MIL-88A(Fe) under visible light (reproduced with permission from ref. [236]).

\subsection{Stability and Reusability of MOFs during Water Purification by Photocatalysis}

Unfortunately, MOFs have relatively inferior stability than other photocatalysts, such as those based on $\mathrm{TiO}_{2}, \mathrm{CdS}, \mathrm{BiVO}_{4}, \mathrm{~g}_{-} \mathrm{C}_{3} \mathrm{~N}_{4}$, and their heterojunctions. Their instability can be mainly related to the self-dissolution of some components into the aqueous reaction medium, and some irreversible reaction of metal clusters and/or the organic linkers with some component (reactant, products, or by-products) of the water medium $[163,194]$. The main factor controlling the stability of MOFs in water is the strength of the metal-ligand bonds, although the crystallinity, metal-ligand coordination geometry, and porosity must be also considered $[115,240]$. The methodologies commonly used to study the stability of MOFs are the characterization of the recovered used-MOF after the reaction, mainly studying the surface morphology and crystalline structure, the metal leaching analysis, and the reusability tests. It must be taken into account that one of the main aims in terms of environmental protection is to avoid the leaching of transition metals into the reaction solutions. Nevertheless, it is also important to avoid the leaching of organic compounds, such as the ligands, whose toxicity could be even higher than that of the pollutants to be removed. In this respect, although the stability of the MOFs is currently under study, so far the reported works on the use of MOFs in photocatalysis do not provide information about the toxicity associated to the leachate or to some by-products. This issue should be taken into account regarding future implementation. Reusability is also a very relevant criterion for the use of MOFs. The main reasons established for the reduction of the photocatalytic activity after several cycles of use were: (i) the inevitable dissolution of some MOF's components during the photocatalytic reaction and (ii) the deactivation of the MOF surface due to the adsorption of some reactant or product [164]. Regarding the stability and reusability, some MOFs and MOF-based composites have been demonstrated to exhibit reasonable stability and reusability for the catalytic removal of water contaminants.

As it has been mentioned before, MIL-53(Fe) has been one of the most studied MOF in photocatalysis. However, some works reveals that its photocatalytic activity decreased significantly after reutilization for degrading several dyes under visible light. Feng et al. [204] showed that the conversion rate for MB degradation with MIL-53(Fe) decreased from $90 \%$ to $30 \%$ after only three cycles of use. Worse results were obtained by Araya et al. [241] with this MOF, whose photocatalytic performance disappeared after five cycles during RhB degradation. In this case, the instability was due to the iron leaching on the reaction medium. However, both works reported interesting solutions to avoid the MIL-53(Fe) instability based on combining the MIL-53(Fe) with other components. The degradation of MB was enhanced by synthesizing a magnetic $\mathrm{Fe}_{2} \mathrm{O}_{3}$-MIL-53 composite, maintaining a $60 \%$ conversion rate after 
three cycles [204], while more than $90 \%$ was kept for RhB removal by using a novel hybrid material Amberlite-MIL-53 combining the MOF with a resin [241].

In addition, many efforts are currently focused on the development of multicomponent MOFs, also called MOFs-hybrid materials or MOFs-composites, looking for a synergistic effect that enhances the stability and reusability, the photocatalytic activity, and a better use of the visible light. However, as it has been affirmed before, the majority of the researches have been focused on the photodegradation of dyes. The application of MOFs on degrading other pollutants is an important aim to be pursued in future investigations, shifting, for instance, to the removal of inorganic species, emerging pollutants, or, even, pathogens from water, focusing the attention on the use of solar light as energy source. It is also important to remark that the use of MOFs as photocatalysts for water treatment has not been commercially implemented. That would require solving some important questions. The stability and reusability are main issues, as discussed throughout this review. The MOF must be stable under the reaction conditions without any leaching of the metal or of the organic constituents and it must maintain its photocatalytic performance after successive uses. Nevertheless, synthesis procedures are also crucial. As discussed above, the solvothermal method is the most commonly used, which requires temperature $\left(80-180^{\circ} \mathrm{C}\right)$, long reaction time, and the use of organic solvents, such as DMF. This method has been criticized for both environmental and economic reasons, being important limitations regarding potential application of MOFs. Thus, researchers seek alternative methods for obtaining MOF structures using water as solvent and other synthesis methods to overcome these drawbacks. In this respect, the mechano-chemical synthesis arises as a promising alternative to avoid the use of solvents [91,92,242]. Surely, further studies are required to find a sustainable and environmental-friendly synthesis method.

\section{Conclusions and Outlooks}

MOFs are a relatively novel class of porous inorganic-organic materials with the repetitive structure from unit cell being composed by organic linkers and clusters or metal nodes (SBUs). The combination of these components allows for synthesizing MOFs with tailored properties for specific applications, such as photocatalytic degradation of pollutants from water. In order to much widen the application of MOFs for the photocatalytic water purification process, a deeper understanding of the structural parameters controlling their activity is needed. Furthermore, most of the studies performed up to date are focused in the degradation of dyes using UV light as energy source. A more complete analysis of the degradation of other compounds is advisable, including the photocatalytic degradation of emerging contaminants and the reduction of heavy metals.

For real application and as compared to traditional semiconductors, such as $\mathrm{TiO}_{2}$ or $\mathrm{ZnO}$, two aspects must be improved. First, the synthesis conditions should allow for obtaining higher amounts of MOFs in continuous operation, solvothermal processes are limited by the slow reaction rates, and at a lower cost. Second, the stability of MOFs in water should be assured. However, MOFs can be more easily modulated to absorb light in the visible range and therefore they can be considered as more efficient photocatalysts under solar irradiation. With the achievement of these requirements, MOFs can become a real alternative with promising future for the removal of different pollutants that are present in water by photocatalysis.

Author Contributions: J.B., V.M.-R., M.P.-G., A.G.-A., J.J.R. and C.B. wrote and revised the manuscript.

Funding: This research was funded by Spanish MINECO project CTQ2016-78576-R.

Acknowledgments: The authors acknowledge the financial support from Spanish MINECO (project CTQ2016-78576-R). V. Muelas-Ramos thanks to MCIU for BES-2017-082613 grant. M. Peñas-Garzón is indebted to Spanish MECD for FPU16/00576 predoctoral contract.

Conflicts of Interest: The authors declare no conflict of interest. 


\section{References}

1. Wada, Y.; Flörke, M.; Hanasaki, N.; Eisner, S.; Fischer, G.; Tramberend, S.; Satoh, Y.; Van Vliet, M.T.H.; Yillia, P.; Ringler, C.; et al. Modeling global water use for the 21st century: The Water Futures and Solutions (WFaS) initiative and its approaches. Geosci. Model Dev. 2016, 9, 175-222. [CrossRef]

2. WWAP (United Nations World Water Assessment Programme)/UN-Water. The United Nations World Water Development Report 2018: Nature-Based Solutions for Water; WWAP: Paris, France, 2018.

3. Veldkamp, T.I.E.; Wada, Y.; Aerts, J.C.J.H.; Döll, P.; Gosling, S.N.; Liu, J.; Masaki, Y.; Oki, T.; Ostberg, S.; Pokhrel, Y.; et al. Water scarcity hotspots travel downstream due to human interventions in the 20th and 21st century. Nat. Commun. 2017, 8, 15697. [CrossRef] [PubMed]

4. OECD. OECD Environmental Performance Reviews: Chile 2016; OECD Environmental Performance Reviews; OECD Publishing: Paris, France, 2016.

5. United Nations, Department of Economic and Social Affairs, Population Division. World Population Prospects: The 2017 Revision, Key Findings and Advance Tables; United Nations: New York, NY, USA, 2017.

6. De, A.; Bose, R.; Kumar, A.; Mozumdar, S. Targeted Delivery of Pesticides Using Biodegradable Polymeric Nanoparticles; Springer Briefs in Molecular Science; Springer: New Delhi, India, 2014.

7. Freyria, F.; Geobaldo, F.; Bonelli, B.; Freyria, F.S.; Geobaldo, F.; Bonelli, B. Nanomaterials for the Abatement of Pharmaceuticals and Personal Care Products from Wastewater. Appl. Sci. 2018, 8, 170. [CrossRef]

8. Taheran, M.; Naghdi, M.; Brar, S.K.; Verma, M.; Surampalli, R.Y. Emerging contaminants: Here today, there tomorrow! Environ. Nanotechnol. Monit. Manag. 2018, 10, 122-126. [CrossRef]

9. United Nations Environment Programme. Good Practices for Regulating Wastewater Treatment: Legislation, Policies and Standards; United Nations Environment Programme: Nairobi, Kenya, 2015.

10. Yang, Y.; Ok, Y.S.; Kim, K.H.; Kwon, E.E.; Tsang, Y.F. Occurrences and removal of pharmaceuticals and personal care products (PPCPs) in drinking water and water/sewage treatment plants: A review. Sci. Total Environ. 2017, 596-597, 303-320. [CrossRef]

11. Abu-Ghunmi, D.; Abu-Ghunmi, L.; Kayal, B.; Bino, A. Circular economy and the opportunity cost of not 'closing the loop' of water industry: The case of Jordan. J. Clean. Prod. 2016, 131, 228-236. [CrossRef]

12. Mohammad, A.W.; Teow, Y.H.; Ang, W.L.; Chung, Y.T.; Oatley-Radcliffe, D.L.; Hilal, N. Nanofiltration membranes review: Recent advances and future prospects. DES 2014, 356, 226-254. [CrossRef]

13. Grandclément, C.; Seyssiecq, I.; Piram, A.; Wong-Wah-Chung, P.; Vanot, G.; Tiliacos, N.; Roche, N.; Doumenq, P. From the conventional biological wastewater treatment to hybrid processes, the evaluation of organic micropollutant removal: A review. Water Res. 2017, 111, 297-317. [CrossRef]

14. Burkhardt-Holm, P. Linking Water Quality to Human Health and Environment: The Fate of Micropollutants; Institute of Water Policy, National University of Singapore: Singapore, 2011; 62p.

15. Thomaidi, V.S.; Stasinakis, A.S.; Borova, V.L.; Thomaidis, N.S. Is there a risk for the aquatic environment due to the existence of emerging organic contaminants in treated domestic wastewater? Greece as a case-study. J. Hazard. Mater. 2015, 283, 740-747. [CrossRef]

16. Deng, Y.; Zhao, R. Advanced Oxidation Processes (AOPs) in Wastewater Treatment. Curr. Pollut. Rep. 2015, 1,167-176. [CrossRef]

17. Ribeiro, A.R.; Nunes, O.C.; Pereira, M.F.R.; Silva, A.M.T. An overview on the advanced oxidation processes applied for the treatment of water pollutants defined in the recently launched Directive 2013/39/EU. Environ. Int. 2015, 75, 33-51. [CrossRef] [PubMed]

18. Singh, S.; Barick, K.C.; Bahadur, D. $\mathrm{Fe}_{3} \mathrm{O}_{4}$ embedded $\mathrm{ZnO}$ nanocomposites for the removal of toxic metal ions, organic dyes and bacterial pathogens. J. Mater. Chem. A 2013, 1, 3325. [CrossRef]

19. Litter, M.I. Mechanisms of removal of heavy metals and arsenic from water by $\mathrm{TiO}_{2}$-heterogeneous photocatalysis. Pure Appl. Chem. 2015, 87, 557-567. [CrossRef]

20. Di, G.; Zhu, Z.; Zhang, H.; Zhu, J.; Lu, H.; Zhang, W.; Qiu, Y.; Zhu, L.; Küppers, S. Simultaneous removal of several pharmaceuticals and arsenic on Zn-Fe mixed metal oxides: Combination of photocatalysis and adsorption. Chem. Eng. J. 2017, 328, 141-151. [CrossRef]

21. Zhang, L.; Qin, M.; Yu, W.; Zhang, Q.; Xie, H.; Sun, Z.; Shao, Q.; Guo, X.; Hao, L.; Zheng, Y.; et al. Heterostructured $\mathrm{TiO}_{2} / \mathrm{WO}_{3}$ Nanocomposites for Photocatalytic Degradation of Toluene under Visible Light. J. Electrochem. Soc. 2017, 164, H1086-H1090. [CrossRef] 
22. Bilgin Simsek, E. Solvothermal synthesized boron doped $\mathrm{TiO}_{2}$ catalysts: Photocatalytic degradation of endocrine disrupting compounds and pharmaceuticals under visible light irradiation. Appl. Catal. B Environ. 2017, 200, 309-322. [CrossRef]

23. Carp, O.; Huisman, C.L.; Reller, A. Photoinduced reactivity of titanium dioxide. Prog. Solid State Chem. 2004, 32, 33-177. [CrossRef]

24. Ahmed, N. Heterogeneous photocatalysis and its potential applications in water and wastewater treatment: A review. Nanotechnology 2018, 29, 342001. [CrossRef]

25. Hopfield, J.J. On the energy dependence of the absorption constant and photoconductivity near a direct band gap. J. Phys. Chem. Solids 1961, 22, 63-72. [CrossRef]

26. Chong, M.N.; Jin, B.; Chow, C.W.K.; Saint, C. Recent developments in photocatalytic water treatment technology: A review. Water Res. 2010, 44, 2997-3027. [CrossRef]

27. Turchi, C.S.; Ollis, D.F. Photocatalytic degradation of organic water contaminants: Mechanisms involving hydroxyl radical attack. J. Catal. 1990, 122, 178-192. [CrossRef]

28. Wold, A. Photocatalytic properties of titanium dioxide $\left(\mathrm{TiO}_{2}\right)$. Chem. Mater. 1993, 5, 280-283. [CrossRef]

29. Llabres i Xamena, F.; Gascon, J. (Eds.) Metal Organic Frameworks as Heterogeneous Catalysts; Catalysis Series; Royal Society of Chemistry: Cambridge, UK, 2013.

30. Mamaghani, A.H.; Haghighat, F.; Lee, C.S. Photocatalytic oxidation technology for indoor environment air purification: The state-of-the-art. Appl. Catal. B Environ. 2017, 203, 247-269. [CrossRef]

31. Gimeno, O.; García-Araya, J.F.; Beltrán, F.J.; Rivas, F.J.; Espejo, A. Removal of emerging contaminants from a primary effluent of municipal wastewater by means of sequential biological degradation-solar photocatalytic oxidation processes. Chem. Eng. J. 2016, 290, 12-20. [CrossRef]

32. Lee, S.-Y.; Park, S.-J. $\mathrm{TiO}_{2}$ photocatalyst for water treatment applications. J. Ind. Eng. Chem. 2013, 19, 1761-1769. [CrossRef]

33. Daghrir, R.; Drogui, P.; Robert, D. Modified $\mathrm{TiO}_{2}$ For Environmental Photocatalytic Applications: A Review. Ind. Eng. Chem. Res. 2013, 52, 3581-3599. [CrossRef]

34. Zhang, W.; Zou, L.; Dionysio, D. A parametric study of visible-light sensitive $\mathrm{TiO}_{2}$ photocatalysts synthesis via a facile sol-gel N-doping method. J. Exp. Nanosci. 2015, 10, 1153-1165. [CrossRef]

35. Lee, K.M.; Lai, C.W.; Ngai, K.S.; Juan, J.C. Recent developments of zinc oxide based photocatalyst in water treatment technology: A review. Water Res. 2016, 88, 428-448. [CrossRef]

36. Kumar, S.G.; Rao, K.S.R.K. Comparison of modification strategies towards enhanced charge carrier separation and photocatalytic degradation activity of metal oxide semiconductors $\left(\mathrm{TiO}_{2}, \mathrm{WO}_{3}\right.$ and $\left.\mathrm{ZnO}\right)$. Appl. Surf. Sci. 2017, 391, 124-148. [CrossRef]

37. Fagan, R.; McCormack, D.E.; Dionysiou, D.D.; Pillai, S.C. A review of solar and visible light active $\mathrm{TiO}_{2}$ photocatalysis for treating bacteria, cyanotoxins and contaminants of emerging concern. Mater. Sci. Semicond. Process. 2016, 42, 2-14. [CrossRef]

38. Mondal, C.; Singh, A.; Sahoo, R.; Sasmal, A.K.; Negishi, Y.; Pal, T. Preformed ZnS nanoflower prompted evolution of $\mathrm{CuS} / \mathrm{ZnS} \mathrm{p}-\mathrm{n}$ heterojunctions for exceptional visible-light driven photocatalytic activity. New J. Chem. 2015, 39, 5628-5635. [CrossRef]

39. Lee, G.-J.; Wu, J.J. Recent developments in ZnS photocatalysts from synthesis to photocatalytic applications-A review. Powder Technol. 2017, 318, 8-22. [CrossRef]

40. Wang, C.; Lin, H.; Xu, Z.; Cheng, H.; Zhang, C. One-step hydrothermal synthesis of flowerlike $\mathrm{MoS}_{2} / \mathrm{CdS}$ heterostructures for enhanced visible-light photocatalytic activities. RSC Adv. 2015, 5, 15621-15626. [CrossRef]

41. Mourão, H.A.J.L.; Lopes, O.F.; Ribeiro, C.; Mastelaro, V.R. Rapid hydrothermal synthesis and pH-dependent photocatalysis of strontium titanate microspheres. Mater. Sci. Semicond. Process. 2015, 30, 651-657. [CrossRef]

42. Rastogi, M.; Kushwaha, H.S.; Vaish, R. Highly efficient visible light mediated azo dye degradation through barium titanate decorated reduced graphene oxide sheets. Electron. Mater. Lett. 2016, 12, 281-289. [CrossRef]

43. Hua, Z.; Zhang, X.; Bai, X.; Lv, L.; Ye, Z.; Huang, X. Nitrogen-doped perovskite-type $\mathrm{La}_{2} \mathrm{Ti}_{2} \mathrm{O}_{7}$ decorated on graphene composites exhibiting efficient photocatalytic activity toward bisphenol A in water. J. Colloid Interface Sci. 2015, 450, 45-53. [CrossRef] [PubMed]

44. Zhang, J.; Yuan, X.; Jiang, L.; Wu, Z.; Chen, X.; Wang, H.; Wang, H.; Zeng, G. Highly efficient photocatalysis toward tetracycline of nitrogen doped carbon quantum dots sensitized bismuth tungstate based on interfacial charge transfer. J. Colloid Interface Sci. 2018, 511, 296-306. [CrossRef] 
45. Sethi, Y.A.; Praveen, C.S.; Panmand, R.P.; Ambalkar, A.; Kulkarni, A.K.; Gosavi, S.W.; Kulkarni, M.V.; Kale, B.B. Perforated N-doped monoclinic $\mathrm{ZnWO}_{4}$ nanorods for efficient photocatalytic hydrogen generation and RhB degradation under natural sunlight. Catal. Sci. Technol. 2018, 8, 2909-2919. [CrossRef]

46. Thalluri, S.M.; Hernández, S.; Bensaid, S.; Saracco, G.; Russo, N. Green-synthesized W- and Mo-doped $\mathrm{BiVO}_{4}$ oriented along the $\{040\}$ facet with enhanced activity for the sun-driven water oxidation. Appl. Catal. B Environ. 2016, 180, 630-636. [CrossRef]

47. Kubacka, A.; Fernández-García, M.; Colón, G. Advanced Nanoarchitectures for Solar Photocatalytic Applications. Chem. Rev. 2012, 112, 1555-1614. [CrossRef]

48. Zhang, C.; Li, Y.; Shuai, D.; Shen, Y.; Xiong, W.; Wang, L. Graphitic carbon nitride $\left(\mathrm{g}-\mathrm{C}_{3} \mathrm{~N}_{4}\right)$-based photocatalysts for water disinfection and microbial control: A review. Chemosphere 2019, 214, 462-479. [CrossRef] [PubMed]

49. Wen, J.; Xie, J.; Chen, X.; Li, X. A review on g- $\mathrm{C}_{3} \mathrm{~N}_{4}$-based photocatalysts. Appl. Surf. Sci. 2017, 391, 72-123. [CrossRef]

50. Shi, L.; Wang, T.; Zhang, H.; Chang, K.; Meng, X.; Liu, H.; Ye, J. An amine-functionalized iron(III) Metal-Organic Framework as efficient visible-light photocatalyst for $\mathrm{Cr}(\mathrm{VI})$ reduction. Adv. Sci. 2015, 2, 1500006. [CrossRef] [PubMed]

51. Huang, Y.; Fan, W.; Long, B.; Li, H.; Zhao, F.; Liu, Z.; Tong, Y.; Ji, H. Visible light $\mathrm{Bi}_{2} \mathrm{~S}_{3} / \mathrm{Bi}_{2} \mathrm{O}_{3} / \mathrm{Bi}_{2} \mathrm{O}_{2} \mathrm{CO}_{3}$ photocatalyst for effective degradation of organic pollutions. Appl. Catal. B Environ. 2016, 185, 68-76. [CrossRef]

52. Sun, M.; Li, S.; Yan, T.; Ji, P.; Zhao, X.; Yuan, K.; Wei, D.; Du, B. Fabrication of heterostructured $\mathrm{Bi}_{2} \mathrm{O}_{2} \mathrm{CO}_{3} / \mathrm{Bi}_{2} \mathrm{O}_{4}$ photocatalyst and efficient photodegradation of organic contaminants under visible-light. J. Hazard. Mater. 2017, 333, 169-178. [CrossRef]

53. Madhusudan, P.; Ran, J.; Zhang, J.; Yu, J.; Liu, G. Novel urea assisted hydrothermal synthesis of hierarchical $\mathrm{BiVO}_{4} / \mathrm{Bi}_{2} \mathrm{O}_{2} \mathrm{CO}_{3}$ nanocomposites with enhanced visible-light photocatalytic activity. Appl. Catal. B Environ. 2011, 110, 286-295. [CrossRef]

54. Li, X.; Shen, R.; Ma, S.; Chen, X.; Xie, J. Graphene-based heterojunction photocatalysts. Appl. Surf. Sci. 2018, 430, 53-107. [CrossRef]

55. Rowsell, J.L.C.; Yaghi, O.M. Metal-organic frameworks: A new class of porous materials. Microporous Mesoporous Mater. 2004, 73, 3-14. [CrossRef]

56. Eddaoudi, M.; Kim, J.; Rosi, N.; Vodak, D.; Wachter, J.; O’Keeffe, M.; Yaghi, O.M. Systematic design of pore size and functionality in isoreticular MOFs and their application in methane storage. Science 2002, 295, 469-472. [CrossRef]

57. Zhu, L.; Liu, X.-Q.; Jiang, H.-L.; Sun, L.-B. Metal-Organic Frameworks for Heterogeneous Basic Catalysis. Chem. Rev. 2017, 117, 8129-8176. [CrossRef]

58. Huang, Y.-B.; Liang, J.; Wang, X.-S.; Cao, R. Multifunctional metal-organic framework catalysts: Synergistic catalysis and tandem reactions. Chem. Soc. Rev. 2017, 46, 126-157. [CrossRef] [PubMed]

59. Yu, Z.-T.; Liao, Z.-L.; Jiang, Y.-S.; Li, G.-H.; Li, G.-D.; Chen, J.-S. Construction of a microporous inorganic-organic hybrid compound with uranyl units. Chem. Commun. 2004, 1814-1815. [CrossRef] [PubMed]

60. Wang, D.; Jia, F.; Wang, H.; Chen, F.; Fang, Y.; Dong, W.; Zeng, G.; Li, X.; Yang, Q.; Yuan, X. Simultaneously efficient adsorption and photocatalytic degradation of tetracycline by Fe-based MOFs. J. Colloid Interface Sci. 2018, 519, 273-284. [CrossRef] [PubMed]

61. Butova, V.V.; Soldatov, M.A.; Guda, A.A.; Lomachenko, K.A.; Lamberti, C. Metal-organic frameworks: structure, properties, methods of synthesis and characterization. Russ. Chem. Rev. 2016, 85, 280-307. [CrossRef]

62. Wei, Z. New Design and Synthetic Strategies of Metal-Organic Frameworks. Ph.D. Thesis, Texas A\&M University, College Station, TX, USA, 2014.

63. Sharmin, E.; Zafar, F. Introductory Chapter: Metal Organic Frameworks (MOFs). In Metal-Organic Frameworks; InTech: Munich/Garching, Germany, 2016.

64. Yaghi, O.M.; Li, G.; Li, H. Selective binding and removal of guests in a microporous metal-organic framework. Nature 1995, 378, 703-706. [CrossRef]

65. Perez, E.; Karunaweera, C.; Musselman, I.; Balkus, K.; Ferraris, J.; Perez, E.V.; Karunaweera, C.; Musselman, I.H.; Balkus, K.J.; Ferraris, J.P. Origins and Evolution of Inorganic-Based and MOF-Based Mixed-Matrix Membranes for Gas Separations. Processes 2016, 4, 32. [CrossRef] 
66. Kuppler, R.J.; Timmons, D.J.; Fang, Q.-R.; Li, J.-R.; Makal, T.A.; Young, M.D.; Yuan, D.; Zhao, D.; Zhuang, W.; Zhou, H.-C. Potential applications of metal-organic frameworks. Coord. Chem. Rev. 2009, 253, 3042-3066. [CrossRef]

67. Hu, Y.H.; Zhang, L. Hydrogen Storage in Metal-Organic Frameworks. Adv. Mater. 2010, 22, E117-E130. [CrossRef]

68. Rosi, N.L.; Eckert, J.; Eddaoudi, M.; Vodak, D.T.; Kim, J.; O’Keeffe, M.; Yaghi, O.M. Hydrogen storage in microporous metal-organic frameworks. Science 2003, 300, 1127-1129. [CrossRef]

69. Lin, Y.; Kong, C.; Zhang, Q.; Chen, L. Metal-Organic Frameworks for Carbon Dioxide Capture and Methane Storage. Adv. Energy Mater. 2017, 7, 1601296. [CrossRef]

70. Ma, S.; Zhou, H.-C. Gas storage in porous metal-organic frameworks for clean energy applications. Chem. Commun. 2010, 46, 44-53. [CrossRef] [PubMed]

71. He, Y.; Zhou, W.; Qian, G.; Chen, B. Methane storage in metal-organic frameworks. Chem. Soc. Rev. 2014, 43, 5657-5678. [CrossRef] [PubMed]

72. Li, H.; Wang, K.; Sun, Y.; Lollar, C.T.; Li, J.; Zhou, H.-C. Recent advances in gas storage and separation using metal-organic frameworks. Mater. Today 2018, 21, 108-121. [CrossRef]

73. DeCoste, J.B.; Peterson, G.W. Metal-Organic Frameworks for Air Purification of Toxic Chemicals. Chem. Rev. 2014, 114, 5695-5727. [CrossRef] [PubMed]

74. Sun, C.-Y.; Qin, C.; Wang, X.-L.; Su, Z.-M. Metal-organic frameworks as potential drug delivery systems. Expert Opin. Drug Deliv. 2013, 10, 89-101. [CrossRef] [PubMed]

75. Abánades Lázaro, I.; Forgan, R.S. Application of zirconium MOFs in drug delivery and biomedicine. Coord. Chem. Rev. 2019, 380, 230-259. [CrossRef]

76. Furukawa, H.; Cordova, K.E.; O'Keeffe, M.; Yaghi, O.M. The Chemistry and Applications of Metal-Organic Frameworks. Science 2013, 341, 1230444. [CrossRef]

77. Silva, C.G.; Corma, A.; García, H. Metal-organic frameworks as semiconductors. J. Mater. Chem. 2010, 20, 3141-3156. [CrossRef]

78. Wang, C.C.; Li, J.R.; Lv, X.L.; Zhang, Y.Q.; Guo, G. Photocatalytic organic pollutants degradation in metal-organic frameworks. Energy Environ. Sci. 2014, 7, 2831-2867. [CrossRef]

79. Dias, E.M.; Petit, C. Towards the use of metal-organic frameworks for water reuse: A review of the recent advances in the field of organic pollutants removal and degradation and the next steps in the field. J. Mater. Chem. A 2015, 3, 22484-22506. [CrossRef]

80. Dey, C.; Kundu, T.; Biswal, B.P.; Mallick, A.; Banerjee, R. Crystalline metal-organic frameworks (MOFs): Synthesis, structure and function. Acta Crystallogr. Sect. B Struct. Sci. Cryst. Eng. Mater. 2014, 70, 3-10. [CrossRef] [PubMed]

81. Dai, J.; Xiao, X.; Duan, S.; Liu, J.; He, J.; Lei, J.; Wang, L. Synthesis of novel microporous nanocomposites of ZIF-8 on multiwalled carbon nanotubes for adsorptive removing benzoic acid from water. Chem. Eng. J. 2018, 331, 64-74. [CrossRef]

82. Farha, O.K.; Hupp, J.T. Rational Design, Synthesis, Purification, and Activation of Metal-Organic Framework Materials. Acc. Chem. Res. 2010, 43, 1166-1175. [CrossRef] [PubMed]

83. Liu, J.; Liu, T.; Wang, C.; Yin, X.; Xiong, Z. Introduction of amidoxime groups into metal-organic frameworks to synthesize MIL-53(Al)-AO for enhanced U(VI) sorption. J. Mol. Liq. 2017, 242, 531-536. [CrossRef]

84. Sánchez-Sánchez, M.; Getachew, N.; Díaz, K.; Díaz-García, M.; Chebude, Y.; Díaz, I. Synthesis of metal-organic frameworks in water at room temperature: Salts as linker sources. Green Chem. 2015, 17, 1500-1509. [CrossRef]

85. Yoo, Y.; Varela-Guerrero, V.; Jeong, H.-K. Isoreticular Metal-Organic Frameworks and Their Membranes with Enhanced Crack Resistance and Moisture Stability by Surfactant-Assisted Drying. Langmuir 2011, 27, 2652-2657. [CrossRef] [PubMed]

86. Ni, Z.; Masel, R.I. Rapid Production of Metal-Organic Frameworks via Microwave-Assisted Solvothermal Synthesis. J. Am. Chem. Soc. 2006, 128, 12394-12395. [CrossRef] [PubMed]

87. Klinowski, J.; Almeida Paz, F.A.; Silva, P.; Rocha, J. Microwave-Assisted Synthesis of Metal-Organic Frameworks. Dalton Trans. 2011, 40, 321-330. [CrossRef]

88. Son, W.-J.; Kim, J.; Kim, J.; Ahn, W.-S. Sonochemical synthesis of MOF-5. Chem. Commun. 2008, 47, 6336-6338. [CrossRef] 
89. Khan, N.A.; Jhung, S.H. Synthesis of metal-organic frameworks (MOFs) with microwave or ultrasound: Rapid reaction, phase-selectivity, and size reduction. Coord. Chem. Rev. 2015, 285, 11-23. [CrossRef]

90. Safarifard, V.; Morsali, A. Applications of ultrasound to the synthesis of nanoscale metal-organic coordination polymers. Coord. Chem. Rev. 2015, 292, 1-14. [CrossRef]

91. Pichon, A.; Lazuen-Garay, A.; James, S.L. Solvent-free synthesis of a microporous metal-organic framework. CrystEngComm 2006, 8, 211-214. [CrossRef]

92. Klimakow, M.; Klobes, P.; Thünemann, A.F.; Rademann, K.; Emmerling, F. Mechanochemical Synthesis of Metal-Organic Frameworks: A Fast and Facile Approach toward Quantitative Yields and High Specific Surface Areas. Chem. Mater. 2010, 22, 5216-5221. [CrossRef]

93. Friščić, T.; Reid, D.G.; Halasz, I.; Stein, R.S.; Dinnebier, R.E.; Duer, M.J. Ion- and Liquid-Assisted Grinding: Improved Mechanochemical Synthesis of Metal-Organic Frameworks Reveals Salt Inclusion and Anion Templating. Angew. Chem. Int. Ed. 2010, 49, 712-715. [CrossRef] [PubMed]

94. Martinez Joaristi, A.; Juan-Alcañiz, J.; Serra-Crespo, P.; Kapteijn, F.; Gascon, J. Electrochemical Synthesis of Some Archetypical $\mathrm{Zn}^{2+}, \mathrm{Cu}^{2+}$, and $\mathrm{Al}^{3+}$ Metal Organic Frameworks. Cryst. Growth Des. 2012, 12, 3489-3498. [CrossRef]

95. Rubio-Martinez, M.; Avci-Camur, C.; Thornton, A.W.; Imaz, I.; Maspoch, D.; Hill, M.R. New synthetic routes towards MOF production at scale. Chem. Soc. Rev. 2017, 46, 3453-3480. [CrossRef]

96. Carné-Sánchez, A.; Imaz, I.; Cano-Sarabia, M.; Maspoch, D. A spray-drying strategy for synthesis of nanoscale metal-organic frameworks and their assembly into hollow superstructures. Nat. Chem. 2013, 5, 203-211. [CrossRef]

97. Bian, Y.; Xiong, N.; Zhu, G.; Bian, Y.; Xiong, N.; Zhu, G. Technology for the Remediation of Water Pollution: A Review on the Fabrication of Metal Organic Frameworks. Processes 2018, 6, 122. [CrossRef]

98. Dhanya, V.S.; Sudarsanakumar, M.R.; Suma, S.; Ng, S.W.; Augustine, M.S.; Roy, S.M. Crystal structure, thermal decomposition, photoluminescence and magnetic studies of a new two dimensional metal-organic framework constructed from infinite chains of edge-sharing $\mathrm{CeO}_{6}\left(\mathrm{H}_{2} \mathrm{O}\right)_{2}\left(\mathrm{NO}_{3}\right)$ polyhedron with bullet shaped channels. Inorg. Chem. Commun. 2013, 35, 140-143. [CrossRef]

99. Parnham, E.R.; Morris, R.E. Ionothermal Synthesis of Zeolites, Metal-Organic Frameworks, and Inorganic-Organic Hybrids. Acc. Chem. Res. 2007, 40, 1005-1013. [CrossRef]

100. Nelson, A.P.; Farha, O.K.; Mulfort, K.L.; Hupp, J.T. Supercritical Processing as a Route to High Internal Surface Areas and Permanent Microporosity in Metal-Organic Framework Materials. J. Am. Chem. Soc. 2009, 131, 458-460. [CrossRef] [PubMed]

101. Espín, J.; Garzón-Tovar, L.; Carné-Sánchez, A.; Imaz, I.; Maspoch, D. Photothermal Activation of Metal-Organic Frameworks Using a UV-Vis Light Source. ACS Appl. Mater. Interfaces 2018, 10, 9555-9562. [CrossRef] [PubMed]

102. Farrusseng, D. Metal-Organic Frameworks: Applications from Catalysis to Gas Storage; Wiley-VCH: Hoboken, NJ, USA, 2011.

103. Hendon, C.H.; Tiana, D.; Fontecave, M.; Sanchez, C.; D'Arras, L.; Sassoye, C.; Rozes, L.; Mellot-Draznieks, C.; Walsh, A. Engineering the optical response of the titanium-MIL-125 metal-organic framework through ligand functionalization. J. Am. Chem. Soc. 2013, 135, 10942-10945. [CrossRef] [PubMed]

104. Wang, Z.; Cohen, S.M. Postsynthetic modification of metal-organic frameworks. Chem. Soc. Rev. 2009, 38, 1315-1329. [CrossRef] [PubMed]

105. Burrows, A.D.; Frost, C.G.; Mahon, M.F.; Richardson, C. Post-Synthetic Modification of Tagged Metal-Organic Frameworks. Angew. Chem. Int. Ed. 2008, 47, 8482-8486. [CrossRef] [PubMed]

106. Cohen, S.M. Postsynthetic Methods for the Functionalization of Metal-Organic Frameworks. Chem. Rev. 2012, 112, 970-1000. [CrossRef]

107. Aijaz, A.; Karkamkar, A.; Choi, Y.J.; Tsumori, N.; Rönnebro, E.; Autrey, T.; Shioyama, H.; Xu, Q. Immobilizing Highly Catalytically Active Pt Nanoparticles inside the Pores of Metal-Organic Framework: A Double Solvents Approach. J. Am. Chem. Soc. 2012, 134, 13926-13929. [CrossRef]

108. Sun, D.; Li, Z. Double-Solvent Method to Pd Nanoclusters Encapsulated inside the Cavity of $\mathrm{NH}_{2}-\mathrm{UiO}-66(\mathrm{Zr})$ for Efficient Visible-Light-Promoted Suzuki Coupling Reaction. J. Phys. Chem. C 2016, 120, 19744-19750. [CrossRef]

109. O'Regan, B.; Grätzel, M. A low-cost, high-efficiency solar cell based on dye-sensitized colloidal $\mathrm{TiO}_{2}$ films. Nature 1991, 353, 737-740. [CrossRef] 
110. He, J.; Wang, J.; Chen, Y.; Zhang, J.; Duan, D.; Wang, Y.; Yan, Z. A dye-sensitized Pt@UiO-66(Zr) metal-organic framework for visible-light photocatalytic hydrogen production. Chem. Commun. 2014, 50, 7063-7066. [CrossRef]

111. Yuan, Y.-P.; Yin, L.-S.; Cao, S.-W.; Xu, G.-S.; Li, C.-H.; Xue, C. Improving photocatalytic hydrogen production of metal-organic framework UiO-66 octahedrons by dye-sensitization. Appl. Catal. B Environ. 2015, 168-169, 572-576. [CrossRef]

112. Qin, J.; Wang, S.; Wang, X. Visible-light reduction $\mathrm{CO}_{2}$ with dodecahedral zeolitic imidazolate framework ZIF-67 as an efficient co-catalyst. Appl. Catal. B Environ. 2017, 209, 476-482. [CrossRef]

113. Wilmer, C.E.; Leaf, M.; Lee, C.Y.; Farha, O.K.; Hauser, B.G.; Hupp, J.T.; Snurr, R.Q. Large-scale screening of hypothetical metal-organic frameworks. Nat. Chem. 2012, 4, 83-89. [CrossRef] [PubMed]

114. Holland, T.J.B.; Redfern, S.A.T. Unit cell refinement from powder diffraction data: The use of regression diagnostics. Mineral. Mag. 1997, 61, 65-77. [CrossRef]

115. West, A.R. Solid State Chemistry and Its Applications; John Wiley \& Sons Ltd.: Hoboken, NJ, USA, 1987.

116. Burtch, N.C.; Jasuja, H.; Walton, K.S. Water stability and adsorption in metal-organic frameworks. Chem. Rev. 2014, 114, 10575-10612. [CrossRef] [PubMed]

117. Lee, P.A.; Citrin, P.H.; Eisenberger, P.; Kincaid, B.M. Extended X-ray absorption fine structure-Its strengths and limitations as a structural tool. Rev. Mod. Phys. 1981, 53, 769-806. [CrossRef]

118. Alp, E.E.; Mini, S.M.; Ramanathan, M. X-Ray Absorption Spectroscopy: EXAFS and XANES-A Versatile Tool to Study the Atomic and Electronic Structure of Materials. In Synchrotron X-Ray Sources and New Opportunities in the Soil and Environmental Sciences; Schulze, D., Anderson, S., Mattigod, S., Eds.; Argonne National Lab.: Lemont, IL, USA, 1990; pp. 25-36.

119. Thommes, M. Physical adsorption characterization of nanoporous materials. Chemie-Ingenieur-Technik 2010, 82, 1059-1073. [CrossRef]

120. Sing, K.S.W.; Everett, D.H.; Haul, R.A.W.; Moscou, L.; Pierotti, R.S.; Rouquerol, J.; Siemieniewska, T. International Union of Pure Commission on Colloid and Surface Chemistry Including Catalysis-Reporting physisorption data for gas/solid systems with special reference to the determination of surface area and porosity. Pure Appl. Chem. 1985, 57, 603-619. [CrossRef]

121. Thommes, M.; Kaneko, K.; Neimark, A.V.; Olivier, J.P.; Rodriguez-Reinoso, F.; Rouquerol, J.; Sing, K.S.W. Physisorption of gases, with special reference to the evaluation of surface area and pore size distribution (IUPAC Technical Report). Pure Appl. Chem. 2015, 87, 1051-1069. [CrossRef]

122. Chung, Y.G.; Camp, J.; Haranczyk, M.; Sikora, B.J.; Bury, W.; Krungleviciute, V.; Farha, O.K.; Sholl, D.S.; Snurr, R.Q. Computation-Ready, Experimental Metal-Organic Frameworks: A Tool To Enable High-Throughput Screening of Nanoporous Crystals. Chem. Mater. 2014, 26, 6185-6192. [CrossRef]

123. Mondloch, J.E.; Katz, M.J.; Planas, N.; Semrouni, D.; Gagliardi, L.; Hupp, J.T.; Farha, O.K. Are Zr6-based MOFs water stable? Linker hydrolysis vs. capillary-force-driven channel collapse. Chem. Commun. 2014, 50, 8944-8946. [CrossRef] [PubMed]

124. Brunauer, S.; Emmett, P.H.; Teller, E. Adsorption of Gases in Multimolecular Layers. J. Am. Chem. Soc. 1938, 60, 309-319. [CrossRef]

125. Howarth, A.J.; Peters, A.W.; Vermeulen, N.A.; Wang, T.C.; Hupp, J.T.; Farha, O.K. Best Practices for the Synthesis, Activation, and Characterization of Metal-Organic Frameworks. Chem. Mater. 2017, 29, $26-39$. [CrossRef]

126. Storck, S.; Bretinger, H.; Maier, W.F. Characterization of micro and mesoporous solids by physisorption methods and poro size analysis. Appl. Catal. A Gen. 1998, 174, 137-146. [CrossRef]

127. Landers, J.; Gor, G.Y.; Neimark, A.V. Density functional theory methods for characterization of porous materials. Colloids Surf. A Physicochem. Eng. Asp. 2013, 437, 3-32. [CrossRef]

128. Sing, K.S.W. Characterization of porous materials: Past, present and future. Colloids Surf. A Physicochem. Eng. Asp. 2004, 241, 3-7. [CrossRef]

129. Sing, K. The use of nitrogen adsorption for the characterisation of porous materials. Colloids Surf. A Physicochem. Eng. Asp. 2001, 187-188, 3-9. [CrossRef]

130. Li, Y.; Xu, H.; Ouyang, S.; Ye, J. Metal-organic frameworks for photocatalysis. Phys. Chem. Chem. Phys. 2016, 18, 7563-7572. [CrossRef] 
131. Horiuchi, Y.; Toyao, T.; Saito, M.; Mochizuki, K.; Iwata, M.; Higashimura, H.; Anpo, M.; Matsuoka, M. Visible-Light-Promoted Photocatalytic Hydrogen Production by Using an Amino-Functionalized Ti(IV) Metal-Organic Framework. J. Phys. Chem. C 2012, 116, 20848-20853. [CrossRef]

132. Tauc, J. Absorption edge and internal electric fields in amorphous semiconductors. Mater. Res. Bull. 1970, 5, 721-729. [CrossRef]

133. Butler, M.A. Photoelectrolysis and physical properties of the semiconducting electrode $\mathrm{WO}_{2}$. J. Appl. Phys. 1977, 48, 1914-1920. [CrossRef]

134. Wu, Z.; Huang, X.; Zheng, H.; Wang, P.; Hai, G.; Dong, W.; Wang, G. Aromatic heterocycle-grafted $\mathrm{NH}_{2}$-MIL-125(Ti) via conjugated linker with enhanced photocatalytic activity for selective oxidation of alcohols under visible light. Appl. Catal. B Environ. 2018, 224, 479-487. [CrossRef]

135. Liang, R.; Jing, F.; Shen, L.; Qin, N.; Wu, L. M@MIL-100(Fe) (M = Au, Pd, Pt) nanocomposites fabricated by a facile photodeposition process: Efficient visible-light photocatalysts for redox reactions in water. Nano Res. 2015, 8, 3237-3249. [CrossRef]

136. Gao, G.; Nie, L.; Yang, S.; Jin, P.; Chen, R.; Ding, D.; Wang, X.C.; Wang, W.; Wu, K.; Zhang, Q. Well-defined strategy for development of adsorbent using metal organic frameworks (MOF) template for high performance removal of hexavalent chromium. Appl. Surf. Sci. 2018, 457, 1208-1217. [CrossRef]

137. Fassel, V.A.; Kniseley, R.N. Inductively coupled plasma. Optical emission spectroscopy. Anal. Chem. 1974, 46, 1110A-1120A. [CrossRef]

138. Nehra, M.; Dilbaghi, N.; Singhal, N.K.; Hassan, A.A.; Kim, K.H.; Kumar, S. Metal organic frameworks MIL-100(Fe) as an efficient adsorptive material for phosphate management. Environ. Res. 2019, 169, 229-236. [CrossRef] [PubMed]

139. Luz, I.; Soukri, M.; Lail, M. Transformation of single MOF nanocrystals into single nanostructured catalysts within mesoporous supports: A platform for pioneer fluidized-nanoreactor hydrogen carriers. Chem. Commun. 2018, 54, 8462-8465. [CrossRef] [PubMed]

140. Gómez-Avilés, A.; Peñas-Garzón, M.; Bedia, J.; Dionysiou, D.D.; Rodríguez, J.J.; Belver, C. Mixed Ti-Zr metal-organic-frameworks with solar photocatalytic applications. Appl. Catal. B Environ. Environ. 2018, submitted.

141. Shen, L.; Huang, L.; Liang, S.; Liang, R.; Qin, N.; Wu, L. Electrostatically derived self-assembly of $\mathrm{NH}_{2}$-mediated zirconium MOFs with graphene for photocatalytic reduction of $\mathrm{Cr}(\mathrm{vi})$. RSC Adv. 2014, 4, 2546-2549. [CrossRef]

142. Sofi, F.A.; Majid, K.; Mehraj, O. The visible light driven copper based metal-organic-framework heterojunction:HKUST-1@Ag- $\mathrm{Ag}_{3} \mathrm{PO}_{4}$ for plasmon enhanced visible light photocatalysis. J. Alloys Compd. 2018, 737, 798-808. [CrossRef]

143. Shan, A.Y.; Ghazi, T.I.M.; Rashid, S.A. Immobilisation of titanium dioxide onto supporting materials in heterogeneous photocatalysis: A review. Appl. Catal. A Gen. 2010, 389, 1-8. [CrossRef]

144. Zheng, X.; Shen, Z.-P.; Shi, L.; Cheng, R.; Yuan, D.-H.; Zheng, X.; Shen, Z.-P.; Shi, L.; Cheng, R.; Yuan, D.-H. Photocatalytic Membrane Reactors (PMRs) in Water Treatment: Configurations and Influencing Factors. Catalysts 2017, 7, 224. [CrossRef]

145. Janssens, R.; Mandal, M.K.; Dubey, K.K.; Luis, P. Slurry photocatalytic membrane reactor technology for removal of pharmaceutical compounds from wastewater: Towards cytostatic drug elimination. Sci. Total Environ. 2017, 599-600, 612-626. [CrossRef] [PubMed]

146. Zhang, W.; Ding, L.; Luo, J.; Jaffrin, M.Y.; Tang, B. Membrane fouling in photocatalytic membrane reactors (PMRs) for water and wastewater treatment: A critical review. Chem. Eng. J. 2016, 302, 446-458. [CrossRef]

147. Molinari, R.; Lavorato, C.; Argurio, P. Recent progress of photocatalytic membrane reactors in water treatment and in synthesis of organic compounds. A review. Catal. Today 2017, 281, 144-164. [CrossRef]

148. Molinari, R.; Argurio, P.; Palmisano, L. Photocatalytic membrane reactors for water treatment. In Advances in Membrane Technologies for Water Treatment; Elsevier: Amsterdam, The Netherlands, 2015; pp. 205-238.

149. Palmisano, G.; Loddo, V.; Augugliaro, V.; Bellardita, M.; Camera Roda, G.; Parrino, F. Validation of a two-dimensional modeling of an externally irradiated slurry photoreactor. Chem. Eng. J. 2015, 262, 490-498. [CrossRef]

150. Leblebici, M.E.; Stefanidis, G.D.; Van Gerven, T. Comparison of photocatalytic space-time yields of 12 reactor designs for wastewater treatment. Chem. Eng. Process. Process Intensif. 2015, 97, 106-111. [CrossRef] 
151. Zeghioud, H.; Khellaf, N.; Djelal, H.; Amrane, A.; Bouhelassa, M. Photocatalytic Reactors Dedicated to the Degradation of Hazardous Organic Pollutants: Kinetics, Mechanistic Aspects, and Design-A Review. Chem. Eng. Commun. 2016, 203, 1415-1431. [CrossRef]

152. Spasiano, D.; Marotta, R.; Malato, S.; Fernandez-Ibañez, P.; Di Somma, I. Solar photocatalysis: Materials, reactors, some commercial, and pre-industrialized applications. A comprehensive approach. Appl. Catal. B Environ. 2015, 170-171, 90-123. [CrossRef]

153. Kowalska, E.; Rau, S. Photoreactors for wastewater treatment: A review. Recent Pat. Eng. 2010, 4, $242-266$. [CrossRef]

154. Bora, L.V.; Mewada, R.K. Photoreactors for heterogeneous photocatalysis for wastewater treatment. Int. Res. J. Eng. Technol. 2016, 3, 1011-1014.

155. Malato, S.; Fernández-Ibáñez, P.; Maldonado, M.I.; Blanco, J.; Gernjak, W. Decontamination and disinfection of water by solar photocatalysis: Recent overview and trends. Catal. Today 2009, 147, 1-59. [CrossRef]

156. Gaya, U.I.; Abdullah, A.H. Heterogeneous photocatalytic degradation of organic contaminants over titanium dioxide: A review of fundamentals, progress and problems. J. Photochem. Photobiol. C Photochem. Rev. 2008, 9, 1-12. [CrossRef]

157. Chong, M.N.; Lei, S.; Jin, B.; Saint, C.; Chow, C.W.K. Optimisation of an annular photoreactor process for degradation of Congo Red using a newly synthesized titania impregnated kaolinite nano-photocatalyst. Sep. Purif. Technol. 2009, 67, 355-363. [CrossRef]

158. Saquib, M.; Muneer, $\mathrm{M}$. $\mathrm{TiO}_{2}$-mediated photocatalytic degradation of a triphenylmethane dye (gentian violet), in aqueous suspensions. Dyes Pigment. 2003, 56, 37-49. [CrossRef]

159. Wang, D.; Li, Z. Iron-based metal-organic frameworks (MOFs) for visible-light-induced photocatalysis. Res. Chem. Intermed. 2017, 43, 5169-5186. [CrossRef]

160. Chi, L.; Xu, Q.; Liang, X.; Wang, J.; Su, X. Iron-Based Metal-Organic Frameworks as Catalysts for Visible Light-Driven Water Oxidation. Small 2016, 12, 1351-1358. [CrossRef]

161. Cheng, C.; Fang, J.; Lu, S.; Cen, C.; Chen, Y.; Ren, L.; Feng, W.; Fang, Z. Zirconium metal-organic framework supported highly-dispersed nanosized $\mathrm{BiVO}_{4}$ for enhanced visible-light photocatalytic applications. J. Chem. Technol. Biotechnol. 2016, 91, 2785-2792. [CrossRef]

162. Glatzmaier, G.C.; Nix, R.G.; Mehos, M.S. Solar destruction of hazardous chemicals. J. Environ. Sci. Health Part A Environ. Sci. Eng. Toxicol. 1990, 25, 571-581. [CrossRef]

163. Zeng, L.; Guo, X.; He, C.; Duan, C. Metal-Organic Frameworks: Versatile Materials for Heterogeneous Photocatalysis. ACS Catal. 2016, 6, 7935-7947. [CrossRef]

164. Sharma, V.K.; Feng, M. Water depollution using metal-organic frameworks-catalyzed advanced oxidation processes: A review. J. Hazard. Mater. 2017. [CrossRef] [PubMed]

165. Alvaro, M.; Carbonell, E.; Ferrer, B.; Llabrés i Xamena, F.X.; Garcia, H. Semiconductor behavior of a metal-organic framework (MOF). Chem. Eur. J. 2007, 13, 5106-5112. [CrossRef] [PubMed]

166. Hausdorf, S.; Wagler, J.; Mossig, R.; Mertens, F.O.R.L. Proton and water activity-controlled structure formation in zinc carboxylate-based metal organic frameworks. J. Phys. Chem. A 2008, 112, 7567-7576. [CrossRef] [PubMed]

167. Laurier, K.G.M.; Vermoortele, F.; Ameloot, R.; De Vos, D.E.; Hofkens, J.; Roeffaers, M.B.J. Iron(III)-based metal-organic frameworks as visible light photocatalysts. J. Am. Chem. Soc. 2013, 135, 14488-14491. [CrossRef]

168. Qiu, J.; Zhang, X.; Feng, Y.; Zhang, X.; Wang, H.; Yao, J. Modified metal-organic frameworks as photocatalysts. Appl. Catal. B Environ. 2018, 231, 317-342. [CrossRef]

169. Cui, Y.; Zhang, J.; He, H.; Qian, G. Photonic functional metal-organic frameworks. Chem. Soc. Rev. 2018, 47, 5740-5785. [CrossRef] [PubMed]

170. Liang, R.; Luo, S.; Jing, F.; Shen, L.; Qin, N.; Wu, L. Environmental strategy for fabrication of Pd@MIL-100(Fe) nanocomposite as a visible-light-driven photocatalyst for the treatment of pharmaceuticals and personal care products (PPCPs). Appl. Catal. B Environ. 2015, 176-177, 240-248. [CrossRef]

171. Mosleh, S.; Rahimi, M.R. Intensification of abamectin pesticide degradation using the combination of ultrasonic cavitation and visible-light driven photocatalytic process: Synergistic effect and optimization study. Ultrason. Sonochem. 2017, 35, 449-457. [CrossRef]

172. Wu, Z.; Yuan, X.; Zhang, J.; Wang, H.; Jiang, L. Photocatalytic Decontamination of Wastewater Containing Organic Dyes by Metal-Organic Frameworks and their Derivatives. ChemCatChem 2017, 9, 41-64. [CrossRef] 
173. Jiang, D.; Xu, P.; Wang, H.; Zeng, G.; Huang, D.; Chen, M.; Lai, C.; Zhang, C.; Wan, J.; Xue, W. Strategies to improve metal organic frameworks photocatalyst's performance for degradation of organic pollutants. Coord. Chem. Rev. 2018, 376, 449-466. [CrossRef]

174. Gao, J.; Miao, J.; Li, P.Z.; Teng, W.Y.; Yang, L.; Zhao, Y.; Liu, B.; Zhang, Q. A p-type Ti(IV)-based metal-organic framework with visible-light photo-response. Chem. Commun. 2014, 50, 3786-3788. [CrossRef] [PubMed]

175. Pi, Y.; Li, X.; Xia, Q.; Wu, J.; Li, Y.; Xiao, J.; Li, Z. Adsorptive and photocatalytic removal of Persistent Organic Pollutants (POPs) in water by metal-organic frameworks (MOFs). Chem. Eng. J. 2018, 337, 351-371. [CrossRef]

176. Bala, S.; Bhattacharya, S.; Goswami, A.; Adhikary, A.; Konar, S.; Mondal, R. Designing functional metal-organic frameworks by imparting a hexanuclear copper-based secondary building unit specific properties: Structural correlation with magnetic and photocatalytic activity. Cryst. Growth Des. 2014, 14, 6391-6398. [CrossRef]

177. Liu, L.; Ding, J.; Huang, C.; Li, M.; Hou, H.; Fan, Y. Polynuclear CdII polymers: Crystal structures, topologies, and the photodegradation for organic dye contaminants. Cryst. Growth Des. 2014, 14, 3035-3043. [CrossRef]

178. Zhang, C.; Ma, D.; Zhang, X.; Ma, J.; Liu, L.; Xu, X. Preparation, structure and photocatalysis of metal-organic frameworks derived from aromatic carboxylate and imidazole-based ligands. J. Coord. Chem. 2016, 69, 985-995. [CrossRef]

179. Jing, H.-P.; Wang, C.-C.; Zhang, Y.-W.; Wang, P.; Li, R. Photocatalytic degradation of methylene blue in ZIF-8. RSC Adv. 2014, 4, 54454-54462. [CrossRef]

180. Zhang, Q.; Chen, D.; He, X.; Huang, S.; Huang, J.; Zhou, X.; Yang, Z.; Li, J.; Li, H.; Nie, F. Structures, photoluminescence and photocatalytic properties of two novel metal-organic frameworks based on tetrazole derivatives. Cryst. Eng. Comm. 2014, 16, 10485-10491. [CrossRef]

181. Wang, F.; Li, F.-L.; Xu, M.-M.; Yu, H.; Zhang, J.-G.; Xia, H.-T.; Lang, J.-P. Facile synthesis of a Ag-doped coordination polymer with enhanced catalytic performance in the photodegradation of azo dyes in water. J. Mater. Chem. A 2015, 3, 5908-5916. [CrossRef]

182. George, P.; Dhabarde, N.R.; Chowdhury, P. Rapid synthesis of Titanium based Metal Organic framework (MIL-125) via microwave route and its performance evaluation in photocatalysis. Mater. Lett. 2017, 186, 151-154. [CrossRef]

183. Liang, R.; Jing, F.; Shen, L.; Qin, N.; Wu, L. MIL-53(Fe) as a highly efficient bifunctional photocatalyst for the simultaneous reduction of $\mathrm{Cr}(\mathrm{VI})$ and oxidation of dyes. J. Hazard. Mater. 2015, 287, 364-372. [CrossRef]

184. Du, J.J.; Yuan, Y.P.; Sun, J.X.; Peng, F.M.; Jiang, X.; Qiu, L.G.; Xie, A.J.; Shen, Y.H.; Zhu, J.F. New photocatalysts based on MIL-53 metal-organic frameworks for the decolorization of methylene blue dye. J. Hazard. Mater. 2011, 190, 945-951. [CrossRef] [PubMed]

185. Xu, W.T.; Ma, L.; Ke, F.; Peng, F.M.; Xu, G.S.; Shen, Y.H.; Zhu, J.F.; Qiu, L.G.; Yuan, Y.P. Metal-organic frameworks MIL-88A hexagonal microrods as a new photocatalyst for efficient decolorization of methylene blue dye. Dalton Trans. 2014, 43, 3792-3798. [CrossRef] [PubMed]

186. Qiao, Y.; Zhou, Y.F.; Guan, W.S.; Liu, L.H.; Liu, B.; Che, G.B.; Liu, C.B.; Lin, X.; Zhu, E.W. Syntheses, structures, and photocatalytic properties of two new one-dimensional chain transition metal complexes with mixed N,O-donor ligands. Inorg. Chim. Acta 2017, 466, 291-297. [CrossRef]

187. Masoomi, M.Y.; Bagheri, M.; Morsali, A. High efficiency of mechanosynthesized Zn-based metal-organic frameworks in photodegradation of congo red under UV and visible light. RSC Adv. 2016, 6, 13272-13277. [CrossRef]

188. Pu, S.; Xu, L.; Sun, L.; Du, H. Tuning the optical properties of the zirconium-UiO-66 metal-organic framework for photocatalytic degradation of methyl orange. Inorg. Chem. Commun. 2015, 52, 50-52. [CrossRef]

189. Xu, X.Y.; Chen, Q.C.; Yu, Y.D.; Huang, X.C. Ligand Induced Anionic Cuprous Cyanide Framework for Cupric Ion Turn on Luminescence Sensing and Photocatalytic Degradation of Organic Dyes. Inorg. Chem. 2016, 55, 75-82. [CrossRef] [PubMed]

190. Wang, X.-L.; Liu, D.-N.; Lin, H.-Y.; Liu, G.-C.; Rong, X. Different Anderson-Type Polyoxometalate-Directed Metal-Organic Complexes Based on 2-Pyrazine Carboxylic Acid: Assembly, Structures and Properties. J. Clust. Sci. 2016, 27, 169-181. [CrossRef]

191. Wang, A.; Zhou, Y.; Wang, Z.; Chen, M.; Sun, L.; Liu, X. Titanium incorporated with UiO-66(Zr)-type Metal-Organic Framework (MOF) for photocatalytic application. RSC Adv. 2016, 6, 3671-3679. [CrossRef] 
192. Zhang, T.; Lin, W. Metal-organic frameworks for artificial photosynthesis and photocatalysis. Chem. Soc. Rev. 2014, 43, 5982-5993. [CrossRef]

193. Dhakshinamoorthy, A.; Asiri, A.M.; García, H. Metal-Organic Framework (MOF) Compounds: Photocatalysts for Redox Reactions and Solar Fuel Production. Angew. Chem. Int. Ed. 2016, 55, 5414-5445. [CrossRef]

194. Jiao, L.; Wang, Y.; Jiang, H.L.; Xu, Q. Metal-Organic Frameworks as Platforms for Catalytic Applications. Adv. Mater. 2017, 30. [CrossRef] [PubMed]

195. Lu, L.; Wang, J.; Cai, S.-L.; Xie, B.; Li, B.-H.; Man, J.-H.; He, Y.-X.; Singh, A.; Kumar, A. Efficient photocatalytic degradation of methyl violet with two metall-organic frameworks. J. Coord. Chem. 2017, 70, 3409-3421. [CrossRef]

196. Mu, X.; Jiang, J.; Chao, F.; Lou, Y.; Chen, J. Ligand modification of UiO-66 with an unusual visible light photocatalytic behavior for RhB degradation. Dalton Trans. 2018, 47, 1895-1902. [CrossRef] [PubMed]

197. Belver, C.; Bedia, J.; Gómez, A.; Peñas-Garzón, M.; Rodriguez, J.J. Semiconductor Photocatalysis for water purification. In Nanoscale Materials in Water Purification; Thomas, S., Pasiquin, D., Leu, S.-Y., Gopakumar, D., Eds.; Elsevier: Amsterdam, The Netherlands, 2019.

198. Li, R.; Ren, X.; Ma, H.; Feng, X.; Lin, Z.; Li, X.; Hu, C.; Wang, B. Nickel-substituted zeolitic imidazolate frameworks for time-resolved alcohol sensing and photocatalysis under visible light. J. Mater. Chem. A 2014, 2, 5724-5729. [CrossRef]

199. Abdelhameed, R.M.; Simões, M.M.Q.; Silva, A.M.S.; Rocha, J. Enhanced Photocatalytic Activity of MIL-125 by Post-Synthetic Modification with CrIIIand Ag Nanoparticles. Chem. Eur. J. 2015, 21, 11072-11081. [CrossRef]

200. Cao, J.; Yang, Z.; Xiong, W.; Zhou, Y.; Peng, Y.; Li, X.; Zhou, C.; Xu, R.; Zhang, Y. One-step synthesis of Co-doped UiO-66 nanoparticle with enhanced removal efficiency of tetracycline: Simultaneous adsorption and photocatalysis. Chem. Eng. J. 2018, 353, 126-137. [CrossRef]

201. Tabatabaei, N.; Dashtian, K.; Ghaedi, M.; Sabzehmeidani, M.M.; Ameri, E. Novel visible light-driven $\mathrm{Cu}$-based $\mathrm{MOFs} / \mathrm{Ag}_{2} \mathrm{O}$ composite photocatalysts with enhanced photocatalytic activity toward the degradation of orange G: Their photocatalytic mechanism and optimization study. New J. Chem. 2018, 42, 9720-9734. [CrossRef]

202. Binh, N.T.; Thu, P.T.; Le, N.T.H.; Tien, D.M.; Khuyen, H.T.; Giang, L.T.K.; Huong, N.T.; Lam, T.D. Study on preparation and properties of a novel photo-catalytic material based on copper-centred metal-organic frameworks (Cu-MOF) and titanium dioxide. Int. J. Nanotechnol. 2015, 12, 447-455. [CrossRef]

203. Liu, X.; Dang, R.; Dong, W.; Huang, X.; Tang, J.; Gao, H.; Wang, G. A sandwich-like heterostructure of TiO2nanosheets with MIL-100(Fe): A platform for efficient visible-light-driven photocatalysis. Appl. Catal. B Environ. 2017, 209, 506-513. [CrossRef]

204. Feng, X.; Chen, H.; Jiang, F. In-situ ethylenediamine-assisted synthesis of a magnetic iron-based metal-organic framework MIL-53(Fe) for visible light photocatalysis. J. Colloid Interface Sci. 2017, 494, 32-37. [CrossRef]

205. Sha, Z.; Sun, J.; On Chan, H.S.; Jaenicke, S.; Wu, J. Bismuth tungstate incorporated zirconium metal-organic framework composite with enhanced visible-light photocatalytic performance. RSC Adv. 2014, 4, 64977-64984. [CrossRef]

206. Ding, J.; Yang, Z.; He, C.; Tong, X.; Li, Y.; Niu, X.; Zhang, H. UiO-66(Zr) coupled with $\mathrm{Bi}_{2} \mathrm{MoO}_{6}$ as photocatalyst for visible-light promoted dye degradation. J. Colloid Interface Sci. 2017, 497, $126-133$. [CrossRef] [PubMed]

207. Yang, J.; Niu, X.; An, S.; Chen, W.; Wang, J.; Liu, W. Facile synthesis of Bi2MoO6-MIL-100(Fe) metal-organic framework composites with enhanced photocatalytic performance. RSC Adv. 2017, 7, 2943-2952. [CrossRef]

208. Sha, Z.; Wu, J. Enhanced visible-light photocatalytic performance of $\mathrm{BiOBr} / \mathrm{UiO}-66(\mathrm{Zr})$ composite for dye degradation with the assistance of UiO-66. RSC Adv. 2015, 5, 39592-39600. [CrossRef]

209. Zhu, S.-R.; Liu, P.-F.; Wu, M.-K.; Zhao, W.-N.; Li, G.-C.; Tao, K.; Yi, F.-Y.; Han, L. Enhanced photocatalytic performance of $\mathrm{BiOBr} / \mathrm{NH}_{2}-\mathrm{MIL}-125$ (Ti) composite for dye degradation under visible light. Dalton Trans. 2016, 45, 17521-17529. [CrossRef]

210. Sha, Z.; Chan, H.S.O.; $\mathrm{Wu}, \mathrm{J} . \mathrm{Ag}_{2} \mathrm{CO}_{3} / \mathrm{UiO}-66(\mathrm{Zr})$ composite with enhanced visible-light promoted photocatalytic activity for dye degradation. J. Hazard. Mater. 2015, 299, 132-140. [CrossRef] [PubMed]

211. Sha, Z.; Sun, J.; Chan, H.S.O.; Jaenicke, S.; Wu, J. Enhanced Photocatalytic Activity of the AgI/UiO-66(Zr) Composite for Rhodamine B Degradation under Visible-Light Irradiation. Chempluschem 2015, 80, 1321-1328. [CrossRef] 
212. Han, Y.; Shi, H.; Bai, C.; Zhang, L.; Wu, J.; Meng, H.; Xu, Y.; Zhang, X. Ag POO $_{4}$-MIL-53(Fe) Composites with Visible-Light-Enhanced Photocatalytic Activities for Rhodamine B Degradation. ChemistrySelect 2018, 3, 8045-8050. [CrossRef]

213. Wang, H.; Yuan, X.; Wu, Y.; Zeng, G.; Chen, X.; Leng, L.; Li, H. Synthesis and applications of novel graphitic carbon nitride/metal-organic frameworks mesoporous photocatalyst for dyes removal. Appl. Catal. B Environ. 2015, 174, 445-454. [CrossRef]

214. Hong, J.; Chen, C.; Bedoya, F.E.; Kelsall, G.H.; O’Hare, D.; Petit, C. Carbon nitride nanosheet/metal-organic framework nanocomposites with synergistic photocatalytic activities. Catal. Sci. Technol. 2016, 6, 5042-5051. [CrossRef]

215. Guo, D.; Wen, R.; Liu, M.; Guo, H.; Chen, J.; Weng, W. Facile fabrication of g-C $\mathrm{N}_{3}$ /MIL-53(Al) composite with enhanced photocatalytic activities under visible-light irradiation. Appl. Organomet. Chem. 2015, 29, 690-697. [CrossRef]

216. Huang, L.; Liu, B. Synthesis of a novel and stable reduced graphene oxide/MOF hybrid nanocomposite and photocatalytic performance for the degradation of dyes. RSC Adv. 2016, 6, 17873-17879. [CrossRef]

217. Wu, Y.; Luo, H.; Wang, H. Synthesis of iron(iii)-based metal-organic framework/graphene oxide composites with increased photocatalytic performance for dye degradation. RSC Adv. 2014, 4, 40435-40438. [CrossRef]

218. Fazaeli, R.; Aliyan, H.; Banavandi, R.S. Sunlight assisted photodecolorization of malachite green catalyzed by MIL-101/graphene oxide composites. Russ. J. Appl. Chem. 2015, 88, 169-177. [CrossRef]

219. Liu, Q.; Zeng, C.; Ai, L.; Hao, Z.; Jiang, J. Boosting visible light photoreactivity of photoactive metal-organic framework: Designed plasmonic Z-scheme Ag/AgCl@MIL-53-Fe. Appl. Catal. B Environ. 2018, 224, 38-45. [CrossRef]

220. Liu, J.; Li, R.; Wang, Y.; Wang, Y.; Zhang, X.; Fan, C. The active roles of ZIF-8 on the enhanced visible photocatalytic activity of $\mathrm{Ag} / \mathrm{AgCl}$ : Generation of superoxide radical and adsorption. J. Alloys Compd. 2017, 693, 543-549. [CrossRef]

221. Gao, S.T.; Liu, W.H.; Shang, N.Z.; Feng, C.; Wu, Q.H.; Wang, Z.; Wang, C. Integration of a plasmonic semiconductor with a metal-organic framework: A case of Ag/AgCl@ZIF-8 with enhanced visible light photocatalytic activity. RSC Adv. 2014, 4, 61736-61742. [CrossRef]

222. Zhou, T.; Zhang, G.; Zhang, H.; Yang, H.; Ma, P.; Li, X.; Qiu, X.; Liu, G. Highly efficient visible-light-driven photocatalytic degradation of rhodamine $\mathrm{B}$ by a novel Z-scheme $\mathrm{Ag}_{3} \mathrm{PO}_{4} / \mathrm{MIL}-101 / \mathrm{NiFe}_{2} \mathrm{O}_{4}$ composite. Catal. Sci. Technol. 2018, 8, 2402-2416. [CrossRef]

223. Yuan, X.; Wang, H.; Wu, Y.; Zeng, G.; Chen, X.; Leng, L.; Wu, Z.; Li, H. One-pot self-assembly and photoreduction synthesis of silver nanoparticle-decorated reduced graphene oxide/MIL-125(Ti) photocatalyst with improved visible light photocatalytic activity. Appl. Organomet. Chem. 2016, 30, 289-296. [CrossRef]

224. Wu, Y.; Luo, H.; Zhang, L. Pd nanoparticles supported on MIL-101/reduced graphene oxide photocatalyst: An efficient and recyclable photocatalyst for triphenylmethane dye degradation. Environ. Sci. Pollut. Res. 2015, 22, 17238-17243. [CrossRef]

225. Singh, R.; Singh, S.; Parihar, P.; Singh, V.P.; Prasad, S.M. Arsenic contamination, consequences and remediation techniques: A review. Ecotoxicol. Environ. Saf. 2015, 112, 247-270. [CrossRef] [PubMed]

226. Fu, Z.; Guo, W.; Dang, Z.; Hu, Q.; Wu, F.; Feng, C.; Zhao, X.; Meng, W.; Xing, B.; Giesy, J.P. Refocusing on Nonpriority Toxic Metals in the Aquatic Environment in China. Environ. Sci. Technol. 2017, 51, 3117-3118. [CrossRef]

227. Feng, M.; Zhang, P.; Zhou, H.C.; Sharma, V.K. Water-stable metal-organic frameworks for aqueous removal of heavy metals and radionuclides: A review. Chemosphere 2018, 209, 783-800. [CrossRef] [PubMed]

228. Jing, F.; Liang, R.; Xiong, J.; Chen, R.; Zhang, S.; Li, Y.; Wu, L. MIL-68(Fe) as an efficient visible-light-driven photocatalyst for the treatment of a simulated waste-water contain $\mathrm{Cr}(\mathrm{VI})$ and Malachite Green. Appl. Catal. B Environ. 2017, 206, 9-15. [CrossRef]

229. Wang, H.; Yuan, X.; Wu, Y.; Zeng, G.; Chen, X.; Leng, L.; Wu, Z.; Jiang, L.; Li, H. Facile synthesis of amino-functionalized titanium metal-organic frameworks and their superior visible-light photocatalytic activity for Cr(VI) reduction. J. Hazard. Mater. 2015, 286, 187-194. [CrossRef] [PubMed]

230. Shen, L.; Wu, W.; Liang, R.; Lin, R.; Wu, L. Highly dispersed palladium nanoparticles anchored on UiO-66 $\left(\mathrm{NH}_{2}\right)$ metal-organic framework as a reusable and dual functional visible-light-driven photocatalyst. Nanoscale 2013, 5, 9374-9382. [CrossRef] [PubMed] 
231. Huang, W.; Liu, N.; Zhang, X.; Wu, M.; Tang, L. Metal organic framework g- $\mathrm{C}_{3} \mathrm{~N}_{4} / \mathrm{MIL}-53(\mathrm{Fe})$ heterojunctions with enhanced photocatalytic activity for $\mathrm{Cr}(\mathrm{VI})$ reduction under visible light. Appl. Surf. Sci. 2017, 425, 107-116. [CrossRef]

232. Liang, R.; Shen, L.; Jing, F.; Qin, N.; Wu, L. Preparation of MIL-53(Fe)-reduced graphene oxide nanocomposites by a simple self-assembly strategy for increasing interfacial contact: Efficient visible-light photocatalysts. ACS Appl. Mater. Interfaces 2015, 7, 9507-9515. [CrossRef] [PubMed]

233. Gasperi, J.; Garnaud, S.; Rocher, V.; Moilleron, R. Priority pollutants in wastewater and combined sewer overflow. Sci. Total Environ. 2008, 407, 263-272. [CrossRef]

234. Surib, N.A.; Sim, L.C.; Leong, K.H.; Kuila, A.; Saravanan, P.; Lo, K.M.; Ibrahim, S.; Bahnemann, D.; Jang, M. $\mathrm{Ag}^{+}, \mathrm{Fe}^{3+}$ and $\mathrm{Zn}^{2+}$-intercalated cadmium(II)-metal-organic frameworks for enhanced daylight photocatalysis. RSC Adv. 2017, 7, 51272-51280. [CrossRef]

235. la Farré, M.; Pérez, S.; Kantiani, L. Fate and toxicity of emerging pollutants, their metabolites and transformation products in the aquatic environment. TrAC Trends Anal. Chem. 2008, 27, 991-1007. [CrossRef]

236. Huang, W.; Jing, C.; Zhang, X.; Tang, M.; Tang, L.; Wu, M.; Liu, N. Integration of plasmonic effect into spindle-shaped MIL-88A(Fe): Steering charge flow for enhanced visible-light photocatalytic degradation of ibuprofen. Chem. Eng. J. 2018, 349, 603-612. [CrossRef]

237. Fan, G.; Zheng, X.; Luo, J.; Peng, H.; Lin, H.; Bao, M.; Hong, L.; Zhou, J. Rapid synthesis of Ag/AgCl@ZIF-8 as a highly efficient photocatalyst for degradation of acetaminophen under visible light. Chem. Eng. J. 2018, 351, 782-790. [CrossRef]

238. Wang, H.; Yuan, X.; Wu, Y.; Zeng, G.; Dong, H.; Chen, X.; Leng, L.; Wu, Z.; Peng, L. In situ synthesis of $\mathrm{In}_{2} \mathrm{~S}_{3} @ \mathrm{MIL}-125(\mathrm{Ti})$ core-shell microparticle for the removal of tetracycline from wastewater by integrated adsorption and visible-light-driven photocatalysis. Appl. Catal. B Environ. 2016, 186, 19-29. [CrossRef]

239. Panneri, S.; Thomas, M.; Ganguly, P.; Nair, B.N.; Mohamed, A.P.; Warrier, K.G.K.; Hareesh, U.S. C $3 \mathrm{~N}_{4}$ anchored ZIF 8 composites: Photo-regenerable, high capacity sorbents as adsorptive photocatalysts for the effective removal of tetracycline from water. Catal. Sci. Technol. 2017, 7, 2118-2128. [CrossRef]

240. Canivet, J.; Fateeva, A.; Guo, Y.; Coasne, B.; Farrusseng, D. Water adsorption in MOFs: Fundamentals and applications. Chem. Soc. Rev. 2014, 43, 5594-5617. [CrossRef]

241. Araya, T.; Jia, M.; Yang, J.; Zhao, P.; Cai, K.; Ma, W.; Huang, Y. Resin modified MIL-53 (Fe) MOF for improvement of photocatalytic performance. Appl. Catal. B Environ. 2017, 203, 768-777. [CrossRef]

242. Hu, P.; Liang, X.; Yaseen, M.; Sun, X.; Tong, Z.; Zhao, Z.; Zhao, Z. Preparation of highly-hydrophobic novel N-coordinated $\mathrm{UiO}-66(\mathrm{Zr})$ with dopamine via fast mechano-chemical method for $\left(\mathrm{CHO}^{-} / \mathrm{Cl}^{-}\right)$-VOCs competitive adsorption in humid environment. Chem. Eng. J. 2018, 332, 608-618. [CrossRef] 